One Horse Race? A study of interoperability in Canada's Future Fighter Capability Project

by

\title{
William Richardson
}

A thesis submitted to the Faculty of Graduate and Postdoctoral Affairs in partial fulfillment of the requirements for the degree of

\section{Master of Arts}

in

International Affairs

Carleton University
Ottawa, Ontario

(C) 2020

William Richardson 


\begin{abstract}
Through the $\$ 19$ billion Future Fighter Capability Project, the Government of Canada will procure a replacement for the $\mathrm{CF}-18$. However, the requirement that the future fighter be "seamlessly interoperable" with key allies calls into question whether the competitive selection process can be run in good faith. ${ }^{1}$ This study argues that contemporary Canadian defence policy is oriented around partnerships with other states, especially the US, and that interoperability would therefore best be attained through the selection of a fifth-generation American platform. However, it is unclear that the FFCP evaluation criteria, which include mandatory and rated technical requirements as well as pillars for cost and industrial offsets, account for high-end tactical networking and new allied technical standards. The FFCP may result in the acquisition of a type that prevents the CAF from interoperating "seamlessly" with allies over its lifecycle. This risk undermines Canada's reliance on partnerships for national defence.
\end{abstract}

\title{
Acknowledgements
}

I wish to thank my supervisor, Dr. Philippe Lagassé, for his continued support during the research and writing process. His input has been invaluable. I also wish to thank my interview subjects, who generously gave of their time and shared their expertise for this study. Finally, thanks go to my family and partner for their support and understanding while I worked on this project. I should be more available now!

\footnotetext{
${ }^{1}$ Department of National Defence, Future Fighter Capability Project: Replacing Canada's Current Fighter Aircraft, by Government of Canada (Ottawa, ON: Government of Canada, 2018), 8.
} 


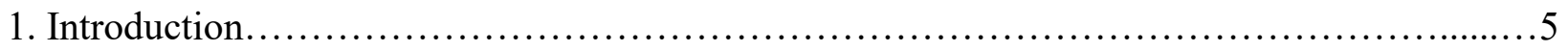

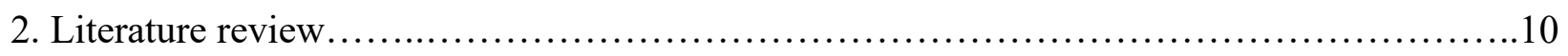

Replacing the CF-18.................................................

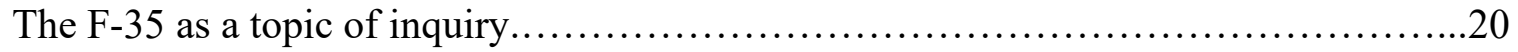

Neoclassical realism.......................................................22

Interoperability in the Canadian context......................................25

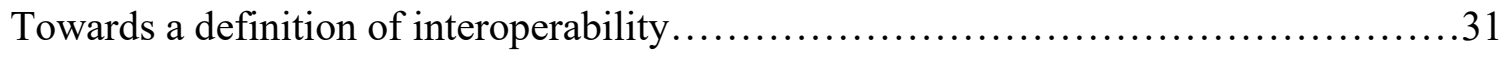

LISI interoperability model................................................. 34

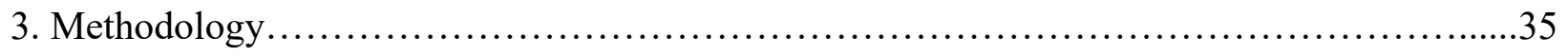

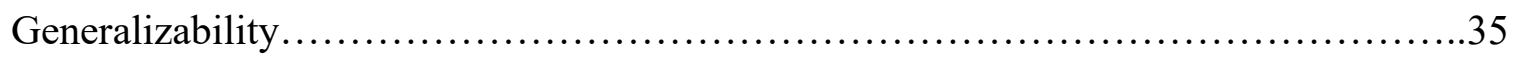

Data collection..........................................................

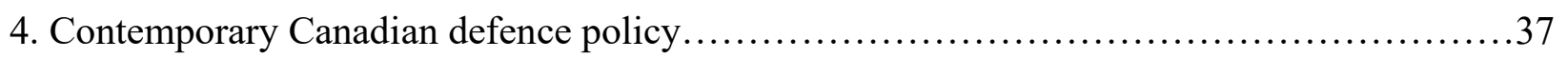

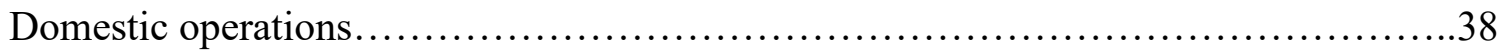

Canada and the US: a unique defence partnership..............................

Canadian defence policy beyond North America..................................44

Canada and the Five Eyes.................................................45

5. Western airpower and the networked battlespace....................................47

Overview of fourth-generation fighter jets.................................47

Overview of fifth-generation fighter jets................................... 48

The multi-domain battlespace and Multi-Domain Command Control (MDC2)..........51

Canada's embrace of information-centricity in national defence......................55

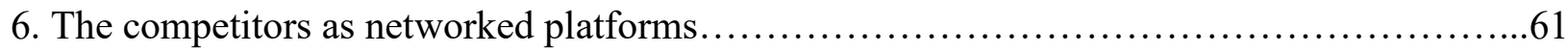

Saab Gripen E as a networked platform....................................61 
Boeing F/A-18E/F Super Hornet Block III as a networked platform..................67

Lockheed Martin F-35 Lightning II as a networked platform........................70

The F-35: airpower transformation and CIS upgrades............................. 75

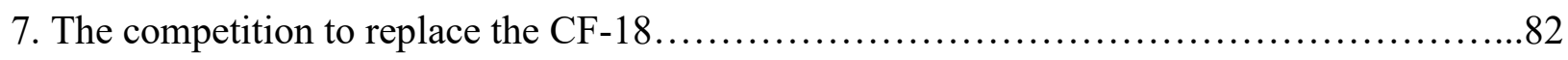

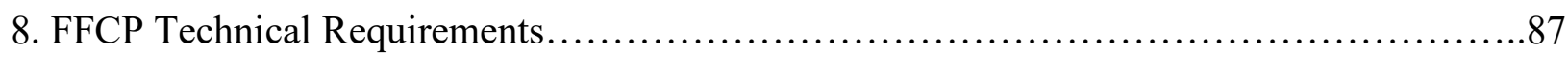

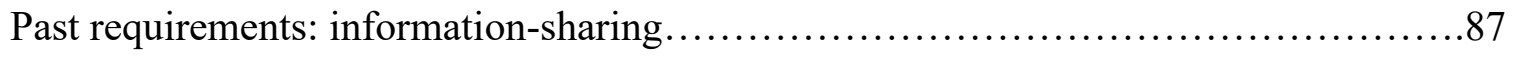

What degree of technical interoperability does Canada consider sufficient today?.........89

Evaluating bids against requirements...................................... 91

Intelligence as a capability driver........................................ 93

Technical compatibility with intelligence flows and information security............93

Information security requirements as a disadvantage?.........................................96

Changing requirements (and deadlines) for the sake of competition...................101

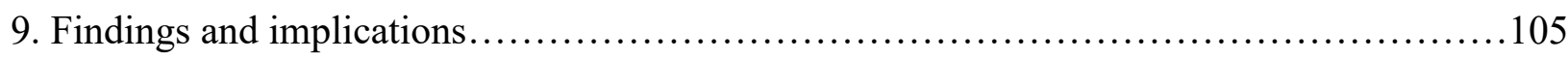

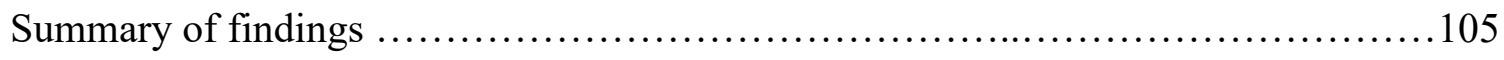

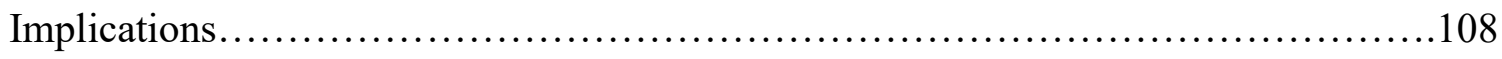

Example of Canada passing up an advanced military capability: BMD..............112

Joint interoperability and the future fighter................................. 113

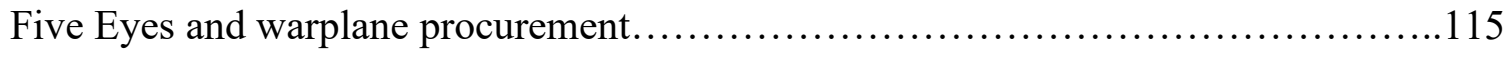

Study limitations..................................................... 117

Future research directions.............................................. 118

10. Conclusion.............................................................. 120

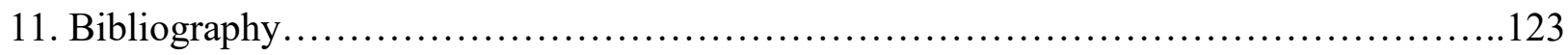




\section{Chapter 1: Introduction}

Canada's current fleet of tactical fighter aircraft is overdue for replacement. The McDonnell Douglas (now Boeing) CF-188A+ Hornet, better known as the CF-18, is the only fast-jet operated by the Canadian Armed Forces (CAF). After being selected from the New Fighter Aircraft Project Competition in 1980, the type entered service with the CAF in 1982. Deliveries continued through $1988 .^{2}$ The CF-18 has been used heavily by the CAF, both at home in its primary North American Aerospace Defense Command (NORAD) mission and overseas in support of North Atlantic Treaty Organization (NATO) operations. Through capability upgrades and life-extension programs, Canada has prolonged the service life of the CF-18 repeatedly. A platform that was initially intended to serve until 2003 is now only expected to be withdrawn from service in 2032. This longevity comes with a growing price. The Office of the Auditor General of Canada (OAG) expects that in order for the CF-18 to reach its fiftieth anniversary, the type's fatigue threshold will need to be further increased and each aircraft will require more intensive regular maintenance. The Department of National Defence (DND) now plans to spend nearly \$3 billion extending the fleet's service life and augmenting it with 18 interim F/A-18As recently retired by the Royal Australian Air Force. ${ }^{3}$ If, as expected, no significant capability upgrades are incorporated before 2032, the OAG assesses that the type risks falling 15 years behind the latest combat technologies. ${ }^{4}$ The venerable CF-18 is clearly on its last legs.

\footnotetext{
${ }^{2}$ For an overview of the CF-18, see Royal Canadian Air Force, "Cf-188 Hornet," Air Force: Aircraft, Government of Canada, accessed January 10, 2020, http://www.rcaf-arc.forces.gc.ca/en/aircraftcurrent/cf-188.page.

${ }^{3}$ Auditor General of Canada, Report 3-Canada's Fighter Force-National Defence (Ottawa, ON: Government of Canada, 2018), https://www.oagbvg.gc.ca/internet/English/parl_oag_201811_03_e_43201.html.

${ }^{4}$ Canada, Report 3-Canada's Fighter Force- $-\bar{N}$ ational Defence.
} 
The CF-18 will be replaced by the winner of the Future Fighter Capability Project, a $\$ 19$ billion capital project administered by DND and Public Services and Procurement Canada (PSPC) which will acquire " 88 advanced jets, associated equipment and weapons, with set-up of training and sustainment services." ${ }^{5}$ The future fighter will be used by the CAF between the mid2020s and at least $2060 .{ }^{6}$ Today, three aircraft manufacturers are eligible to participate in the FFCP and have confirmed that they will submit competitive bids. ${ }^{7}$ Boeing is entering the F/A18E/F Super Hornet Block III, an enlarged and highly evolved version of the CF-18 which is due to enter service with the United States Navy (USN) later this year. Lockheed Martin is entering the F-35 Lightning II, a fifth-generation type developed through the multinational Joint Strike Fighter (JSF) program. The F-35 has been ordered by eight of Canada's NATO allies, including the United States (US) and the United Kingdom (UK). Finally, Saab is entering the Gripen E, an improved version of the Gripen C/D now in service with the Swedish Royal Air Force and several export customers, including NATO allies the Czech Republic and Hungary.

Two eligible suppliers have also declined to compete in the FFCP. In November 2018, French firm Dassault Aviation withdrew from the competition; it was followed by multinational aerospace giant Airbus in August 2019. Both companies were reportedly discouraged from bidding by the stringent technical interoperability and security of information requirements for

\footnotetext{
${ }^{5}$ National Defence, "Future Fighter Capability Project - Canada.Ca," last modified 2020-02-25, accessed February 10, 2020, https://www.canada.ca/en/department-national-defence/services/procurement/fighterjets/future-fighter-capability-project.html.

${ }^{6}$ Public Services and Procurement Canada, "Future Fighter Capability Project," Government of Canada, accessed January 15, 2020, https://www.tpsgc-pwgsc.gc.ca/app-acq/amd-dp/air/snac-nfps/CF-18eng.html.

${ }^{7}$ Amanda Connolly, "Pushing Fighter Jet Deadline Raises Questions on Which Jets Can Do the Work: Experts," Global News, Canada, February 29, 2020, https://globalnews.ca/news/6600416/canada-fighterjet-competition/.; David Pugliese, "Boeing Confirms It Is Taking Part in Canada's Future Fighter Jet Competition," The Ottawa Citizen (Ottawa, ON), News: Defence Watch, 2019, https://ottawacitizen.com/news/national/defence-watch/boeing-confirms-it-is-taking-part-in-canadasfuture-fighter-jet-competition.
} 
the future fighter. ${ }^{8}$ At the time of its withdrawal, Airbus released a statement sharing its concern that "security requirements continue to place too significant of a cost on platforms whose manufacture and repair chains sit outside the United States-Canada Two-Eyes community."9 The Rafale, designed and manufactured by Dassault in France, and the Typhoon, designed and manufactured by a European consortium which includes Airbus, are both in active service within NATO. Further to Airbus' statement, however, the Rafale and Typhoon are not currently manufactured or maintained in high-security facilities in the US or Canada, facilities that have been cleared to handle sensitive intellectual property (IP) unique to the US-Canada Two-Eyes security community. Therefore, neither type is pre-cleared to operate with certain US-origin systems and data. Moreover, while the UK invested heavily in systems security and electronic emissions controls during the development of the Typhoon to clear it for use with intelligence shared by the partners of the Five Eyes (FVEY) intelligence-sharing arrangement, France is not a member of this grouping, and as such the Rafale has also not been cleared to host FVEY data. ${ }^{10}$ Dassault and Airbus concluded that mandatory requirements linked to Canada's defence partnerships would make their offerings costly and uncompetitive in the selection process.

The actions of the two European firms speak to an underlying tension in the FFCP. Though the decision has been taken at the highest levels of government to run an open

\footnotetext{
${ }^{8}$ Daniel Leblanc, "European Fighter-Jet Manufacturer Pulls out of Canadian Competition to Replace Cf18s," The Globe and Mail (Toronto, ON), Canada, 2018, https://www.theglobeandmail.com/canada/article-european-fighter-jet-manufacturer-pulls-out-ofcanadian-competition-to/.; David Pugliese, "Will Other Firms Withdraw from Fighter Jet Competition Leaving F-35 Last Plane Standing?," Ottawa Citizen (Ottawa, ON), News: Defence Watch, 2019, https://ottawacitizen.com/news/national/defence-watch/will-other-firms-withdraw-from-fighter-jetcompetition-leaving-f-35-last-plane-standing.

${ }^{9}$ Lee Berthiaume, "Airbus Pulls out of Canadian Fighter Jet Competition Following Complaints - BNN Bloomberg," BNN Bloomberg (Ottawa, ON), News, 2019, https://www.bnnbloomberg.ca/airbus-pullsout-of-canadian-fighter-jet-competition-following-complaints-1.1309296.

10 "Author Interview with Subject C," interview by William Richardson, November 5, 2019, Ottawa, ON.
} 
competition, it remains unclear how open or competitive the process can really be, given the nature of Canada's alliance commitments and the related interoperability requirements for the future fighter. Stephanie Carvin illustrates Canada's larger procurement dilemma:

Canada is constrained by the requirement that its military be interoperable with its key allies. Being too small to chart its own technological course, yet large enough where its allies expect a substantial contribution to allied and coalition operations, Canada's options are frequently restricted: it can only procure certain equipment, from certain countries that are interoperable with the partners it is likely to work with in an alliance and/or coalition. In this sense, Canada's decision to procure technology is also driven by the need to work with its allies effectively. ${ }^{11}$

Through the FFCP, the Government of Canada will solicit competitive bids for its next generation of fighter aircraft from three suppliers. This is a study of whether interoperability requirements narrow the federal government's choice. The research question is addressed through two lines of inquiry. Fifth-generation fighters incorporate an advanced tactical networking capability that is changing the way allied platforms communicate and cooperate within the battlespace. Canada can expect to engage regularly with fifth-generation fighters and multi-domain concepts in its alliances and security partnerships. With the future fighter set to serve through the middle of the twenty-first century, this study will ascertain whether these developments effectively compel Canada to buy a fifth-generation fighter aircraft. The related second line of inquiry has already been introduced and pertains to the national origin of the selected type. This study will investigate whether Canada must buy an American fighter to guarantee compatibility with Five- and Two-Eyes networks. Finally, the author will assess whether the project requirements take these dynamics into account.

\footnotetext{
${ }^{11}$ Stephanie Carvin, "Canadian Defence and New Technologies," in Canadian Defence Policy in Theory and Practice, ed. Thomas Juneau, Srdjan Vucetic, and Philippe Lagassé, Canada and International Affairs (Cham, Switzerland: Palgrave Macmillan, 2019), 386.
} 
This study argues that contemporary Canadian defence policy is fundamentally oriented around partnerships and interoperability with other states - and especially the US. The requirement that Canada's future fighter be "seamlessly interoperable" with key allies is most clearly satisfied through the selection of a fifth-generation platform that is designed and manufactured in the US. ${ }^{12}$ However, it is unclear that the FFCP evaluation criteria, which include mandatory and rated technical requirements as well as pillars for cost and industrial offsets, account for high-end networking and new allied standards. The resulting risk is to the CAF's ability to interoperate "seamlessly" with key allies over the lifecycle of the future fighter. This risk conflicts with Canada's reliance on external partnerships for national defence.

This study has been divided into chapters. Chapter 2, the literature review, contains a discussion of relevant scholarly titles. It also sets out a working definition of interoperability. In Chapter 3, the chosen methodology will be described. A short survey of Canadian defence policy and its embrace of partnerships follows in Chapter 4. Chapter 5 will describe the next-generation tactical networking and concepts of operations (ConOps) now being implemented by Canada's allies. Chapter 6 provides an assessment of the competing platforms' networked capabilities. Chapter 7 will deal with the origin and structure of the FFCP. Chapter 8 will consider the FFCP technical requirements and their treatment of interoperability. Chapter 9 will survey the study's findings and present the consequences of different selections. The analysis concludes with brief discussions of fighter procurement in the FVEY and joint contexts.

12 Department of National Defence, Future Fighter Capability Project: Replacing Canada's Current Fighter Aircraft, by Government of Canada (Ottawa, ON: Government of Canada, 2018), 8. 


\section{Chapter 2: Literature review}

The literature review is presented in five sections. The first section studies Canada's efforts to replace the CF-18, the second considers two works on the F-35, the third surveys the core literature on neoclassical realism, the fourth engages with the scholarship on interoperability in Canada, and the fifth provides a working definition of the term. This chapter ultimately highlights a selection of works that take different positions on the issues.

\section{Replacing the CF-18}

Canada's attempts to replace the CF-18 date back to 1998, when the country formally joined the JSF program. Agreements signed in 1998, 2002 and 2006 committed Canada first to observe and then invest in the development and production of the JSF, sharing non-recurring costs with other partners. Canadian industry was also permitted to bid for JSF contracts. The federal government committed US \$260 million to the program during this period, but at no point was Canada obligated to purchase the type. ${ }^{13}$ In the fall of 2007 , DND established the Next Generation Fighter Capability Office (NGFC) to manage Canada's participation in the JSF program and evaluate the CAF's options for a replacement for the CF-18. The Director of Air Requirements (DAR) developed a Statement of Operational Requirements (SOR). ${ }^{14}$

In July 2010, the Conservative government announced its intention to conduct a solesource procurement of 65 F-35 Lightning IIs, claiming that the type was Canada's “only choice."15 In 2012, the Spring Report of the Auditor General concluded that the government had

\footnotetext{
${ }^{13}$ Alan S. Williams, Canada, Democracy and the F-35, The Claxton Papers, 16 (Kingston, ON: Defence Management Studies Program, School of Policy Studies, Queen's University, 2012), 7-9.

${ }^{14}$ This was done independently from the NGFC to remove undue bias, see Richard Shimooka, The Fourth Dimension: The F-35 Program, Defence Procurement, and the Conservative Government, 2006-2015 (Ottawa, ON: Conference of Defence Associations Institute, 2016), http://rcafassociation.ca/wpcontent/uploads/2016/09/Vimy_Paper_33.pdf, 8-9.

${ }^{15}$ Srdjan Vucetic, "Canada and the F-35: What's at Stake?," Canadian Foreign Policy Journal 17, no. 3 (2011), https://dx.doi.org/10.1080/11926422.2011.638199.
} 
mishandled the sole-source selection of the F-35 and underestimated the total acquisition cost. ${ }^{16}$ It claimed that "required documents were prepared and key steps were taken out of sequence. Key decisions were made without required approvals or supporting documentation." ${ }^{17}$ In response to these criticisms, the Conservative government established the National Fighter Procurement Secretariat to handle the procurement process and pledged not to sign a contract for new aircraft until a comprehensive series of reviews and consultations had been held. ${ }^{18}$

Canada's attempted F-35 purchase generated significant academic interest. In January 2012, the Canadian Foreign Policy Journal published a special issue entitled "Canada and the F35: What's at Stake?" The articles in this issue contextualize and address "the main questions" in the discourse on Canada's F-35 procurement. ${ }^{19}$ These include the strategic rationale for the purchase, the cost and performance of the F-35, comparisons with past Canadian procurement projects and Canada's other CF-18 replacement options. ${ }^{20}$ In his introduction, guest-editor Srdjan Vucetic writes that the proposed acquisition of the F-35 "is a statement of vision for Canadian and global security; it is an answer to the perennial question of who we are - and who we should be - in the world." ${ }^{21}$ To illustrate this point, Vucetic references DND's justification for the purchase: the F-35 was the only platform capable of meeting the SOR, which was in turn derived from the High Level Mandatory Capabilities required by the CAF to defend Canada, defend

\footnotetext{
${ }^{16}$ National Post Staff, "Stephen Harper Must Resign over Bungled F-35 File, Say Liberals," The National Post, News: Canada, 2012, https://nationalpost.com/news/canada/stephen-harper-must-resign-overbungled-f-35-file-say-liberals.

${ }^{17}$ Auditor General of Canada, Chapter 2: Replacing Canada's Fighter Jets (Ottawa, ON: Office of the Auditor General of Canada, 2020), http://www.oagbvg.gc.ca/internet/English/parl_oag_201204_02_e_36466.html.

${ }_{18}$ Government of Canada Announces Comprehensive Response to Chapter 2 of the 2012 Spring Report of the Auditor General of Canada (Ottawa, ON: Government of Canada, 2012).

${ }^{19}$ Vucetic, "Canada and the F-35: What's at Stake?," 196.

${ }^{20}$ Ibid, 197.

${ }^{21}$ Ibid, 197.
} 
North America in partnership with the US and contribute to international peace and security. ${ }^{22}$ Here, the author defines strategy as "the way in which the government coordinates the nation's capabilities to pursue specific missions." ${ }^{23}$ In 2010, like today, the strategic rationale for the fighter procurement was explicitly linked to the three missions of Canadian defence policy. Then, as now, the choice of fighter allowed the government to simultaneously clarify and advance its vision of Canada in the world. Canada's choice has strategic implications.

In his contribution, James Fergusson notes that the public debate is missing a systematic treatment of the political-strategic context behind the decision to purchase an advanced, multirole fighter aircraft. To correct this failure, he considers the role of airpower in the future of Canadian defence policy and compares the manned multi-role fighter with potential alternatives. After surveying its role in coalition campaigns since the end of the Cold War, Fergusson argues that "the decisive or strategic role of airpower is central to future considerations of war." ${ }^{24}$ In the aerial domain, he suggests that the multi-role fighter remains the most flexible platform and has long been Canada's preferred choice of strike asset because of past decisions not to invest in alternative systems such as cruise missiles. ${ }^{25}$ Fergusson then outlines a "national consensus" wherein Canada contributes to a wide range of multilateral operations in order to curry favour and influence with the US, which as a great power dominates international security politics and makes decisions that affect Canada's security interests. ${ }^{26}$ The implication of Fergusson's article is that the manned multi-role fighter supports this consensus by giving Canada more freedom of

\footnotetext{
${ }^{22}$ Ibid, 197.

${ }^{23}$ Ibid, 197.

${ }^{24}$ James Fergusson, "The Right Debate: Airpower, the Future of War, Canadian Strategic Interests, and the JSF Decision," Canadian Foreign Policy Journal 17, no. 3 (2011), https://dx.doi.org/10.1080/11926422.2011.638195, 208-209.

${ }^{25} \mathrm{Ibid}, 209$.

${ }^{26}$ Ibid, 212.
} 
action on the international stage. To him, the debate over the need for the F-35 boils down to ideological differences over the role of Canada in the world. ${ }^{27}$

Michael Byers and Stewart Webb approach the strategic context of the F-35 purchase differently. They argue that Canada's fighter jets are primarily intended to serve as strategic deterrents within NORAD and NATO and point out that Canada's CF-18s "have only occasionally served overseas." 28 To them, Canada's fighter purchase should be analyzed primarily through the lens of the air defence mission. Their piece constitutes a first pass at this exercise; the authors find the F-35 to be costly and ill-suited to air defence. They conclude that the purchase signals a shift in Canada's strategic priorities towards the overseas strike mission. ${ }^{29}$

Rob Huebert identifies a paucity of academic inquiry addressing the role of airpower in Canada; he suggests that such works can inform the F-35 debate. To fill the vacuum, Huebert considers whether Canada will need to maintain fighter-based airpower for the next 30 to 40 years, and if so, what capability is necessary and what is available. ${ }^{30} \mathrm{He}$ establishes that the mission of the Royal Canadian Air Force (RCAF) is "to control and exploit the aerospace environment for military purposes that contribute to Canadian's 'security and national objectives. ${ }^{, 31}$ Huebert recognizes that a survey of the historical record on Canadian airpower is complicated by the fact that Canada has never used it alone. Instead, Canada has always employed airpower in concert with allies, whether in the context of continental air defence or overseas contingency operations. ${ }^{32}$ Still, the author observes a longstanding Canadian embrace of

\footnotetext{
${ }^{27}$ Ibid, 205.

${ }^{28}$ Michael Byers, and Stewart Webb, "Canada's F-35 Purchase Is a Costly Mistake," Canadian Foreign Policy Journal 17, no. 3 (2011), https://dx.doi.org/10.1080/11926422.2011.638193, 218.

${ }^{29}$ Ibid, 218.

${ }^{30}$ Rob Huebert, "The Future of Canadian Airpower and the F-35," Canadian Foreign Policy Journal 17, no. 3 (2011), https://dx.doi.org/10.1080/11926422.2011.638196, 229.

${ }^{31}$ Ibid, 230.

${ }^{32}$ Ibid, 230-231.
} 
the tactical fighter capability. Looking to the future, he anticipates that state- and non-statecentric threats will remain, while the spiralling costs of fighters will combine with shrinking Western defence budgets to result in quality replacing quantity. Huebert posits that in this environment, Canadian contributions will be needed more than ever in continental air defence and coalition operations. Given the capability promised by the F-35 and the age of alternative platforms, he concludes that Canada should follow through with the acquisition. ${ }^{33}$

Justin Massie argues that the primary determinant in the decision to purchase the F-35 was the Conservative government's desire to "bandwagon" with the US and enhance its status as a "reliable and prominent ally in Western-led air campaigns." 34 This argument echoes Vucetic's observation that the government wished to set out a specific role in the world for Canada through the purchase. Massie takes this logic further, suggesting that the desired role is to support US military operations around the world over the long-term. He arrives at this point by discounting the need for a fifth-generation fighter in the air sovereignty mission. ${ }^{35}$ Given Canada's continental defence partnership with the US, Massie writes that "the United States Air Force's air dominance fighter, the F-22, as well as United States nuclear capabilities [sic] serve as Canada's greatest means of sovereignty protection, through the deterrence they provide vis-à-vis external threats." ${ }^{36}$ Massie posits instead that the F-35 secures Canada's sovereignty against incursions from within the continent. Canada continues to contribute modestly to continental air defence for two reasons: to enhance its status with the US as a reliable ally and preserve its territorial integrity from unwanted American infringements. Here, the author references Nils

\footnotetext{
${ }^{33}$ Ibid, 235-237.

${ }^{34}$ Justin Massie, "Bandwagoning for Status: Canada's Need of the F-35," Canadian Foreign Policy Journal 17, no. 3 (2011), https://dx.doi.org/10.1080/11926422.2011.638197, 251.

${ }^{35}$ Ibid, 256-257.

${ }^{36}$ Ibid, 257.
} 
Ørvik's "defence against help" thesis, or the notion that Canada must maintain armed forces that are sufficiently capable to prevent the US from feeling obliged to interfere in Canada to guarantee its own security. ${ }^{37}$ For Massie then, the F-35 acquisition is an outgrowth of a strategic culture wherein successive Canadian governments have adopted foreign and defence policies that accommodate American interests. ${ }^{38}$ Massie uses the F-35 example to suggest that Canada strives to purchase high-end and fully interoperable military systems so that Canadian forces can follow and demonstrably support US forces wherever they go, thereby securing Canada's status as a willing ally and by extension, its national sovereignty. ${ }^{39}$ This linkage between strategy and the procurement of specific military technologies will be explored in detail in this study.

The arguments against the F-35 in this special issue have become somewhat less relevant with time. In 2011, the JSF program was beset with cost overruns and delays. US Defense Secretary Bob Gates put the program on probation, giving it two years to get back on track before the US government considered cutting its losses and cancelling the program entirely. ${ }^{40} \mathrm{At}$ the time, the F-35 was still years away from entering operational service. Perhaps unsurprisingly, numerous uncertainties remained surrounding its capability and final cost. The contributors who come out strongly against Canada's F-35 acquisition focus mostly on these issues. Today, the flyaway cost of the F-35 has fallen (though flight-hour costs remain high), while the flyaway costs of competing fighter platforms have risen. ${ }^{41}$ Moreover, the F-35's networking capability,

\footnotetext{
${ }^{37}$ Nils Ørvik, "The Basic Issues in Canadian National Security: Defence against Help," Canadian Defence Quarterly 11, no. 1 (1981).

${ }^{38}$ Massie, "Bandwagoning for Status: Canada's Need of the F-35," 258.

${ }^{39}$ Ibid, 258-259.

${ }^{40}$ Nick Zazula, "F-35: Is the Trillion Dollar Fighter Finally Worth It?," Avionics International, 2018, http://interactive.aviationtoday.com/avionicsmagazine/august-september-2018/f-35-is-the-trillion-dollarfighter-finally-worth-it/.

${ }^{41}$ Valerie Insinna, "F-35 Price Falls Below \$90m for First Time in New Deal," Defense News

(Washington D.C.), Air, September, 2018, https://www.defensenews.com/air/2018/09/28/f-35-price-falls-
} 
which will be evaluated in Chapter 6, was not yet realized or even fully apparent in 2011 - and nor were the advanced ConOps that is has enabled. Finally, the 2010s saw the re-emergence of great power competition between the US, a revanchist Russia and an increasingly assertive China. ${ }^{42}$ Today, tensions remain high with a nuclear North Korea and have increased precipitously with Iran because of its adventurism in the Middle East. For Western militaries, high-end threats abound. Arguments disparaging Canada's need of the F-35 ring hollower today. Following the release of the Auditor General's report, the F-35 program became a source of intense political debate in Canada. Contracts had still not been signed in advance of the 2015 federal election. During that campaign, the Liberal Party pledged not to buy the F-35. Instead, it would "immediately launch an open and transparent competition to replace the CF-18 fighter aircraft." ${ }^{43}$ In June 2017, the Liberal government released a new defence policy entitled Strong, Secure, Engaged (SSE). This document reiterated the promise of a competition, continuing that the CAF would receive " 88 advanced fighter aircraft to meet Canada's NORAD and NATO commitments." These would need to be "capable, upgradeable, resilient and interoperable with our allies and partners."44 The FFCP was launched in December 2017.

The current process has garnered less attention from scholars than its predecessor did, no doubt owing in part to the faltering nature of the CF-18 replacement file and the ever-more protracted timelines associated with it. Still, one recent piece of scholarship addressing the FFCP will be highly influential in this study. In a report published in May 2019, Al Stephenson breaks

before-90m-for-first-time-ever-in-new-deal/.; "Author Phone Interview with Subject A," interview by William Richardson, October 22, 2019, Ottawa, ON.

${ }^{42}$ Department of National Defence, Strong, Secure, Engaged: Canada's Defence Policy (Ottawa, ON: Government of Canada, 2017), 50.

${ }^{43}$ Liberal Party of Canada, Real Change: A New Plan for a Strong Middle Class (Liberal Party of Canada, 2015), https://www.liberal.ca/wp-content/uploads/2015/10/New-plan-for-a-strong-middleclass.pdf, 70.

${ }^{44}$ Defence, Strong, Secure, Engaged: Canada's Defence Policy, 38. 
down the FFCP into its military, technological, economic and political dimensions. ${ }^{45}$ He writes that the four (now three) fighter aircraft being offered by the eligible suppliers represent two significant cleavages. These have implications for the dimensions of the government's decision.

The first cleavage concerns long-term sustainment costs and future technological adaptability. The differences here are between the F-35, an advanced fifth-generation fighter, and its fourth-generation competitors, the Boeing Super Hornet, Saab Gripen and at the time of the article's publication, the Eurofighter Typhoon. Stephenson contrasts the generations:

Adapting to evolving technologies, fifth-generation are purpose-built, lowobservable designs to enhance survivability against increasingly lethal defensive missile systems. Embedded multi-sensors networked with integrated avionics, along with sensor fusion to external sources, provide the pilot with unprecedented situation awareness and ability to perform multi-mission objectives simultaneously ...Fifth-generation aircraft have immense growth potential with a projected life expectancy to 2070 ...Fourth-generation fighters are based on proven 1970/1980 platform designs that have been updated with contemporary avionics and sensors but are unable to incorporate fusion technology. These aircraft are categorized as 4.5-generation and although fitted with leading-edge defensive electronic countermeasure suites, the observable airframes are highly vulnerable to modern air defence systems. Fourth-generation aircraft have very limited growth potential in their architecture and long-term sustainability is questionable as air forces plan on divesting the majority of these aircraft by the mid-2040s. ${ }^{46}$

The author recognizes that fifth-generation fighters will be operated by Canada's allies through the middle of this century. A regular cadence of in-service upgrades will ensure that they remain combat relevant. Meanwhile, fourth-generation fighter aircraft will gradually be phased out of allied air forces. The implication is that a fleet of fourth-generation future fighters would quickly become orphans in Canadian service, with Canada forced to go it alone on sustainment measures

\footnotetext{
${ }^{45}$ Al Stephenson, Anatomy of a Buy: The Four Dimensions of Procuring a Fighter Fighter for Canada (Canadian Global Affairs Institute, 2019), https://d3n8a8pro7vhmx.cloudfront.net/cdfai/pages/4197/attachments/original/1559008095/Anatomy_of_ a_Buy_The_Four_Dimensions_of_Procuring_a_Future_Fighter_for_Canada.pdf? 1559008095, 2. ${ }^{46}$ Ibid, 4.
} 
and costly upgrades. ${ }^{47}$ Moreover, the operational relevance of this fleet would diminish sharply after the fourth-generation fleets of Canada's allies have been retired. ${ }^{48}$ This decision-point impacts the technological and military dimensions of the purchase. Throughout its service life, the future fighter will need to deter against sovereignty challenges and remain integral to the NORAD C2 structure, even as American technical standards and ConOps change. ${ }^{49}$ It is unclear whether each of the competitors can achieve this.

The second cleavage is European-versus-American and concerns security requirements and the Industrial and Technological Benefits (ITB) policy. Stephenson notes that the federal government has signalled its willingness to accommodate technological transfer challenges in the FFCP bidding process. He writes that if Canada selects the Saab Gripen, proprietary US-origin technologies will need to be integrated into the platform before it can enter service. Given the commercial sensitivity of such technologies and recent announcements that two European consortiums are launching so-called sixth-generation fighter projects, Stephenson posits that the US will be protective of technology transfers to non-American platforms. ${ }^{50}$ This challenge may explain the relaxation of the Five- and Two-Eyes security requirements, with firms now only required to submit a plan for how, when and at what price they will meet them. The suggestion is that this change is related to the federal government's desire to maintain a competitive process and protect the more tailorable economic packages offered by European suppliers. ${ }^{51}$ Stephenson writes that "without significant weighting of economic benefits in the RFP, it is unlikely the

\footnotetext{
${ }^{47}$ Stephenson notes that in October 2018, the government of Belgium chose the F-35 over the Typhoon in a competitive process based largely on price and the cost-savings accrued over the 40-year life of the aircraft, see Stephenson, Anatomy of a Buy: The Four Dimensions of Procuring a Fighter Fighter for Canada, 13.

${ }^{48}$ Ibid, 12.

${ }^{49}$ Ibid, 5-8.

${ }^{50}$ Ibid, 5 .

${ }^{51}$ Ibid, 15.
} 
European companies would compete at all." 52 The change therefore serves the project's political and economic dimensions to the detriment of its military and technological dimensions. Changes accommodating less advanced European types could also result in the selection of a platform that adversely affects Canada's defence relations with the US. ${ }^{53}$

Stephenson introduces two of this study's focuses: Five- and Two-Eyes security requirements and the multi-domain operating environment being established by the US. However, as his stated intention is to touch upon each of the major issues in the FFCP, he leaves key aspects of these issues unexplored and relies on supposition in his arguments. In his discussion of technology transfers, Stephenson implicates but does not explicitly discuss sensitive Five- and Two-Eyes communications technologies. He glosses over the costly multinational accreditation process that must be undertaken to permit a networked platform to use Five- and Two-Eyes data. Instead, he cites nascent European design studies as the basis for a more general and cursory claim that the US will be "far more protective" of its technologies. ${ }^{54}$ While this explanation is reasonable, it is imprecise and unsubstantiated. The discussion lacks the evidence and depth to draw conclusions on whether Canada must buy an American type.

Stephenson links the fifth-generation fighter to the multi-domain battlespace, writing:

Advances in computer technology and emerging artificial intelligence (AI) are true game-changers in any future battlespace. The advent of fifth-generation fighter designs incorporates such emerging technologies, thereby introducing the potential for fighter aircraft to move beyond performing multi-role tasks to being a multimission platform that can be networked as localized command, control, communications, computer ISR (C4ISR) assets on future multi-domain battlefields. ${ }^{55}$

\footnotetext{
${ }^{52}$ Ibid, 15.

${ }^{53}$ Ibid, 15.

${ }^{54}$ Ibid, 4-5.

${ }^{55}$ Ibid, 3.
} 
Fifth-generation fighter aircraft will inform and direct joint forces. Such innovations will increasingly be integrated into NORAD, and specifically, the forthcoming replacement for the North Warning System (NWS). ${ }^{56}$ This topic is central to the question of whether Canada should buy a fifth-generation fighter - the first cleavage in Canada's decision. However, the discussion is conspicuously missing one type: the Block III Super Hornet. This aircraft does not necessarily fit into Stephenson's framework. On the one hand, the Super Hornet is an evolved fourthgeneration fighter with a dated basic airframe design. One the other, the Block III standard represents the latest in a series of capability upgrades, which will permit the type to interoperate closely with the F-35 in the USN beyond $2040 .{ }^{57}$ Moreover, the US-made fighter is cleared to receive Five- and Two-Eyes intelligence by design. The inclusion of this type in the FFCP raises questions about interoperability that Stephenson fails to answer. This study modifies Stephenson's cleavages to provide a more nuanced explanation.

\section{The F-35 as a topic of inquiry}

In a report entitled "Maximum Value from the F-35: Harnessing Transformational FifthGen Capabilities for the UK Military," Justin Bronk gives a detailed description of the networked capability of the F-35 and considers its interoperability with other platforms in service with the British military. He outlines the ConOps now being implemented by the US military for the F-35 and discusses their application in the Royal Navy and Royal Air Force. ${ }^{58}$ The piece is tailored to Britain's operational context and capability needs, which differ from Canada's. In the

\footnotetext{
${ }^{56}$ Ibid, 5; 6-7.

${ }^{57}$ Justin Bronk, Maximum Value for the F-35: Harnessing Transformational Fifth-Generation Capabilities for the Uk Military (London, UK: Royal United Services Institute for Defence and Security Studies, 2016), https://rusi.org/sites/default/files/20160201_whp_maximum_value_from_the_f35 _web.pdf, 3 .

${ }^{58}$ Ibid, 8-15.
} 
Royal Navy, short-takeoff and vertical landing (STOVL) F-35Bs will operate from two new Queen-Elizabeth class aircraft carriers; in the RAF, F-35Bs will replace the retired British Aerospace Harrier and Panavia Tornado strike aircraft. Bronk concludes that the F-35 should initially be seen and employed as a force multiplier, especially when operators field mixedgeneration fast-jet fleets and have relatively few of the type at their disposal. ${ }^{59}$ Bronk's survey of the F-35 and its associated ConOps will inform discussion of the type's utility to Canada.

In a short piece entitled "F-35 Sales are America's Belt and Road," Vucetic likens the network of F-35 operators to China's Belt and Road Initiative, writing:

Imagine a globe-spanning economic and security project—with a cost of over a trillion dollars and whose members encompass 46 percent of the global economy - designed to advance the interests and influence of the lead state, even as it binds the smaller ones into an asymmetric interdependence. Recipients get large economic rewards for participating, but they will find it even more expensive to extract themselves from the network in the long run. ${ }^{60}$

This project is the JSF program. The author argues that it has produced a uniquely advanced platform which has yet to lose a procurement competition. Once a nation purchases the F-35, it becomes difficult to rationalize embracing other, less capable types. Furthermore, Vucetic recognizes that aviation industries around the world have become dependent upon JSF program contracts, thereby ensuring continued international participation in the program and additional procurement contracts. ${ }^{61}$ While the US directly influences foreign operators by controlling their access to the program, membership ultimately affords these states prestige, access to state-of-theart technology and lucrative economic contracts, as well as close security ties with the US.

\footnotetext{
${ }^{59}$ Ibid, 2.

${ }^{60}$ Srdjan Vucetic, "F-35 Sales Are America's Belt and Road," CIPS Blog, Centre for International Policy Studies, University of Ottawa, 2020, acessed May 6, 2020, https://www.cips-cepi.ca/2019/09/22/f-35sales-are-americas-belt-and-road/.

${ }^{61}$ Ibid.
} 
Vucetic concludes that external partners must balance the potential for dependency with these benefits. ${ }^{62}$ His piece introduces the rationale for purchasing the F-35, as well as the risks. This study will argue that Canada is already largely dependent upon the US for national defence. For Canada then, the benefits of operating the type would far outweigh the risks.

\section{Neoclassical realism}

The neoclassical realist theory of international politics is used to explain this case study of interoperability and Canada's future fighter decision. The following section draws on three foundational works to set out this theory. These are "Neoclassical Realism and Theories of Foreign Policy," written by Gideon Rose and published in World Politics in 1998; Neoclassical Realism, the State, and Foreign Policy, edited by Norrin Ripsman, Jeffrey Taliaferro and Stephen Lobell and published in 2009; and Neoclassical Realist Theory of International Politics, edited by Ripsman, Taliaferro and Lobell and published in 2016. Rose first identified neoclassical realism in his review article, writing that the works demonstrated the suitability of a new approach to the study of foreign policy outcomes. ${ }^{63}$ In their two volumes, Ripsman, Taliaferro and Lobell consider the neoclassical realist paradigm in greater detail, first as a more balanced approach to the study of foreign policy and subsequently as a comprehensive theory of international politics. Arguments from each piece are synthesized hereafter.

Like its neorealist and classical realist progenitors, neoclassical realism interprets international politics as a struggle between states for power and influence in a world of uncertainty and finite resources. ${ }^{64}$ Neoclassical realism draws from neorealism in its assignment

\footnotetext{
${ }^{62}$ Ibid.

${ }^{63}$ Gideon Rose, "Neoclassical Realism and Theories of Foreign Policy," World Politics 51, no. 1 (1998), https://dx.doi.org/10.1017/S0043887100007814, 146.

${ }^{64}$ Norrin M. Ripsman, Jeffrey W. Taliaferro, and Steven E. Lobell, Neoclassical Realist Theory of International Politics (New York: Oxford University Press, 2016).
} 
of causal primacy to power shifts within the international system. In Rose's words, neoclassical realists "argue that the scope and ambition of a country's foreign policy is driven first and foremost by its place in the international system and specifically by its relative material power capabilities. ${ }^{.65}$ Here, as in neorealism, territorial states are the primary units in the international system and its most consequential actors. ${ }^{66}$ The international system can be viewed as a hierarchical structure, with states ranked according to relative material power. A state's relative material power is its material capability, manifest in attributes that include GDP, level of defence spending, size and composition of armed forces, size of population, natural resource endowments and size of territory. ${ }^{67} \mathrm{~A}$ change in the relative material power of a state can be expected to alter its foreign policy outcomes and reshape the international system. Rose concludes: "the more material power - the more ambitious the foreign policy." ${ }^{968}$

Neoclassical realism adopts the neorealist characterization of the international system as anarchic. In neorealism, international anarchy, or the "lack of guidance from an overarching authority," forces states into a self-help environment, where one state's pursuit of security for survival threatens the security and thereby the survival of other states ${ }^{69}$ Here, international anarchy is an independent causal force. In neoclassical realism, however, anarchy is a permissive condition. ${ }^{70}$ Rose characterizes anarchy as "rather murky and difficult to read," writing:

States existing within [anarchy] have a hard time seeing clearly whether security is plentiful or scarce and must grope their way forward in twilight, interpreting partial and problematic evidence according to subjective rules of thumb. ${ }^{71}$

http://www.oxfordscholarship.com/10.1093/acprof:oso/9780199899234.001.0001/acprof9780199899234, 43.

${ }^{65}$ Rose, "Neoclassical Realism and Theories of Foreign Policy," 146.

${ }^{66}$ Ripsman, Taliaferro, and Lobell, Neoclassical Realist Theory of International Politics, 35.

${ }^{67}$ Ibid, 44.

${ }^{68}$ Rose, "Neoclassical Realism and Theories of Foreign Policy," 152.

${ }^{69}$ Ibid, 37.

${ }^{70}$ Ibid, 43.

${ }^{71}$ Rose, "Neoclassical Realism and Theories of Foreign Policy," 152. 
Because it is changing and subjective - interpreted by imperfect human actors - anarchy permits a range of interpretations of the state system and a range of possible reactions to it. When states do wield power, they do so against perceived threats. Clarity is useful in discerning the "signals and information the international system presents to states."72

Like classical realism, neoclassical realism accounts for the role of the state in policy formulation. Rose writes that systemic pressures are translated into foreign policy "through intervening variables at the unit level," rendering the relationship between relative material power and policy "indirect and complex."73 In their second volume, Lobell, Ripsman and Taliaferro organize the intervention of the state into four clusters: leader images, strategic culture, state-society relations and domestic institutional arrangements. ${ }^{74}$ Rose recognizes their influence in his argument that states with comparable material power but different political and economic systems will often arrive at different foreign policy outcomes. ${ }^{75}$

The international system and domestic constraints can be competing influences in the policy process. In the short-term, Lobell, Ripsman and Taliaferro write that "the policies states pursue are rarely objectively efficient or predictable based upon a purely systemic analysis.”76 Rose would tend to agree, observing that the pressures of the international system are not strong or precise enough to dictate a state's short-term behaviour. ${ }^{77}$ Over the long-term, however, neoclassical realism maintains that foreign policy outcomes will mirror the distribution of

\footnotetext{
${ }^{72}$ Ripsman, Taliaferro, and Lobell, Neoclassical Realist Theory of International Politics, 46.

${ }^{73}$ Rose, "Neoclassical Realism and Theories of Foreign Policy," 146.

${ }^{74}$ Ripsman, Taliaferro, and Lobell, Neoclassical Realist Theory of International Politics, 8-9.

${ }^{75}$ Rose, "Neoclassical Realism and Theories of Foreign Policy," 147.

${ }^{76}$ Steven E. Lobell, Norrin M. Ripsman, and Jeffrey W. Taliaferro, Neoclassical Realism, the State, and Foreign Policy (GB: Cambridge University Press - M.U.A, 2009). https://ebookcentral-proquestcom.proxy.library.carleton.ca/lib/oculcarleton-ebooks/reader.action?docID=412786, 4 .

${ }^{77}$ Rose, "Neoclassical Realism and Theories of Foreign Policy," 147.
} 
material power among states. Political leaders must eventually heed systemic incentives, for a prolonged failure to do so "puts their state's very survival at risk.",78

\section{Interoperability in the Canadian context}

Interoperability with key allies has long been a major component of Canadian defence policy. One of the earliest and most influential treatments of this topic is "The Canadian Forces and the Doctrine of Interoperability: The Issues," written by Danford W. Middlemiss and Denis Stairs and published in the June 2002 edition of Policy Matters. The authors write that the terrorist attacks of September 11, 2001 and resulting combat operations in Afghanistan drew attention in Canada to the relationship between the CAF and the US defence establishment. They find that "wherever [the relationship] is headed...it has been heading there for some time."79

In their introduction, Middlemiss and Stairs react to a DND/CAF policy document written in 1999 and entitled Shaping the Future of Canadian Defence: A Strategy for 2020:

[Interoperability] cropped up in several places [sic], often accompanied by reference to the need to take advantage of new military technologies, and to do so in the company of "our main defence partners in the UN, NATO and coalition operations." 80 This clearly meant, above all others, the United States of America. ${ }^{81}$

The authors contend that the new language is linked to contracting defence budgets and limited defence assets in the post-Cold War period. In this context, they posit that Canada may only be able to contribute to multinational operations "as a wholly integrated (or at least integration-

\footnotetext{
${ }^{78}$ Lobell, Ripsman, and Taliaferro, Neoclassical Realism, the State, and Foreign Policy, 7.

${ }^{79}$ Danford W. Middlemiss, and Denis Stairs, The Canadian Forces and the Doctrine of Interoperability: The Issues (Montreal, QC: Institute for Research on Public Policy, 2002), https://irpp.org/wpcontent/uploads/assets/research/national-security-and-interoperability/new-research-article7/pmvol3no2.pdf, 4.

${ }^{80}$ Department of National Defence, Shaping the Future of Canadian Defence: A Strategy for 2020, Ottawa: Department of National Defence, June 1999, in Middlemiss, and Stairs, The Canadian Forces and the Doctrine of Interoperability: The Issues, 9.

${ }^{81}$ Middlemiss, and Stairs, The Canadian Forces and the Doctrine of Interoperability: The Issues, 9.
} 
capable) component of the defence establishments of coalition partners." ${ }^{" 22}$ This could be the only affordable way for Canada to maintain fully deployable and combat-capable armed forces.

Middlemiss and Stairs write that while the wholesale adoption of interoperability by the CAF could have implications for its freedom of action, these consequences hinge on what is meant by interoperability in practical terms. ${ }^{83}$ Their piece explores this issue. The authors start with a conceptual discussion of interoperability, citing a DND Strategic Capability Planning document from June 2000 which states: "The capability to work seamlessly with our most important allies in an operational setting ensures that we can participate effectively in those crises most likely to affect our vital national interest." ${ }^{\not 4}$ Interoperability overcomes the obstacles to effective multinational cooperation and permits Canada to make militarily relevant and costefficient contributions to multinational security efforts. Such contributions can impart political dividends, including participation in strategic planning and decision-making, improved access to coalition intelligence resources and a measurable enhancement of diplomatic influence. ${ }^{85}$ This argument informs this study's conceptualization of Canadian defence policy.

Middlemiss and Stairs contend that Canada's defence posture has always accommodated a patron state. Between 1867 and 1918, this power was the UK. Since the late 1930s, Canada's primary security partner has been the US. The authors survey the bilateral agreements that formalize the defence partnership with the US, emphasizing their egalitarian nature and

\footnotetext{
${ }^{82}$ Ibid, 10.

${ }^{83}$ Ibid, 10.

${ }^{84}$ Vice Chief of the Defence Staff. "Glossary for Strategic Capability Planning for the CF." Strategic Capability Planning for the Canadian Forces. Ottawa: VCDS, Department of National Defence, June 2000. In Middlemiss, and Stairs, The Canadian Forces and the Doctrine of Interoperability: The Issues, 11-12.

${ }^{85}$ Middlemiss, and Stairs, The Canadian Forces and the Doctrine of Interoperability: The Issues, 12.
} 
overarching sensitivity to Canada's concern for its sovereignty. ${ }^{86}$ They write that the zenith of bilateral interoperability is NORAD. This unique binational military command gives Canada unparalleled access to the US defence establishment and US policymaking. Middlemiss and Stairs suggest that should Canada opt out of NORAD, its interests would either be benignly neglected or deliberately ignored by the US. ${ }^{87}$ Though it is clearly the junior partner in the framework, Canada's full participation affords it some control over continental defence. These points inform discussion of Canadian defence policy in Chapter 4 and support this study's contention that the type selected as the future fighter must be totally interoperable with NORAD.

The authors write that reduced defence budgets caused many NATO allies to fall behind US technological standards just as the alliance's tempo of operations increased in the post-Cold War period. They consider Canada's use of CF-18s in expeditionary campaigns to explain how interoperability deficiencies impacted Canadian contributions and the operations themselves. For example, the CF-18's lack of secure communications equipment forced coalition air operations in Kosovo to be "dumbed down," thereby greatly increasing operational risk. ${ }^{88}$ Middlemiss and Stairs suggest that in the digital age, states that wish to participate in operations alongside the US military must meet certain technical standards. This study examines and tests this imperative.

Indeed, the authors write that Canadian defence procurement demonstrates that planners "have been moving towards greater interoperability with the United States in a manner that is far more comprehensive and rapidly paced than most Canadians realize." 89 Because it has a finite

\footnotetext{
${ }^{86}$ Middlemiss, and Stairs, The Canadian Forces and the Doctrine of Interoperability: The Issues, 15-16.

${ }^{87}$ Ibid, 19.

${ }^{88}$ The CF-18 was not the only allied type lacking a secure communications capability in Kosovo. See Middlemiss, and Stairs, The Canadian Forces and the Doctrine of Interoperability: The Issues, 22.

${ }^{89}$ Ibid, 26.
} 
defence capital budget, each acquisition must enable Canada to "keep up" with the US and interoperate in the future. ${ }^{90}$ The authors recognize that planned investments in the CAF's command and control (C2) and intelligence, surveillance and reconnaissance (ISR) capabilities, as well as planned upgrades to the CF-18 through the Incremental Modernization Project, will serve these ends. ${ }^{91}$ The doctrine of interoperability shapes Canadian defence procurement.

Middlemiss and Stairs are struck by how DND planning documents "demonstrate that the concept of interoperability is now seamlessly, consistently and centrally woven into both the thinking and the fabric of the defence establishment. ${ }^{" 92}$ Canada implicitly accepts that the CAF cannot achieve strategic objectives by itself when deployed abroad and must instead work with partner militaries. If Canadian forces are to always be deployed as part of larger coalitions, the authors warn that the federal government risks losing operational control over them. For example, Royal Canadian Navy (RCN) warships often join USN carrier battlegroups on deployment and would be subsumed into the integrated unit during combat operations. ${ }^{93}$ Should integration with the US defence establishment continue apace, the authors suggest that Washington could conceivably compel Ottawa to deploy the CAF at times of its choosing. ${ }^{94}$

The piece concludes with the question of whether Canada has a choice. To preserve a degree of foreign influence and remain a constructive player in international affairs, the authors argue that Canada must maintain an expeditionary capability. In the absence of a sudden and

\footnotetext{
${ }^{90}$ Ibid, 26.

${ }^{91}$ Ibid, 26-27.

92 The documents are Strategy 2020, Defence Plan 2001 and Report on Plans and Priorities 2001-2002, see Middlemiss, and Stairs, The Canadian Forces and the Doctrine of Interoperability: The Issues, 24.

${ }^{93}$ Ibid, 25.

${ }^{94}$ Ibid, 30.
} 
uncharacteristic increase in the defence budget, "interoperability with the Americans is the only game in town." 95 This may be no bad thing:

[Interoperability] offers what Canadian diplomacy wants most from the military game, which is the enhancement of its political credit where it really counts: in the capitals of the foreign powers that matter most to Canada. And at the most mundane level, it makes the best of a bad budget. ${ }^{96}$

If interoperability is a fact of life, then it should be fully funded to protect Canada's freedom of action. In keeping with Ørvik's defence against help thesis, sufficient military capability must be maintained to prevent the US from defending Canada "whether Canadians liked it or not."97 Canada must invest in capabilities of value to the US to secure its status as a dependable ally. Middlemiss and Stairs warn of "a direct functional connection between interoperability "on the cheap' and loss of autonomy." "98 This is the risk of Canada choosing the wrong fighter.

"The Canadian Forces and the Doctrine of Interoperability: The Issues" gave rise to significant scholarly debate in Canada, much of which is encapsulated in The Canadian Forces and Interoperability: Panacea or Perdition? edited by Ann Griffiths. In his contribution, Douglas Bland contrasts the military definition of "burden-sharing interoperability" with what he describes as the Canadian political tradition of "free-riding interoperability." 99 This is merely the newest term for an assumption that has defined Canadian defence policy for generations: "there is no threat, and if there were, then the Americans would save us." ${ }^{100}$ Bland argues that Canadian

\footnotetext{
${ }^{95}$ Ibid, 28.

${ }^{96}$ Ibid, 29.

${ }^{97}$ Ibid, 31.

${ }^{98}$ Ibid, 30.

${ }^{99}$ Douglas Bland, "Military Interoperability: As Canadian as a Beaver," in The Canadian Forces and Interoperability: Panacea or Perdition?, ed. Ann Lynn Griffiths (Halifax, N.S: Centre for Foreign Policy Studies, Dalhousie University, 2002), 51.

${ }^{100}$ Ibid, 51.
} 
politicians will continue to pursue free-riding interoperability, which saves "not only money, but also time and defence planning." 101 To this end, interoperability is not a threat to Canadian sovereignty, but precisely the amount of sovereignty preferred by political leaders.

Other contributors take different positions. Ann Crosby emphasizes the influence that the US exercises on Canada through NORAD and other bilateral mechanisms. ${ }^{102}$ Joseph Jockel writes of the trust that the US places in Canada through NORAD and argues that Canada must invest in the CAF to maintain its privileged status. ${ }^{103}$ Kim Richard Nossal largely echoes Bland's sentiment, adding that Canada's pursuit of interoperability with the US is especially rational because of the "hyperpower" status obtained by the US in the post-Cold War period. ${ }^{104}$ Jeremy Stocker writes that while the US underpins Canada's security and prosperity, Canada can only influence US policy by shouldering some of its military burden. However, he questions whether Canada needs to influence the US at all and recognizes that free-riding is a rational choice for policymakers focused on safeguarding budgets. ${ }^{105}$ This study aligns with the sentiments of Bland and Stocker in its characterization of interoperability as a cost-efficient method of earning security guarantees from the US and other key allies. It also aligns with Jockel's view that Canada must equip the CAF to be closely partnered with the US.

\footnotetext{
${ }^{101}$ Ibid, 57.

${ }^{102}$ Ann Crosby, "Defining the Debate: A Response to Danford Middlemiss and Denis Stairs," in The Canadian Forces and Interoperability: Panacea or Perdition?, 98-99.

${ }^{103}$ Joseph Jockel, "Norad: Interoperability At "The Zenith"," in The Canadian Forces and Interoperability: Panacea or Perdition?, 133.

${ }^{104}$ Kim Richard Nossal, "Canada and the United States in a Hyperpower Era," in The Canadian Forces and Interoperability: Panacea or Perdition?, 172.

105 Jeremy Stocker, "The Canadian Military Relationship with the United States: An Overseas Commentary," in The Canadian Forces and Interoperability: Panacea or Perdition?, 203, 205-207.
} 


\section{Towards a definition of interoperability}

Interoperability is centred around the ability of nations and militaries to cooperate. ${ }^{106}$ The prevailing focuses of this cooperation have evolved over time. The term originates from a 1980s program to rationalize logistics within NATO using alliance-wide standards (Standardization Agreements, or STANAGs). ${ }^{107}$ Interoperability has since evolved to include training and military doctrine. Today, the term is often used to reference signals connectivity between platforms and "intelligence flow," or the ability of platforms to host classified mission data. ${ }^{108}$ Interoperability has become an "umbrella term" with different meanings for different users. ${ }^{109}$

Interoperability lies near the middle of the integration continuum. At the low end of this scale is compatibility, where two systems or forces can operate side-by-side but do not interfere with one another's functioning. At the top end is complete integration, where two elements are functionally interdependent. ${ }^{110}$ Interoperability includes direct interaction between two systems or forces. But while their interaction is mutually beneficial, the exchange is not required for either element to function properly. Thomas Ford et al. find that the most common definition of interoperability is "the ability of systems, units, or forces to provide and accept services from other systems, units, or forces, and to use the services so exchanged to enable them to operate effectively together." ${ }^{111}$ Though this broad definition encompasses several areas where interoperability exists, it reveals little about the forms or purposes of the associated transactions.

\footnotetext{
106 "Author Interview with Subject G," interview by William Richardson, December 6, 2019, Ottawa, ON. ${ }^{107}$ Bland, "Military Interoperability: As Canadian as a Beaver," in The Canadian Forces and Interoperability: Panacea or Perdition?, 52-53.; "Author Interview with Subject G." 108 Ibid.

109 "Author Interview with Subject F," interview by William Richardson, November 22, 2019, Ottawa, ON.

${ }^{110}$ Middlemiss, and Stairs, The Canadian Forces and the Doctrine of Interoperability: The Issues, 11.

111 Thomas Ford et al., "A Survey on Interoperability Measurement," Proceedings of the 12th International Command and Control Research and Technology Symposium. Newport, R.I., June 19-21,
} 
The current NATO definition of interoperability refines the concept further. This reads that interoperability is "the ability to act together coherently, effectively and efficiently to achieve allied tactical, operational and strategic objectives." ${ }^{112}$ Interoperability has distinct applications at each level of military planning. Strategic interoperability entails states harmonizing worldviews and political objectives; alliances are strategically interoperable. ${ }^{113}$ At the operational and tactical levels, interoperability addresses the "interchangeability of force elements and units." 114 Military units exchange services, which can include ConOps, tactical assessments, C2 elements and ISR assets. ${ }^{115}$ Tactical and operational interoperability make combined forces more resilient and efficient in their pursuit of common strategic objectives.

The final level is technical interoperability, which is described by NATO as "the condition achieved among CIS [Communications and Information Systems] or items of CIS equipment when information or services can be exchanged directly and satisfactorily between them and/or their users." 116 The US Department of Defense's (DoD) interoperability definition echoes this one closely. ${ }^{117}$ Technical interoperability does not necessarily require that partner states use the same military equipment or CIS. Systems must simply be able to communicate

2007, In Christopher Pernin et al., Targeted Interoperability: A New Imperative for Multinational Operations (RAND Corporation, 2019), 15.

${ }^{112}$ NATO Glossary of Terms and Definitions (Brussels, Belgium: North Atlantic Treaty Organization, 2018), https://nso.nato.int/nso/zzlinks/terminology_public_non-classified $\% 20$ nato\%20glossaries.html, 68.

${ }^{113}$ Myron Hura, Interoperability: A Continuing Challenge in Coalition Air Operations, ed. Myron Hura (2000), 9 .

${ }^{114}$ Ibid, 12.

${ }^{115}$ Anthony W. Faughn, Interoperability: Is It Achievable? (Cambridge, MA: Harvard University, 2002), http://www.pirp.harvard.edu/pubs_pdf/faughn/faughn-p02-6.pdf., 6.; Eric Larson, Interoperability of U.S. And Nato Allied Air Forces Supporting Data and Case Studies, ed. Gustav Lindstrom et al. (Santa Monica: RAND Corporation, 2003), xiv-xv.

${ }^{116}$ NATO Standard AJP-6: Allied Joint Doctrine for Communication and Information Systems, by North Atlantic Treaty Organization (NATO Standardization Office, 2017) , 1-4.

${ }^{117}$ Department of Defense, "Dictionary of Military and Associated Terms," https://fas.org/irp/doddir/dod/jp1_02.pdf, 118. 
securely using common standards. ${ }^{118}$ This information-sharing directly enables tactical and operational interoperability; the services listed above cannot be transferred without it. ${ }^{119}$ The achievement of technical interoperability is complicated, however, by the evolution of CIS. ${ }^{120}$

Interoperability is generally strongest at one level when it has been satisfied at all levels. Likewise, a problem at one level can be expected to have knock-on effects at other levels. For example, disagreement over the strategic objectives of a coalition campaign can affect the types of operations undertaken, which has implications for the tactics and types of military equipment employed. Similarly, a lack of secure communications between tactical formations can reduce their resiliency and efficacy to the extent that partners cannot conduct combined operations in certain environments, thereby frustrating the achievement of strategic objectives. ${ }^{121}$ At all levels, interoperability enhances the ability of partner states to jointly attain shared strategic objectives.

To date, the inquiries of Canadian scholars have focused primarily on interoperability and questions of sovereignty, status and domestic politics. Such treatments are theoretical. They do not stray meaningfully from the boundaries of strategic interoperability, and in so doing neglect the links between government policy and the capabilities of the CAF. A greater understanding is required of the technical, tactical and operational imperatives that Canada's pursuit of strategic interoperability with key allies imposes on the CAF. Similarly, the effects of technical, tactical and operational interoperability issues at the strategic level are unclear. Stephenson flags some of these issues, but more systematic treatments are needed. ${ }^{122}$

\footnotetext{
${ }^{118}$ NATO, Backgrounder: Interoperability for Joint Operations (Brussels, Belgium: North Atlantic Treaty Organization, 2006), https://www.nato.int/nato_static_f12014/assets/pdf/pdf_publications/20120116_interoperability-en.pdf, 1. ${ }^{119}$ Faughn, Interoperability: Is It Achievable?, 6.

${ }^{120}$ Ibid, 24.

${ }^{121}$ Larson, Interoperability of U.S. And NATO Allied Air Forces Supporting Data and Case Studies, xiii. 122 The RAND Corporation has surveyed the interoperability challenges experienced in a number of multinational coalition operations in a larger study, see Hura, Interoperability: A Continuing Challenge in
} 
This study is one such piece. It will investigate the CIS interoperability of each competitor in the FFCP and the degree of technical interoperability that is formally required. It establishes that the requirement of interoperability is rooted in Canada's embrace of strategic interoperability for national defence. The analysis will investigate how the various CIS capabilities of the competing platforms could affect Canada's participation in defence partnerships. Interoperability at all levels is crucial to Canada's national defence.

\section{LISI interoperability model}

The Levels of Information Systems Interoperability (LISI) model was created by the DoD in 1998 to measure and classify CIS interoperability. ${ }^{123}$ The LISI model considers four enabling attributes: the procedures that enable CIS to exchange data and services; the CIS themselves; supporting infrastructure; and the required data formats and protocols. ${ }^{124}$ There are five LISI levels. Level 0 is isolated interoperability in a manual environment. This refers to stand-alone systems. Level 1 is connected interoperability in a peer-to-peer environment. Here, systems can transmit homogenous data types. Level 2 is functional interoperability in a distributed environment, where heterogeneous datasets can be passed between systems operating on a local network. Level 3 is domain-based interoperability in an integrated environment. Here, individual applications can share information within a Wide Area Network (WAN). Level 4 is enterprise-based interoperability in a universal environment, where the information space exists across domains and multiple users can access and modify heterogeneous data simultaneously. ${ }^{125}$

Coalition Air Operations.; Larson, Interoperability of U.S. And NATO Allied Air Forces Supporting Data and Case Studies.

${ }^{123}$ C4ISR Architectures Working Group, Levels of Information Systems Interoperability (Arlington, VA: Department of Defense, 1998), http://web.cse.msstate.edu/ hamilton/C4ISR/LISI.pdf, ES-7.

${ }^{124}$ Ibid, 2-8.

${ }^{125}$ Ibid, 2-5 to $2-7$. 


\section{Chapter 3: Methodology}

A generalized specific explanation will be used to explain the role of interoperability in Canada's future fighter decision. This method uses a general theory to explain a specific case. ${ }^{126}$ The chosen theory for this study is neoclassical realism. Specific explanations are comprised of causal, intervening and caused phenomena. ${ }^{127}$ The causal phenomenon is the requirement of interoperability for the future fighter as set out in the FFCP request for proposals (RFP). This is the study phenomenon. ${ }^{128}$ The intervening phenomena are the FFCP's weighted evaluation criteria for industrial benefits provided to Canadian industry and cost, each valued at 20 percent of the total bid evaluation criteria. ${ }^{129}$ The caused phenomenon is the selection of a platform that incorporates certain interoperable technologies.

\section{Generalizability}

Because this is a single- $n$ case study, the findings cannot effectively be generalized to other Canadian or allied procurement projects. Indeed, the specific causal and intervening phenomena are unique to Canada and the FFCP. However, this study is of broader relevance in three ways. First, this study's conceptualization of interoperability as a military capability, with the lower levels supporting the state's achievement of strategic interoperability, is applicable to other defence procurements and clarifies some of the conditions that Canada's pursuit of strategic interoperability imposes on the CAF. Second, the notion of the SOR effectively competing with the cost and industrial offsets pillars in the RFP for determinative weight in the

\footnotetext{
${ }^{126}$ Stephen Van Evera, Guide to Methods for Students of Political Science (Ithaca, NY: Cornell University Press, 1997). www.jstor.org/stable/10.7591/j.ctvrf8bm7, 41.

${ }^{127}$ Ibid, 15.

${ }^{128}$ Van Evra writes that the higher the value on the study phenomenon, the lower the number of third factors that might be strong enough to produce the result predicted by theory, see Van Evera, Guide to Methods for Students of Political Science, 52-53.

129 "Author Interview with Subject D," interview by William Richardson, November 19, 2019, Ottawa, ON.
} 
bid evaluation process illustrates a common tension in Canadian defence capital projects. Third, this study is of relevance to Canada's FVEY partners, each of whom must incorporate high-end CIS interoperability into their warplanes.

\section{Data collection}

Two methods of research have been employed for this study. First, the author has examined the literature on Canada's program to replace the CF-18, interoperability and Canadian defence policy. Given this study's contemporary focus, the author has also consulted periodicals. Second, the author conducted seven semi-structured research interviews, with each lasting between one and two hours. Three defence researchers, one current senior official and three retired senior officials were interviewed. Subjects were selected based on their work experience and expertise. Research ethics clearance was obtained from Carleton University in October 2019 and interviews took place between October and December 2019. Interview subjects participated in the study voluntarily; their input has been anonymized. During interviews, each subject responded to a list of pre-prepared questions before answering impromptu follow-up queries. Discussion topics included the pursuit and achievement of interoperability by the CAF, Canada's participation in alliances, the FFCP requirements and the capabilities of the competing types. The evidence provided by interviewees was often more detailed and unvarnished than what is publically available; the material has been subjected to corroboratory research and is cited throughout this study. During the study, two interview subjects revealed to the author that they have ongoing business relationships with one of the suppliers participating in the FFCP. These individuals maintained that their answers remained unaffected by undue bias and grounded in their public-sector experiences. The author, aware of potential conflicts of interest, undertook additional questioning with these individuals and researched the evidence provided accordingly. 


\section{Chapter 4: Contemporary Canadian defence policy}

SSE sets out Canada's perception of the international system and its strategic decisions. It establishes that interoperability with the US and other allies is central to Canada's national defence. At the start of the document, the defence team is directed to:

Actively address threats abroad for security at home; Field an agile, well-educated, flexible, diverse, combat-ready military; Develop sophisticated awareness of its operating environment to better predict and respond to crises; Act as a responsible, value-added partner with NORAD, NATO and Five-Eyes partners; Work with the United States to ensure that NORAD is modernized to meet existing and future challenges; Balance traditional relationships with the need to engage emerging powers; Field advanced capabilities to keep pace with allies and maintain an advantage over potential adversaries. ${ }^{130}$

These core pursuits position Canada as a valuable partner, with military capability acquired in part to remain abreast of allied developments. The implication is that Canada receives security in exchange for alliance contributions. Though the "new strategic vision" laid out is not actually new at all, it is in keeping with this cooperative theme. ${ }^{131}$ SSE envisages a Canada that is:

(1) Strong at home, its sovereignty well-defended by a Canadian Armed Forces also ready to assist in times of natural disaster, other emergencies, and search and rescue; (2) Secure in North America, active in a renewed defence partnership in NORAD and with the United States; (3) Engaged in the world, with the Canadian Armed Forces doing its part in Canada's contributions to a more stable, peaceful world, including through peace support operations and peacekeeping. ${ }^{132}$

These are the three missions of Canadian defence policy. Two of them explicitly involve partners and the other relies on allies implicitly. SSE sets expectations for the CAF rather than a "grand strategic vision." ${ }^{133}$ A major component is working productively with allies and partners -

\footnotetext{
${ }^{130}$ Defence, Strong, Secure, Engaged: Canada's Defence Policy, 14.

${ }^{131}$ Ibid, 14.

${ }^{132}$ Ibid, 14.

${ }^{133}$ Adam Chapnick and J. Craig Stone, "From Policy and Strategy to Outcomes," in Canadian Defence Policy in Theory and Practice, 85.
} 
defence policy is executed "through a strategy of commitments" to them. ${ }^{134}$

\section{Domestic operations}

The CAF's first mission is to "detect, deter and defend against threats to or attacks on Canada." ${ }^{135}$ This includes surveillance of Canada's territory and its approaches, with specific emphasis on the Arctic region. SSE directs that assets be maintained at high readiness to respond to potential threats. ${ }^{136}$ While the CAF handles domestic missions on its own, external partners remain relevant in two ways. First, as a member of NATO, Canada is subject to Article V of the Washington Treaty, which provides for the collective defence of all members. ${ }^{137}$ Second, inbound threats would almost certainly be detected through the NORAD framework, thereby directly implicating the US in Canada's defence.

\section{Canada and the US: a unique defence partnership}

The second focus is the maintenance of the bilateral defence partnership with the US. This unique relationship is rooted in geography and relative material power - core tenets of neoclassical realism. The RCAF Future Air Operating Concept reads that "since the end of the Cold War, US military power has been unrivalled. Indeed, the defining feature of the post-Cold War period has been the preponderance of US military, economic and technological strength." 138

\footnotetext{
${ }^{134}$ Douglas Bland in ibid, 91.

${ }^{135}$ Defence, Strong, Secure, Engaged: Canada's Defence Policy, 83.

${ }^{136}$ Ibid, 83.

${ }^{137}$ NATO, "Strategic Concepts," North Atlantic Treaty Organization, 2018, accessed February 10, 2020, http://www.nato.int/cps/en/natohq/topics_56626.htm.

${ }^{138}$ Royal Canadian Air Force, Future Concepts Directive Part 2: Future Air Operating Concept (Ottawa, ON: National Defence and the Canadian Armed Forces, 2016), http://www.rcafarc.forces.gc.ca/assets/AIRFORCE_Internet/docs/en/cf-aerospace-warfare-centre/elibrary/futureconcepts-directive-part-2-future-air-operating-concept.pdf, 10.
} 
The authors of SSE assert that the US "is still unquestionably the only superpower." 139 They continue that the bilateral partnership "remains integral to continental security and the United States continues to be Canada's most important military ally." 140 These sentiments betray the primacy of the US in Canada's strategic calculus. The Canada-US defence partnership is central to national defence and has been called "the only coalition that matters to Canada." 141 It has also enabled successive Canadian governments to devote relatively modest resources to the file.

As the risk of war in Europe grew in the late 1930s, President Franklin Roosevelt pledged that the US would not "stand idly by" if Canada should be threatened by an external enemy. In response, Prime Minister Mackenzie King committed Canada to securing its territory against armed incursion so that it could not be used to threaten the US. ${ }^{142}$ The US guarantee provided Canada with more security than it could provide for itself at a low cost to the state, but Canada was "no longer free to pursue a completely autonomous defence policy." 143 The US became part of Canada's strategic geography; Canada would need to avoid becoming a strategic liability. ${ }^{144}$ These understandings were formalized in the Ogdensburg Agreement of 1940, which committed both countries to mutual defence and established the Permanent Joint Board on Defence (PJBD).

Bilateral cooperation has flowed from there. Other key developments include the establishment of the Military Cooperation Committee in 1946 for the management of military

\footnotetext{
${ }^{139}$ Defence, Strong, Secure, Engaged: Canada's Defence Policy, 50.

${ }^{140}$ Defence, Strong, Secure, Engaged: Canada's Defence Policy, 60.

${ }^{141}$ Douglas Bland, "Canada and Military Coalitions: Where, Who and with Whom?," in Geopolitical Integrity, ed. Hugh Segal, Canadian Electronic Library. Books Collection. (Montreal, QC: IRPP, 2005), 123.

${ }^{142}$ Kim Richard Nossal, "The Imperatives of Canada's Strategic Geography," in Canadian Defence Policy in Theory and Practice, 14.

143 Ibid, 14.

${ }^{144}$ Justin Massey and Srdjan Vucetic, "Canadian Strategic Cultures: From Confederation to Trump," in Canadian Defence Policy in Theory and Practice, 35.
} 
planning and the Canada-United States Defence Production and Defence Development Sharing Agreements of 1956 and 1963, respectively, which integrated the continental defence industrial base. ${ }^{145}$ Of particular relevance is the $35^{\text {th }}$ recommendation of the PJBD, issued in 1947 , which commits both countries to the "adoption, as far as practicable, of common designs and standards in arms, equipment, organization [and] methods of training." ${ }^{\prime 46}$ A major focus of the partnership has been to ensure that interoperability exists from the strategic level down to the technical level. Today, there are more than 80 treaty-level defence agreements between Canada and the US, more than 250 MOUs between the two defence departments and approximately 145 bilateral forums in which defence issues are discussed. ${ }^{147}$ SSE recognizes that "Canadian and American services are well-integrated and interoperable, both from a materiel and doctrinal perspective."148

The clearest manifestation of shared strategic geography and bilateral interoperability is NORAD. ${ }^{149}$ In SSE, the CAF is directed to "detect, deter and defend against threats to or attacks on North America in partnership with the United States, including through NORAD."150 Established in 1958, NORAD is the only permanent binational military command in the world and elevates Canada to a rarified station as an ally of the US. NORAD is charged with the provision of aerospace warning, air sovereignty and protection across Canada and the US. Complex sovereignty is at play. The conceptualization of continental air defence as one problem permits Canada to cost-effectively expropriate US resources for its own defence, while the NORAD C2 framework grants Canada unparalleled access to US intelligence and a unique

\footnotetext{
${ }^{145}$ Hugh Segal, "Geopolitical Integrity for Canada," in Geopolitical Integrity, 25.

${ }^{146}$ Middlemiss, and Stairs, The Canadian Forces and the Doctrine of Interoperability: The Issues, 16.

${ }^{147}$ Segal, "Geopolitical Integrity for Canada," in Geopolitical Integrity, 25.

${ }^{148}$ Defence, Strong, Secure, Engaged: Canada's Defence Policy, 83.

${ }^{149}$ See Nossal, "The Imperatives of Canada's Strategic Geography.," 17.

${ }^{150}$ Defence, Strong, Secure, Engaged: Canada's Defence Policy, 106.
} 
opportunity to participate in strategic decision-making. ${ }^{151}$ NORAD further protects Canada's sovereignty by enabling the US to satisfy a national security imperative without encroaching on Canadian territory. ${ }^{152}$ NORAD is headquartered in Colorado Springs, Colorado. It has a US Commander and a Canadian Deputy Commander. Personnel are deployed in both countries.

Canada's sole contribution to NORAD's response element is its tactical fighter capability. In testimony before the Parliamentary Standing Committee on National Defence, Deputy Commander of NORAD Lieutenant-General Pierre St-Amand said that "when you think of what NORAD does, just imagine a triangle with fighter aircraft at the tip. That fighter aircraft, of course, is critical to control. This is how we control the airspace." ${ }^{153}$ Under the NORAD framework, Canada and the US must each maintain predetermined numbers of fighter aircraft on constant alert, ready to intercept inbound threats. This is a hard commitment for both countries.

Canadian and American interceptors are operationally interchangeable on NORAD missions. ${ }^{154}$ Stephenson writes that the fighters are "the only Canadian military force that is operationally interdependent with the US in day-to-day operations." ${ }^{155} \mathrm{CF}-18$ s are loaded with highly sensitive CAN/US mission data on NORAD operations - the very same data loaded onto American interceptors conducting the same missions. CF-18s are also networked to CAN/US C2

\footnotetext{
${ }^{151}$ James Fergusson, Beneath the Radar: Change and Transformation in the Canada-U.S. North American Defence Relationship (Calgary, AB: Canadian Defence and Foreign Affairs Institute, 2009), https://d3n8a8pro7vhmx.cloudfront.net/cdfai/pages/41/attachments/original/1413661866/Beneath_the_Ra dar.pdf?1413661866,\%205-6, 5-6.; Middlemiss, and Stairs, The Canadian Forces and the Doctrine of Interoperability: The Issues, 18-19.

${ }^{152}$ Nossal, "The Imperatives of Canada's Strategic Geography," 17.; Vucetic, "Canadian Strategic Cultures: From Confederation to Trump," 36.

${ }^{153}$ House of Commons, Canada and the Defence of North America: NORAD and Aerial Readiness, 42 Parliament., 1 sess., by Standing Committee on National Defence (Ottawa, ON: Government of Canada, 2016), 43.

154 "Author Interview with Subject F."

${ }^{155}$ Stephenson, Anatomy of a Buy: The Four Dimensions of Procuring a Fighter Fighter for Canada, 6.
} 
assets on NORAD operations. Canada's fighter force must therefore be fully interoperable with its American counterpart, with one interviewee concluding: "the more seamless [the] interoperability, the better." ${ }^{156}$ Indeed, General St-Amand testified that the interoperability of the future fighter in NORAD "is absolutely critical." ${ }^{157}$ He continued that interoperability concerns everything from runway length and base location to sensor-to-sensor communications, manmachine interfaces and weapons used. ${ }^{158}$ Lieutenant General Michael Hood, then-Commander of the RCAF, testified similarly that "for Canada, being interoperable with the US Air Force is number one." ${ }^{\prime 59}$ Canada's fighters must be fully integrated into the North American battlespace.

The NWS underpins NORAD's detection element. It is comprised of 50 land-based early warning radar sites situated along the arctic coast, 47 in Canada and three in Alaska. Returns are fed to the Canadian Air Defence Sector located at 22 Wing in North Bay, Ontario. ${ }^{160}$ The NWS was constructed between 1986 and 1992 and is now in need of replacement:

While the current NWS is approaching the end of its life expectancy from a technological and functional perspective, unfortunately the range of potential threats to the continent, such as that posed by adversarial cruise missiles and ballistic missiles, has become more complex and increasingly difficult to detect. ${ }^{161}$

The NWS lacks the range to track Russian bombers before they reach points over the arctic from which they can launch advanced cruise missiles. It is also unable to track these weapons in

\footnotetext{
156 "Author Interview with Subject F."

${ }^{157}$ Canada and the Defence of North America: Norad and Aerial Readiness, by Defence, 43.

${ }^{158}$ Ibid, 43.

${ }^{159}$ Ibid, 42.

${ }^{160}$ The Alaskan sites are managed and maintained by the US, see National Defence and the Canadian Armed Forces, "North Warning System," Government of Canada, 2012, accessed January 25, 2020 , http://www.forces.gc.ca/en/news/article.page?doc=north-warning-system/hgq87x9w.

${ }^{161}$ Defence, Strong, Secure, Engaged: Canada's Defence Policy, 79.
} 
flight. ${ }^{162}$ Finally, the system's detection radius does not encompass Canada's newly expanded Air Defence Identification Zone, which now reaches to the edge of the Arctic Archipelago. ${ }^{163}$ Bilateral discussions on a modernized NWS are ongoing. The new system will be a central component of the modernized NORAD framework. ${ }^{164}$

Canada's defence partnership with the US requires that it generate sufficient military power to avoid being considered a liability. This is in keeping with Ørvik's “defence against help" thesis. ${ }^{165}$ Canada must earn the defence partnership. Rear-Admiral Scott Bishop, Director General of International Security Policy at DND, spoke to this imperative in 2016:

Being interoperable with the United States to pursue military operations is not surrendering Canadian sovereignty. In fact, it's exactly the opposite. Being interoperable with the United States lets us remain an equal partner because we have capabilities to work shoulder to shoulder with our most important ally. ${ }^{166}$

Middlemiss and Stairs argue that as America's junior partner, Canada must maintain its military standards. ${ }^{167}$ If Canada wishes to obtain guarantees of security and sovereignty from the US, then it must continue to bring useful military capabilities to the bilateral partnership. While NORAD is well established, national roles can always be revised. ${ }^{168}$ When Canada relinquishes a military capability, it relinquishes a degree of choice and control over its defence. As a

\footnotetext{
${ }^{162}$ Andrea Charron, and Jim Fergusson, Norad: Beyond Modernization (Winnipeg, MB: University of Manitoba, 2019), http://umanitoba.ca/centres/cdss/media/NORAD_beyond_modernization_2019.pdf, 13. ${ }^{163}$ Ibid, 25-26.

${ }^{164}$ Justin Doubleday, U.S., Canada to Finish North Warning System Analysis by Next Spring, vol. 33 (Arlington: Inside Washington Publishers, 2017).

${ }^{165}$ See Ørvik, "The Basic Issues in Canadian National Security: Defence against Help."

${ }^{166}$ Canada and the Defence of North America: Norad and Aerial Readiness, by Defence, 44.

${ }^{167}$ Middlemiss, and Stairs, The Canadian Forces and the Doctrine of Interoperability: The Issues, 14.

168 "Author Interview with Subject C."
} 
neighbour and senior partner, the US has an interest in accommodating Canada, but like any security-seeking state, it remains self-interested and most likely to prioritize its own defence. ${ }^{169}$

\section{Canadian defence policy beyond North America}

The third focus of Canadian defence policy is the away game. SSE reads that "combating threats to global stability reinforces security and prosperity at home." ${ }^{\prime 70}$ Canada will help protect the US-led Western international order. The CAF is to be prepared for three missions abroad:

(1) Lead and/or contribute forces to NATO and coalition efforts to deter and defeat adversaries, including terrorists, to support global stability; (2) Lead and/or contribute to international peace operations and stabilization missions with the United Nations, NATO and other multilateral partners; (3) Engage in capacity building to support the security of other nations and their ability to contribute to security abroad. ${ }^{171}$

The first of these missions is the most relevant to this study. The CAF will "be prepared to operate with its close allies and partners to defeat armed adversaries and respond to instability, around the world and in international waters." ${ }^{172}$ In the expeditionary context too, Canada remains first and foremost a team player, serving as a valued contributor to larger operations. Canadian policymakers and military strategists alike understand that Canada lacks the resources, structures and culture to "go in and do any of this stuff on our own."173

NATO, which has traditionally been led by the US, serves as the vehicle for many of Canada's contributions to global stability. SSE reaffirms Canada's commitment to its NATO

\footnotetext{
169 "Author Interview with Subject C."; Fergusson, "The Right Debate: Airpower, the Future of War, Canadian Strategic Interests, and the JSF Decision," 212.

${ }^{170}$ Defence, Strong, Secure, Engaged: Canada's Defence Policy, 83.

${ }^{171}$ Ibid, 106.

172 Ibid, 83.

173 "Author Interview with Subject F."
} 
allies and collective defence. The CAF is directed to "contribute to efforts to deter aggression by potential adversaries in all domains." ${ }^{174}$ But compared to NORAD, NATO is more diverse and has a broader remit. Canada's NATO contributions can usually be negotiated or exchanged with other members. ${ }^{175}$ Still, interoperability has an important place in the alliance, with the NATO Standardization Office (NSO) coordinating initiatives and supporting STANAG development. ${ }^{176}$

\section{Canada and the Five Eyes}

The final piece in Canada's focus on partnerships for defence policy is FVEY. This is not an alliance and lacks a formal framework. Rather, FVEY is a cooperative intelligence-sharing arrangement between the US, UK, Canada, Australia and New Zealand. The partnership is rooted in cultural similarities, shared liberal democratic values and complementary national interests; the FVEY partners are strategically interoperable. ${ }^{177}$ Each member contributes unique intelligence-gathering capabilities and surveils a specific world region. ${ }^{178} \mathrm{FVEY}$ officials meet regularly to review the performance of the network and plan for its future. While deliberations are collaborative, the US is the primary producer of intelligence and most influential member. ${ }^{179}$

FVEY does not slot neatly into one of SSE's three focuses. Instead, it contributes to each:

Canadian security and defence preparedness benefits tremendously from connectivity with our closest allies, particularly the Five-Eyes network...This partnership, in which Five-Eyes partners share much of the information collected by their respective military assets, enhances Canada's ability to understand existing conflict zones and predict future ones, and allows cost-saving and

\footnotetext{
174 Ibid, 83, 50.

175 "Author Interview with Subject E."

176 There are more than 1200 STANAGs in effect today, see "NATO Standardization Office (NSO)," North Atlantic Treaty Organization, 2017, accessed February 6, 2020, http://www.nato.int/cps/en/natohq/topics_124879.htm.

177 James Cox, "Canada and the Five Eyes Intelligence Community," Open Canada (December 18 2020).

178 "Author Interview with Subject C."; Cox, "Canada and the Five Eyes Intelligence Community."

${ }^{179}$ Cox, "Canada and the Five Eyes Intelligence Community."
} 
burden-sharing among partner nations...Canada will continue to foster and

strengthen intelligence sharing relationships in a spirit of reciprocity. ${ }^{180}$

FVEY permits Canadian decision-makers to get inside the decision cycles of adversaries and furnishes the CAF with a significant operational advantage. Intelligence informs Canadian decision-making at the strategic, operational and tactical levels. Furthermore, FVEY membership is resource-efficient for Canada, which lacks an overseas intelligence agency.

FVEY cooperation extends beyond intelligence-sharing. A number of forums exist to enhance the interoperability of the five partner militaries. The Combined Communications Electronics Board (CCEB) is tasked with enhancing the technical interoperability of the partner militaries and includes working groups dedicated to the technical details and operations of CIS. ${ }^{181}$ The Five Eyes Air Force Interoperability Council (AFIC) facilitates cooperation between partner air forces and implements Air Standards. Subordinate working groups address interoperability in force protection, ISR, information-security and networked informationsharing. The AFIC also ensures that member air forces have compatible logistics available for partner aircraft when needed. ${ }^{182}$ These mechanisms signal the scope of FVEY standardization efforts and the sophistication of the joint capabilities being pursued.

\footnotetext{
${ }^{180}$ Defence, Strong, Secure, Engaged: Canada's Defence Policy, 64-65.

${ }^{181}$ Department of the U.S. Army, Army Regulation 34-1: Multinational Force Interoperability, 2015, 18. ${ }^{182}$ Army Regulation 34-1: Multinational Force Interoperability, 17; "Defense Standardization Program: International Standardization," United States Department of Defense, accessed February 15, 2020, https://www.dsp.dla.mil/Programs/International-Standardization/.; C.J. England, "Air and Space Interoperability Council and the RCAF" (Canadian Forces College, 2016), https://www.cfc.forces.gc.ca/259/290/298/286/england.pdf, 35-36.; "Author Interview with Subject G."
} 


\section{Chapter 5: Western airpower and the networked battlespace}

Canada is renewing its tactical fighter capability during a period of transformation in Western airpower. First, with the entry into service of the F-35, Canada's defence partners are starting to transition away from fourth-generation fighters and embrace the capabilities offered by fifth-generation types. Second, the advent of the F-35 is driving the development of innovative $\mathrm{C} 2$ concepts. In its analysis of these trends and Canada's early efforts to embrace them, this chapter provides the allied context for Canada's fighter purchase.

\section{Overview of fourth-generation fighter jets}

Western fast-jets are classified by generation. Stephenson writes that while short-term technical advances can generally be accommodated in existing airframes, generational changes are structural in nature; new design concepts and systems architectures promising innovative capabilities are largely incompatible with older platforms. ${ }^{183}$ Today, most of the 3,100 fighter and attack aircraft operated by the US military and the 2,030 fighter and attack aircraft operated by the European NATO allies are either fourth-generation or evolved fourth-generation types the 77 CF-18s presently in service with the RCAF are fundamentally fourth-generation aircraft. ${ }^{184}$ Types of this generation are characterized by fly-by-wire control systems, air- and ground-search radars, externally mounted weapons including precision munitions and highstrength airframes designed for maneuverability. Most fourth-generation fighter aircraft are multirole platforms. Evolved fourth-generation types are essentially similar, but can add any combination of active electronically scanned array (AESA) radars, reduced radar signatures,

\footnotetext{
${ }^{183}$ Stephenson, Anatomy of a Buy: The Four Dimensions of Procuring a Fighter Fighter for Canada, 8. ${ }^{184}$ World Air Forces 2018, FlightGlobal (Reed Business Information Limited, December 2017).; see "A History of Canada's CF-18 Hornets | CBC News," CBC News, Canada: In Depth, 2011, https://www.cbc.ca/news/canada/cf-18-hornets-1.1003648.
} 
high-capacity datalinks, advanced avionics, and new weapons payloads. ${ }^{185}$ All fourth-generation types are based on 1970s or 1980s basic airframe designs, which according to Stephenson, "limits the growth potential in their architecture." 186 While evolved fourth-generation fighter aircraft may be fitted with advanced electronic countermeasures suites, their airframes remain vulnerable to modern air defence systems. Though such types employ advanced avionics and high-capacity datalinks, their federated mission computers have limited capacity to fuse the data received from on- and off-board sensors. All fourth-generation fighters are expected to reach operational obsolescence in the 2040s, from which point they will be retired. ${ }^{187}$

\section{Overview of fifth-generation fighter jets}

The first transition underway in Western airpower is the widespread introduction of the F-35, a fifth-generation strike fighter which first entered service with the US Air Force (USAF) in July 2016. The type is set to enter full-rate production within the next year, with LockheedMartin expecting to build between 130 and 160 planes annually. ${ }^{188}$ Though the F-35 is not actually the first fifth-generation type to enter service - that distinction goes to the USAF's Lockheed Martin F-22 Raptor, it is the first to be exported. The US military plans to purchase a total of 2,456 F-35s. Ten other countries - including the UK, Australia, Italy, Norway, the

\footnotetext{
${ }^{185}$ AESA radars are a relatively recent innovation on fighter aircraft and surpass older mechanically scanned sets in the categories of multiple simultaneous target tracking, high resolution air and ground mapping, low probability of detection and electronic attack, see Justin Bronk, Maximizing European Combat Air Power: Unlocking the Eurofighter's Full Potential (London, UK: Royal United Services Institute for Defence and Security Studies, 2015), https://rusi.org/sites/default/files/whr_115_maximising_european_combat_air_power_0.pdf, 6.; For one categorization of fighter jet generations, see John Tirpak, "The Sixth Generation Fighter," Air Force Magazine, 2009, https://www.airforcemag.com/article/1009fighter/.

${ }^{186}$ Stephenson, Anatomy of a Buy: The Four Dimensions of Procuring a Fighter Fighter for Canada, 4. ${ }^{187}$ Ibid, 12.

${ }^{188}$ Valerie Insinna, "Inside America's Dysfunctional Trillion-Dollar Fighter-Jet Program," The New York Times (New York, NY), At War, 2019, https://www.nytimes.com/2019/08/21/magazine/f35-joint-strikefighter-program.html.
} 
Netherlands, Belgium and Denmark - intend to procure an additional $715 .{ }^{189}$ Because it has been ordered in such large numbers, the F-35 will replace numerous legacy types and increasingly become a mainstay in the air forces of Canada's NATO allies and FVEY partners. The type is expected to remain in widespread service beyond $2070 .{ }^{190}$

The F-35 provides a step-change in capability over its fourth-generation predecessors. According to the US Congressional Research Service, fifth-generation aircraft "incorporate the most modern technology," combining "new developments such as thrust vectoring, composite materials, stealth technology, advanced radar and sensors, and integrated avionics to greatly improve situational awareness." ${ }^{191}$ Lockheed Martin, the prime contractor and manufacturer for the F-35 program, lists the following attributes for fifth-generation fighter aircraft: "Very Low Observable (VLO) stealth, advanced sensors, information fusion and network connectivity - all packaged within a supersonic, long range, highly maneuverable fighter." 192 Fifth-generation characteristics can collectively be divided into two categories.

First, fifth-generation types are high-performance aircraft. The F-22, for example, can "supercruise" above one and a half times the speed of sound without the use of afterburners, a capability which provides a significant time-distance advantage to the operator. ${ }^{193}$ The F-22 also possesses thrust vectoring for enhanced maneuverability compared to legacy platforms, making it a peerless dogfighter. Finally, the type has a VLO capability which improves its operational

\footnotetext{
${ }^{189}$ Lara Seligman, "The Countries Where F-35 Sales Are Taking Off," Foreign Policy (2018); Philip Blenkinsop, "Belgium Chooses Lockheed's F-35 over Eurofighter: Belga," Reuters (2018). ${ }^{190}$ Stephenson, Anatomy of a Buy: The Four Dimensions of Procuring a Fighter Fighter for Canada, 4. ${ }^{191}$ Jeremiah Gertler, F-35 Joint Striker Fighter (JSF) Program (Washington D.C.: Congressional Research Service, 2018), https://fas.org/sgp/crs/weapons/RL30563.pdf. 192 "F-35 Capabilities," Lockheed Martin Corporation, 2018, accessed December 10, 2019, https://www.lockheedmartin.com/en-us/products/f-35/f-35-capabilities.html.

${ }^{193}$ F-22 Demonstrates 'Supercruise' for First Time (Wright-Patterson Air Force Base, OH: Air Force News, 1999).
} 
performance in anti-access/area denial (A2/AD) environments. Such attributes make fifthgeneration types advanced air superiority fighters and fighter/bombers, but they do not fundamentally change the way tactical fighter aircraft can be used. The avionics integrated into fifth-generation platforms enable this change.

While the F-35 also possesses a high-performance VLO airframe, it is first and foremost a networked electronic system. This is the second, more impactful way of conceptualizing fifthgeneration warplanes. Further to the descriptions above, the F-35 uses next-generation sensors, a sophisticated mission computer or "fusion engine" and a VLO broadband communications suite to gather, fuse, analyze and disseminate a wide variety of tactical information around the battlespace in a stealthy manner. ${ }^{194}$ This capability enables the type to enhance the situational awareness and effectiveness of a mixed-generation air formation or joint force. ${ }^{195}$ The F-35's next-generation sensors and processing power, when combined with its VLO attributes, also allow it to serve as a penetrative ISR or defence suppression platform. Fifth-generation types are truly multi-mission aircraft. A fuller analysis of the F-35's CIS capabilities follows in Chapter 6.

A legacy fighter capability is platform-centric - concerned primarily with maximizing the tactical effects that can be generated by a platform or group of platforms, given airframe performance characteristics and available on-board systems. The fifth-generation fighter capabilities now under development in the West are network-centric. Northrop Grumman, the primary supplier of the F-35's avionics, describes fifth-generation aircraft as "key participants in network-centric operations." ${ }^{\prime 196}$ Early F-35 operators recognize that fielding a fifth-generation

\footnotetext{
${ }^{194}$ Nick Zazulia, "F-35 Data Fusion: How the Smartest Fighter Shares What It Sees - Avionics," Avionics International, 2018-09-04, 2018, https://www.aviationtoday.com/2018/09/04/f-35-data-fusion/.

${ }^{195}$ Bronk, Maximizing European Combat Air Power: Unlocking the Eurofighter's Full Potential, 14.

${ }^{196}$ Daniel Akers, Understanding Voice and Data Link Networking: Northrop Grumman's Guide to Secure Tactical Data Links (San Diego, CA: Northrop Grumman, 2014),
} 
aircraft is not inherently equal to fielding a fifth-generation capability. Rather, the F-35 "compels air forces to integrate and network with land and maritime forces in an unprecedented way next-generation air forces will require next-generation joint forces." ${ }^{197}$ The F-35 is only the starting point (and forcing function) for a military's next-generation capability. This is the second transition underway in Western military doctrine.

\section{The multi-domain battlespace and Multi-Domain Command Control (MDC2)}

Warfare is fundamentally oriented around leveraging information to achieve decision superiority over an adversary. Managing information is central to successfully generating effects in a conflict situation. ${ }^{198}$ In the late 1980 s and early 1990 s, military situational awareness in the West (and particularly in the US) was transformed by a new generation of ISR technologies and the widespread introduction of real-time tactical networking between battlefield assets. ${ }^{199}$ Today, the quantity of data being produced by Western militaries is staggering. Governments, including Canada, are struggling to keep up. In 2014, USAF units generated approximately 1600 hours of video footage per day, with more than 10,000 trained professionals needed to process, exploit and disseminate the data. ${ }^{200}$ In addition to the challenge of quantity, the dissemination of data has been complicated by a lack of compatibility between the CIS used by Western militaries. Joint

http://www.northropgrumman.com/Capabilities/DataLinkProcessingAndManagement/Documents/Unders tanding_Voice+Data_Link_Networking.pdf, 8-2.

${ }^{197}$ André Adamson, and Matthew Snyder, The Challenges of Fifth-Generation Transformation (Kalkar, Germany: Joint Air Power Competence Centre, 2018), https://www.japcc.org/the-challenges-of-fifthgeneration-transformation/.

198 "Author Interview with Subject D."; "Author Interview with Subject F."

199 "Author Interview with Subject D."

${ }^{200}$ Jacob Hess et al., The Combat Cloud: Enabling Multidomain Command and Control across the Range of Military Operations (Maxwell Air Force Base, Alabama: Air University: Air Command and Staff College, 2019), https://media.defense.gov/2019/Mar/01/2002095278/-1/1/0/WF_0065_HESS_COMBAT_CLOUD.PDF, 17. 
and multinational operations since the end of the Cold War have regularly been hampered by the inability of ground forces, ships and aircraft to communicate with one another. ${ }^{201}$

Canada's closest allies envisage a multi-domain battlespace wherein data is leveraged to achieve decision superiority over near-peer adversaries. In an interview in 2018, USAF Chief of Staff General David Goldfein argued that networked connectivity provides US forces with an “asymmetric advantage" against potential near-peer adversaries. ${ }^{202}$ Under the concept, each friendly platform participating in an operation serves as a node in a single network spanning the battlespace. Platforms are linked electronically across operational domains and warfighting functions, all exchanging and corroborating tactical data. In keeping with the argument of British Air Chief Marshal Sir Stephen Hillier, the goal of the multi-domain battlespace is to move away from platform-centric situational awareness and towards a network-enabled Common Operating Picture (COP). ${ }^{203}$ This level of connectivity, which moves towards Level 4 of the LISI model, allows the members of a joint force to exchange operational tasks and decision-making. Such a force can observe and prosecute a target in more than one way, with its constituent units free to confer and select the most effective and efficient tactical option. This novel capability produces agility and resiliency in a joint force and has major implications for C2.

General Goldfein has made Multi-Domain Command and Control (MDC2) a first-order priority for the USAF. MDC2 is defined as "the ability to seamlessly analyze, fuse and share what was once domain-centric information into a single $\mathrm{C} 2$ system that supports all domains and

\footnotetext{
${ }^{201}$ Akers, Understanding Voice and Data Link Networking: Northrop Grumman's Guide to Secure Tactical Data Links, 9-2.

${ }^{202}$ Sydney J. Freedberg, "'a Computer That Happens to Fly': USAF, RAF Chiefs on Multi-Domain Future," Breaking Defense, 2018, https://breakingdefense.com/2018/04/a-computer-that-happens-to-flyusaf-raf-chiefs-on-multi-domain-future/.

${ }^{203}$ Ibid.
} 
all levels of war." ${ }^{204}$ Advances in tactical networking have made more distributed C2 functions possible. Channels of operational communication are becoming more numerous and less vertical in orientation, enabling more efficient decision making and execution. Under this concept, emphasis is placed on adapting to the dynamics of an operational scenario as an integrated force. ${ }^{205}$ The commanders of the USAF see value in employing MDC2 in the NATO context. ${ }^{206}$ Stephenson argues that the concept will shape the future C2 environment in US Northern Command (NORTHCOM) and by extension NORAD, especially given the forthcoming renewal of the NWS. ${ }^{207}$ Innovative system of systems concepts being developed by Canada's closest allies promise to transform situational awareness and C2 - jointly known as Command, Control, Communications, Computers, Intelligence, Surveillance and Reconnaissance (C4ISR).

MDC2 is described as an open-architecture framework. According to Air Chief Marshal Hillier, Western air forces should no longer strive to develop CIS that meet strict requirements. This approach endangers interoperability as technology and allied standards evolve over the lifecycle of a system. Instead, militaries should align themselves with the best CIS available and be open to emerging solutions, thereby keeping pace with development and maximizing the potential for collaboration. Hillier believes that the UK and its allies "need to describe a framework [they] can all operate together within" and let countries bring their own systems. ${ }^{208}$

It is unreasonable to assume, however, that all network-enabled platforms currently in service with Western militaries will be compatible with MDC2. Though it is envisaged as an open-architecture, "plug-and-play" framework, Canada and other like-minded nations wishing to

\footnotetext{
${ }^{204}$ Tim Zadalis, Multi-Domain Command and Control (Kalkar, Germany: Joint Air Power Competence Centre, 2018), https://www.japcc.org/multi-domain-command-and-control/.

${ }^{205}$ Freedberg, "A Computer That Happens to Fly': USAF, RAF Chiefs on Multi-Domain Future."

${ }^{206}$ Zadalis, Multi-Domain Command and Control.

${ }^{207}$ Stephenson, Anatomy of a Buy: The Four Dimensions of Procuring a Fighter Fighter for Canada, 7.

${ }^{208}$ Freedberg, "'a Computer That Happens to Fly': USAF, RAF Chiefs on Multi-Domain Future."
} 
participate will need to field military equipment that achieves certain (largely unspecified) information-sharing standards. ${ }^{209}$ As information-centric platforms, the F-35 and, to a lesser extent, the older F-22 are designed for complete integration into the multi-domain battlespace of tomorrow. Fourth-generation types are likely to be less effective in this operational environment. While legacy platforms can be integrated into next-generation electronic networks in varying degrees using connecting technologies, their effectiveness decreases and costs increase as more technical "Band-Aid" measures are needed for them to participate. ${ }^{210}$ In his testimony in 2016, Lieutenant-General Hood recognized that "[the] ability to receive information from space-based assets, from AWACS aircraft, from ground-based sensors, from other aircraft, requires a level of interoperability that not every aircraft has the capability to meet."211

Platforms participating in MDC2 must be capable of sharing a significant quantity and variety of data with friendly off-board systems - but particularly those of the US military. General Goldfein's message on this topic was unambiguous:

What you procure is up to you, but....you're going to want to hitch your wagon to our command and control network. Whatever you procure as an individual platform or sensor or weapon.... you're going to want to be able to tap into the information network, the command and control that we provide. ${ }^{212}$

MDC2 is a predominantly American framework, and as such it will be based on American networking standards. In a piece on the challenges of fifth-generation air force transformation, RAF Wing Commander André Adamson and USAF Colonel Matthew Snyder write:

Effectively, the aim is to create and operate a networked environment where the lines are seamless between sensors, shooters and operators... air forces that do not possess these capabilities are likely to find themselves increasingly relegated to a supporting rather than a leading role in planning for, and executing, future contingency operations. ${ }^{213}$

\footnotetext{
${ }^{209}$ Ibid.

${ }^{210}$ Stephenson, Anatomy of a Buy: The Four Dimensions of Procuring a Fighter Fighter for Canada, 5.

${ }^{211}$ Canada and the Defence of North America: NORAD and Aerial Readiness, by Defence, 42-43.

${ }^{212}$ Freedberg, "'A Computer That Happens to Fly': USAF, RAF Chiefs on Multi-Domain Future."

${ }^{213}$ Adamson, and Snyder, The Challenges of Fifth-Generation Transformation.
} 
The advent of the MDC2 framework has implications for smaller partners, which will need to keep abreast of CIS development or risk a diminished role in future operations - and in Canada's case, even the NORAD framework. To this end, Australia, a FVEY partner, has adopted Plan Jericho, an organizational strategy to achieve a fully-networked "fifth-generation" air force. ${ }^{214}$

With the multi-domain battlespace and MDC2, allied military units will never operate alone. According to General Goldfein, the notion of a direct comparison between an individual American and Chinese or Russian platform is antiquated. Instead:

A J-20 is never going to see an F-35 by itself. It's going to see an F-35 connected to low earth orbiting satellites in several constellations. It's going to see it connected to penetrating ISR, stand-off ISR, to smart weapons technology, to a light maneuver brigade, to an Aegis cruiser, to our allies and partners. ${ }^{215}$

These concepts harness an unprecedented range of warfighting capabilities to generate closelycoordinated joint effects against sophisticated enemies in contested spaces. They move users towards level 4 of the LISI model: Enterprise-based interoperability in a universal environment.

\section{Canada's embrace of information-centricity in national defence}

Chapter 4 of this study has established that Canadian defence policy is fundamentally oriented around partnerships, and particularly with the US. The prospect of all US military combatant commands, including NORTHCOM, adopting MDC2 has important implications for NORAD reform and the DND/CAF more widely. SSE pledges that "Canada will work closely with the United States to ensure NORAD is fully prepared to confront rapidly evolving threats, including by exploring new roles for the command." ${ }^{216}$ Agreement was reached between the two countries on the operational requirements for an evolved NORAD in the middle of 2019, but

\footnotetext{
${ }^{214}$ See Government of Australia Department of Defence, Force of the Future: Towards the World's First 5th Generation Air Force, by Royal Australian Air Force (Canberra, Australia, 2015).

${ }^{215}$ Freedberg, "'A Computer That Happens to Fly': USAF, RAF Chiefs on Multi-Domain Future."

${ }^{216}$ Defence, Strong, Secure, Engaged: Canada's Defence Policy, 60.
} 
decisions have reportedly not yet been taken on which capabilities are to be included in the new framework. ${ }^{217}$ Still, recent studies are grounded in the assumption that future threats to the continent will be multi-domain in nature. ${ }^{218}$ Given NORAD's core functions and its congruency with NORTHCOM in the US military, it is highly probable that the renewed NWS will incorporate advanced ISR capabilities and multi-domain networking. ${ }^{219}$ Indeed, Jim Fergusson and Andrea Charron write that both partners are focused on "deploying a range of ground, air, and space based systems in a single 'system of systems' to provide effective deterrence, detection and defence capabilities. ${ }^{" 220}$ Ongoing bilateral negotiations seem likely to reorient NORAD around the next-generation capabilities and concepts discussed in this chapter. Two recent policy documents: the CAF C4ISR Strategic Vision, Goals and Objectives and the RCAF Future Air Operating Concept, formalize the defence team's embrace of information-centric concepts. While the former document is not publically available, its contents have been referenced in papers, presentations and in the Future Air Operating Concept, which can be accessed online. According to that concept:

[The CAF C4ISR Strategic Vision] is a clear acknowledgement that [the] CAF is now firmly in the contemporary information age and that - in order to exploit existing and future capabilities to operate successfully in challenging operating

\footnotetext{
${ }^{217}$ Murray Brewster, "Canadian, U.S. Military Leaders Agree on Framework to Retool Norad | Cbc News," CBC News, Politics, 2019, https://www.cbc.ca/news/politics/norad-canada-us-military1.5240855.

${ }^{218}$ Andrea Charron and James Fergusson, From NORAD to NOR[A]D: The Future Evolution of North American Defence Cooperation (Calgary, AB: Canadian Global Affairs Institute, 2018), https://d3n8a8pro7vhmx.cloudfront.net/cdfai/pages/3753/attachments/original/1527022907/From_NORA D_to_NOR_A_D_The_Future_Evolution.pdf?1527022907, 5.

${ }^{219}$ The contract for the NWS replacement is expected to be awarded in the mid-2020s, with full operational capability expected approximately one decade later, see Ernie Regehr, Replacing the North Warning System: Strategic Competition or Arctic Confidence? (The Simons Foundation, 2018), http://www.thesimonsfoundation.ca/highlights/replacing-north-warning-system-strategic-competition-orarctic-confidence-building.

${ }^{220}$ Charron, and Fergusson, NORAD: Beyond Modernization, 7.
} 
environments - there is no longer any option but to transform into an integrated and networked force. ${ }^{221}$

In a conference presentation entitled "The CAF C4ISR Strategic Vision," then-Chief of Force Development Rear-Admiral Darren Hawco identified the following areas of focus:

Securing the military communications and computer networks; enhancing interoperability and connectivity of systems; connecting tactical data links to joint forces and multinational operations; enabling mission specific command and control; [and] deploying persistent surveillance and reconnaissance systems. ${ }^{222}$

The CAF is working to become a more closely networked joint force using advanced C4ISR. The objective is to establish a level of electronic connectivity between military platforms that supports MDC2. This will enable commanders and units to "provide the right knowledge to the right people at the right time." ${ }^{.23}$ The Vice Chief of the Defence Staff (VCDS) is directed to oversee the establishment of a "national joint information framework" known as the "military integrated information structure" (MI3), where data and information are seamlessly managed and communicated to relevant CAF users in the integrated, joint and multinational environments. ${ }^{224}$

Canada is taking steps to upgrade its C4ISR capabilities. SSE directs the defence team to improve aerospace and maritime domain awareness and enhance satellite communications. ${ }^{225} \mathrm{In}$ 2018, DND launched the All Domain Situational Awareness Science and Technology Program, which entails an investment of $\$ 133$ million over five years on research that considers improvements to the monitoring of Canada's air and maritime approaches, with emphases on the

\footnotetext{
${ }^{221}$ Royal Canadian Air Force, Future Concepts Directive Part 2: Future Air Operating Concept (Ottawa, ON: National Defence and the Canadian Armed Forces, 2016), http://www.rcafarc.forces.gc.ca/assets/AIRFORCE_Internet/docs/en/cf-aerospace-warfare-centre/elibrary/futureconcepts-directive-part-2-future-air-operating-concept.pdf, 6 .

${ }^{222}$ Nestor Arellano, "Force Development Chief, Military Brass Outline Canada's C4ISR Objectives," Vanguard, 2016, https://vanguardcanada.com/2016/04/21/force-development-chief-military-brassoutline-canadas-c4isr-objectives/.

${ }^{223}$ RCAF, Future Concepts Directive Part 2: Future Air Operating Concept, 6.

${ }^{224}$ Ibid, 6.

${ }^{225}$ Defence, Strong, Secure, Engaged: Canada's Defence Policy, 61.
} 
arctic environment and information-sharing. A variety of technical options are being evaluated; the program entails cooperation with FVEY partners. ${ }^{226}$ Canada also invested $\$ 340$ million in the construction of the Wideband Global SATCOM (WGS-9) constellation satellite under DND's Mercury Global Project, with the satellite launched in March $2017 .{ }^{227}$ Canada's contribution gives it access to the entire constellation of 10 satellites. The WGS program provides increased communications bandwidth for military C4ISR functions. It is run by the US military, with the participation of Canada and several other like-minded partners. Finally, a trio of RADARSAT Constellation Mission satellites was launched in June 2019. These satellites, which are operated by the Canadian Space Agency, use advanced radar sets for a variety of defence and national security applications. The RADARSAT Constellation Mission has cost Canada $\$ 1.2$ billion. ${ }^{228}$

The Tactical Datalink (TDL), which enables the secure, real-time sharing of tactical data between military platforms, is a key enabler of the multi-domain battlespace. The CAF C4ISR Strategic Vision states that all Canadian military platforms will establish a TDL capability that is compatible with the J-series message format used by the ubiquitous Link 16 TDL. ${ }^{229}$ However, there remain issues with the CAF's capacity to use TDLs. The RCAF operates five Ground Entry Stations (GES) in Canada. These installations, which are mostly collocated with RCAF main

\footnotetext{
${ }^{226}$ David Pugliese, "String of Radar Stations in Canadian Arctic Nearly Obsolete — and Modernizing Them Will Cost Billions," The National Post (Cambridge Bay, Nunavut), News, 2018, $\mathrm{https}$ //nationalpost.com/news/modernizing-warning-radars-in-the-arctic-will-cost-canada-and-the-us-billions-ofdollars.; Regehr, Replacing the North Warning System: Strategic Competition or Arctic Confidence? ${ }^{227}$ National Defence and the Canadian Armed Forces, New Satellite Will Enhance Canadian Armed Forces' Communications Capabilities (Ottawa, ON: Government of Canada, 2017).

${ }^{228}$ David Burke, "New Satellite System Could Make Canadian Soldiers Safer Abroad | CBC News," CBC News, Nova Scotia, 2019, https://www.cbc.ca/news/canada/nova-scotia/satellite-department-of-nationaldefence-radarsat-constellation-military-1.5266508.; "Mission Milestones - Radarsat," Canadian Space Agency, Government of Canada, 2019, accessed March 10, 2020, https://www.asccsa.gc.ca/eng/satellites/radarsat/updates.asp. ${ }^{229}$ Jonathan Gilbert, The Neglected Capability: Rcaf Tactical Datalinks (Toronto, ON: Canadian Forces College, 2019), https://www.cfc.forces.gc.ca/259/290/308/192/gilbert.pdf, 2.
} 
operating bases, serve as tactical gateways to overcome the Line of Sight (LOS) limitations of the Link 16 TDL used by the CF-18 (and soon the CP-140 Aurora and CH-148 Cyclone). The GES are connected to ground-to-ground Beyond Line of Sight (BLOS) communications systems and fuse together tactical data from different sources to enhance the situational awareness of nearby RCAF aircraft. However, the existing stations are undermanned and increasingly obsolete. These issues, combined with Canada's vast territory, make the current GES insufficient to support a robust TDL capability across the country. Limited capacity restricts the range at which Canadian fighter aircraft can be integrated into the NORAD COP. ${ }^{230}$

The RCAF Tactical Integrated Command, Control, Communications Air (TIC 3 Air) project is designed to increase domestic TDL capacity. This project includes the deployment of 16 fixed and remotely controllable GES and five deployable ground units. The enlarged network is intended to support real-time data-sharing between RCAF aircraft and C2 centres. However, the project is severely delayed; it has yet to receive implementation approval and is unlikely to be implemented before 2025. Moreover, the planned positioning of the new GES will still leave significant coverage gaps across Canada - and particularly in the north. ${ }^{231}$ Finally, the TIC 3 Air project, while addressing a current capability gap, supports a legacy TDL standard first adopted by the US military in the late 1980s. It does not provide for more advanced TDLs.

The Future Air Operating Concept emphasizes the importance of tactical informationsharing in the joint and binational contexts - both now and in the future:

Integration for the future RCAF will require the ability to seamlessly and continually link systems that share information with the CA, RCN, the United States Air Force (USAF) and other US services as well as information from civilian-radar and air-traffic-management systems. Since the larger continental aerospace defence effort through NORAD is directly tied to the domestic aerospace

\footnotetext{
${ }^{230}$ Ibid, 4-5.

${ }^{231}$ Ibid, $5-6 ; 11$.
} 
defence of Canada, a comprehensive understanding of the evolving US concept of air operations is essential, especially its evolving $\mathrm{C} 2$ concepts. ${ }^{232}$

The RCAF will need to be interoperable with US tactical networks and abreast of evolving American C2 concepts. These requirements are tied to the defence of Canadian airspace - the RCAF's primary mission. Canadian contributions to future US-led coalitions will also need to "possess an unprecedented degree of interoperability with all US services to avoid being a liability." ${ }^{233}$ The force development considerations for maintaining technical interoperability with the US include the deployment of modular, configurable and adaptable systems, the pursuit of a system-of-systems approach for information-sharing, and linking Canadian and American ISR systems to RCAF platforms to enhance joint and shared COPs. ${ }^{234}$ The CAF is looking to preserve interoperability and the bilateral defence partnership over the long-term.

${ }^{232}$ Force, Future Concepts Directive Part 2: Future Air Operating Concept, 18.

${ }^{233}$ Ibid, 10.

${ }^{234} \mathrm{Ibid}, 27-28$. 


\section{Chapter 6: The competitors as networked platforms}

In terms of technical interoperability, the three types in contention to be Canada's future fighter are not made equally, and will not be equally compatible with next-generation C4ISR concepts. This analysis is complicated by the availability of unclassified data. The technical details of the Block III Super Hornet, Gripen E and F-35 are classified. Instead, descriptions of systems and capability are most readily available from military sources cited in the media and the manufacturers themselves. However, suppliers have a vested interest in portraying their offerings in the best possible light, which can result in claims being exaggerated or biased. For example, the Block III Super Hornet is equipped with an ultra-high frequency (UHF) radio system (HAVE QUICK system) that buries its signals in ambient radio noise to avoid detection and disruption. Boeing has argued that it offers a unique and superior capability compared to the F-35 in this area. However, as a VLO platform, the F-35 does not incorporate a HAVE QUICK system or emit UHF signals. ${ }^{235}$ To this end, comparisons and claims of capability from suppliers must be scrutinized. The determinative weight should instead be given to the technical characteristics of CIS, whenever possible.

\section{Saab Gripen $E$ as a networked platform}

The Gripen E is an evolution of the Gripen C/D. The type made its first flight in 2017; the Swedish and Brazilian air forces received their first aircraft in 2019. The Gripen E has a larger airframe and more powerful engine than its predecessor, enabling it to hold more fuel and a greater external payload. ${ }^{236}$ The type also incorporates a new AESA radar and Infrared Search

\footnotetext{
235 "Author Interview with Subject E."

${ }^{236}$ Orvelin Valle, "Saab Just Unveiled Its Attempt to Outdo the F-35," Business Insider, 2016, https://www.businessinsider.com/saab-f-35-competitor-gripen-e-2016-7.; Saab, "Gripen E | Ready for the
} 
and Track (IST) system for enhanced detection capabilities. An updated mission computer, Head-Up Display, in-cockpit Wide Area Display (WAD) and Helmet Mounted Display System are claimed to facilitate sensor fusion; "the multi-sensor control system gives a comprehensive and correlated picture." ${ }^{, 237}$ Saab has made ambitious claims about its new product, stating:

The fighter is developed to counter and defeat the most advanced threats in a modern battlespace and to continuously evolve in order to keep up with new challenges. We have built an intelligent fighter system that rapidly embraces new technology and tactics in a way that will always keep us ahead...Gripen $\mathrm{E} / \mathrm{F}$ is the only fighter which rapidly adapts to unfolding developments and stays relevant over time. $^{238}$

Despite this rhetoric, the Gripen-E is fundamentally an upgraded fourth-generation type.

To this end, it boasts a high-performance airframe and advanced avionics. But the type does not possess "fifth-generation battlefield networking," as claimed by Saab. ${ }^{239}$ In fact, the Gripen E is already well behind the latest allied standards for technical interoperability. This capability deficit is unlikely to improve over the type's lifecycle.

The Gripen E is equipped with not one, but two TDLs. The first is the Tactical Information Data Link System (TIDLS), which is designed and manufactured by Saab in Sweden. ${ }^{240}$ TIDLS permits the pilot to share position, altitude, airspeed, heading, fuel levels,

Future | Saab," Saab AB, 2019, accessed December 5, 2019, https://saab.com/gripen/our-fighters/gripenfighter-system/gripen-e-series/gripen-e/.

${ }^{237}$ John Belanger, Saab Press Briefing, CANSEC 2018 (Ottawa, ON: Saab AB, 2018) , 2-2.; Joetey Attariwala, "Saab Gripen E/F," Canadian Defence Review, 2018, http://www.canadiandefencereview.com/Featured_content?blog/110.

${ }^{238}$ Saab, "Gripen E | Ready for the Future | Saab."

${ }^{239}$ Alex McColl, "Commentary: Alternative Saab Fighter Could Save Navy by Dodging Extravagant F35s," The Chronicle Herald, Opinion, 2019, http://www.thechronicleherald.ca/opinion/nationalperspectives/commentary-alternative-saab-fighter-could-save-navy-by-dodging-extravagant-f-35s$352103 /$.

${ }^{240} \mathrm{Saab}$ has outfitted Swedish fighter aircraft with an indigenous tactical networking capability since the 1970s, see Head to Head: Gripen Vs Typhoon, vol. 46 (Coulsdon: Jane's Information Group, 2013). 
radar returns, targeting information and weapons data with up to three other Gripens and an Airborne Early Warning and Control (AEW\&C) aircraft equipped with specific Saab systems. TIDLS has a range of up to $500 \mathrm{~km}$ and is jam resistant. ${ }^{241}$ The system is clearly geared for use by the Swedish Air Force. However, TIDLS has so far only been fitted to a handful of Saab products, is not compatible with Link 16 and has not been cleared to host Five- and Two-Eyes intelligence flows. These factors compromise the utility of the system for Canada. There is no evidence that TIDLS could be modified to satisfy Canada's operational needs. The second TDL used by the Gripen E is the Multifunctional Information Distribution System (MIDS) terminal, which broadcasts Link 16 J-series messages. The Gripen was first fitted with Link 16 in $2007{ }^{242}$

When it was first introduced, Link 16 represented the cutting edge of tactical networking. Relative to earlier datalinks, it brought nodelessness, jam resistance, improved security, increased data throughput, increased volume and granularity of information exchange, reduced data terminal size, secure voice capability, relative navigation and precise participant location and identification. ${ }^{243}$ Several of these capabilities merit explanation. A nodeless network does not require the participation of any one platform to function. Data forms are standardized and can be received by all compatible terminals within range. Link 16 achieves jam resistance through radio frequency hopping. Encrypted data is transmitted between terminals on one of 51 different frequencies, with the transmission frequency changing every 13 microseconds based on

\footnotetext{
${ }^{241}$ Head to Head: Gripen Vs Typhoon.; Darren Olivier, "The Gripen Data Link," FlightCom: African and Middle East Aviation, 2019, https://www.flightcommagazine.com/single-post/2019/03/05/The-Gripendata-link.

${ }^{242}$ Saab AB, Link 16 Added to Gripen's Datalink Systems (Saab AB, 2007).

${ }^{243}$ Akers, Understanding Voice and Data Link Networking: Northrop Grumman's Guide to Secure Tactical Data Links, 2-2.
} 
a predetermined pseudo-random pattern contained within 128 stacked 'nets. ${ }^{, 244}$ In terms of data throughput, Link 16 data is broadcast in all directions at a rate below 1 megabit per second, out to an effective range of approximately $480 \mathrm{~km}$ for aircraft. ${ }^{245}$ There are Link $16 \mathrm{~J}$-series messages for network management, friendly status, surveillance, electronic warfare, weapons employment, imagery and track management. ${ }^{246}$ Link 16 satisfies Level 2 of the LISI model: Functional interoperability in a distributed environment.

The system is based on 1970s technology and has limited growth potential. Link 16 is described by operators as "a radio with some video and the ability to send text messages...it's sort of about who will take what." ${ }^{247}$ It is typically used by pilots to post and assign threats; the process to disseminate data from onboard sensors using this datalink involves numerous manual inputs. ${ }^{248}$ The pilot must actively manage the Link interface, tagging what they see in their data before posting it. Link 16 is also limited to pushing through radar returns and does not provide integrated functionality for radar warning receivers, infrared warning features or the multiple detection modes of modern AESA radars. The pilot must manually input and broadcast this data over the Link via text or secure voice message and other pilots must manually review the incoming message. Shared intelligence must also be posted in text format. ${ }^{249}$ Link 16 does not share the full operational picture. The same interview subject cited above remarked that "larger,

\footnotetext{
${ }^{244}$ Charlie Cruz, "Netwars Based Study of a Joint Stars Link 16 Network" (Air Force Institute of Technology, 2004), https://apps.dtic.mil/dtic/tr/fulltext/u2/a423871.pdf.

${ }^{245}$ Viasat, "Mids-Lvt Link 16 Tactical Airborne Terminal," Viasat, Inc., 2020, accessed March 4, 2020, https://www.viasat.com/products/link-16-mids-lvt1.; Akers, Understanding Voice and Data Link Networking: Northrop Grumman's Guide to Secure Tactical Data Links, 2-68.

${ }^{246}$ Akers, Understanding Voice and Data Link Networking: Northrop Grumman's Guide to Secure Tactical Data Links, 2-8 to 2-9.

247 "Author Interview with Subject D."

${ }^{248}$ Bronk, Maximizing European Combat Air Power: Unlocking the Eurofighter's Full Potential, 21.

249 "Author Interview with Subject D."
} 
faster and closer-together displays in [evolved fourth-generation] aircraft are a Band-Aid measure. ${ }^{" 250}$ With Link 16, the fighter pilot must act as both tactician and systems operator, interpreting and synthesizing data while flying their aircraft. This TDL is fundamentally incompatible with sensor fusion because it does not permit friendly aircraft to automatically share and correlate a wide variety of mission data. Regardless of the mission computer integrated into their warplane, the pilot conducts the data fusion when using the Link.

There are two more common issues with Link 16. First, the widely-used system is limited by bandwidth, which reduces the potential for all platforms participating in larger operations to benefit from it. ${ }^{251}$ Second, because its broadcasts can easily be detected by adversaries, Link 16 becomes a liability in $\mathrm{A} 2 / \mathrm{AD}$ environments and is used sparingly or shut off altogether when Link-enabled platforms are operating within them. ${ }^{252}$ The reduced availability of tactical networking in these situations adversely affects joint situational awareness when it is most needed. Given its existing limitations, Link 16 is ill-suited for upgrading and upscaling to support next-generation C4ISR concepts.

During a presentation at the Canadian Association of Defence and Security Industries Conference in May 2018, Saab claimed that the Gripen E is "fully US interoperable [through] Link 16/MIDS, HAVE QUICK, secure voice [and Identification Friend or Foe]." ${ }^{253}$ These systems, cited by Saab as facilitators of technical interoperability with NORAD, have been used by the CF-18 for well over a decade. While they may be operationally proven, the Gripen $\mathrm{E}$ offers no discernable improvement in networked capability relative to the CF-18 - no adoption

\footnotetext{
${ }^{250}$ Ibid.

${ }^{251}$ Ibid.

${ }^{252}$ Ibid.

${ }^{253}$ Belanger, "Saab Press Briefing," 2-4.
} 
of higher-throughout or low-observability datalinks. Its reliance on what is effectively a legacy TDL capability would almost certainly impede Canada's participation in MDC2.

Saab boasts of the Gripen E's in-service upgrade potential and claims that "up until 20502060, [the type] will be continuously enhanced with the latest technologies." ${ }^{254}$ The avionics of the Gripen E are split: the 10 percent of the platform's codebase dedicated to critical flightmanagement functions is separated from the 90 percent dedicated to tactical management functions. This reportedly allows for a modular systems architecture where new capabilities can be integrated without the need to re-certify flight-management software. ${ }^{255}$ Furthermore, industry commentators recognize that the Gripen family's relatively narrow manufacturing base has allowed Saab in the past to closely manage the development and testing of new avionics and tactical systems so that they could be integrated soon after being requested. ${ }^{256}$ Gripen E test pilot Robin Nordlander claims that "should Canada select the Gripen E, there is nothing stopping us from integrating the necessary datalinks desired by the customer." 257

Saab's promise of CIS upgrades and adaptability are of little use to Canada for two reasons. First, because the FVEY partners collaborate on fighter upgrades to maintain technical interoperability, Sweden and Brazil are likely to choose different upgrades for the Gripen E than Canada would, should it select the type. Canada would likely need to develop and incorporate its own. Second, as the US, UK and Australia increasingly adopt fifth-generation warplanes and their next-generation CIS, Link 16-enabled RCAF Gripens would simply not be comparable to

\footnotetext{
${ }^{254}$ Saab AB, "The Key to Gripen's Longevity," Saab AB, 2019, accessed March 15, 2020, https://saab.com/gripen/news/blog/gripen-blog/2019/the-key-to-gripens-longevity/.

${ }^{255}$ Ibid.

${ }^{256}$ Head to Head: Gripen Vs Typhoon.

${ }^{257}$ Attariwala, "Saab Gripen E/F."
} 
or compatible with allied C4ISR standards. The Multifunction Advanced Datalink (MADL) integrated into the F-35 has not yet been cleared for use on any other American aircraft apart from the Northrop Grumman B-2 Spirit, and given strong national security and commercial interests, it is doubtful that the TDL will ever be cleared for use on a platform designed and/or manufactured outside the US. Even if MADL were to be cleared for use on the Gripen, the evolved fourth-generation type would not have the sensors or VLO attributes to make use of it. Saab will be unable to develop upgrades for the Gripen E that keep its networked capability abreast of Canada's Five- and Two-Eyes partners. The Gripen E will only fall further behind.

\section{Boeing F/A-18E/F Super Hornet Block III as a networked platform}

The Super Hornet is a multi-role fighter which entered operational service with the USN in 2001. The type is a development of the McDonnell Douglas F/A-18 Hornet and can therefore be classified as an evolved fourth-generation type. The Block III upgrade to the Super Hornet addresses several capability areas. Block III aircraft are designed to have an extended service life compared to the existing Super Hornet. Conformal fuel tanks provide an operational range increase of nearly $500 \mathrm{~km}$. The type is now compatible with a pod-mounted IST sensor, which permits the operator to detect and engage airborne threats passively. A WAD facilitates tracking and targeting functions. Enhanced tactical networking capabilities allow the fighter to process and share more data in real time. ${ }^{258}$ The USN took delivery of its first Block III aircraft in

\footnotetext{
${ }^{258}$ David Szondy, "US Navy Receives First Upgraded F/A-18 Super Hornet Block III," New Atlas, 202002-07, https://newatlas.com/military/us-navy-receives-fa18-super-hornet-block-iii/.
} 
February 2020; Block III capability will largely be delivered through upgrades to existing Super Hornets under the Service Life Modification program. ${ }^{259}$

Tactical networking is dependent upon a platform's ability to generate and process mission data and its ability to transmit and receive mission data. According to Boeing, "advanced datalink and threat detection allow [the Block III] Super Hornet to better receive, process and send key intel." ${ }^{260}$ The threat detection capability cited here is presumably related to the new IST sensor and the existing AN/APG-79 AESA Radar, which can execute air-to-air and air-to-ground attacks simultaneously and conduct high-resolution ground mapping at distance. ${ }^{261}$ These automatically feed returns into the Block III Super Hornet's mission computer, called the Distributed Targeting Processor-Networked (DTP-N) and carried over from the Boeing EA-18G Growler. This system reportedly boasts 17 times the processing speed of the computer fitted to the Block II Super Hornet and has an open architecture for ease of upgrade. ${ }^{262}$ The advanced TDL capability is provided by the Rockwell Collins Tactical Targeting Network Technology (TTNT) datalink, one of the main components of the Block III upgrade. TTNT is compatible with J-series messages, but transmits a greater volume of data faster. Using the system, 10 megabits of data can be transferred per second at a speed of Mach 8, out to an effective range of

\footnotetext{
${ }^{259}$ Megan Eckstein, "Navy Says Ending Super Hornet Line Frees up Resources for Life Extension Work Usni News," USNI News (Capitol Hill), USNI News, 2020, https://news.usni.org/2020/03/10/navy-saysending-super-hornet-line-frees-up-resources-for-life-extension-work.

${ }^{260}$ Boeing Canada, "Super Hornet Block III: The Complete Solution for Canada," The Boeing Company, 2019, accessed February 18, 2020, http://www.boeing.ca/products-and-services/defense-space-security/fa-18-super-hornet.page.

${ }^{261}$ Joetey Attariwala, "FFCP: Set to Replace Cf-18," Canadian Defence Review, 2020, http://www.canadiandefencereview.com/zmags.php?p=Lz1PCWUFaA, 40.

${ }^{262}$ Sydney J. Freedberg Jr., "Navy, Boeing Tout Block III Super Hornet as Partner for F-35," Breaking Defense, 2018, https://breakingdefense.com/2018/05/navy-boeing-tout-block-iii-super-hornet-as-partnerfor-f-35/.; Canada, "Super Hornet Block III: The Complete Solution for Canada."
} 
$550 \mathrm{~km} .{ }^{263}$ TTNT uses statistical analysis to ensure that critical data is always first in the order of transmission, and the system can simultaneously send and receive data from four external platforms. ${ }^{264}$ Like Link 16, TTNT broadcasts pre-formatted data packages and messages, uses radio frequency-hopping to achieve jam resistance and lacks a VLO capability. ${ }^{265}$ Indeed, the TTNT datalink is effectively an improved version of Link 16.

The USN is by far the largest operator of the Super Hornet and already uses the TTNT datalink in the EA-18G and Northrop Grumman E-2D Hawkeye. ${ }^{266}$ The decision to equip the Block III Super Hornet with that system further standardizes the USN's aerial TDL capability and enhances the technical interoperability of that service's air elements. However, the TTNT datalink was rejected for use in the F-22 and F-35 because it is non-stealthy. ${ }^{267}$ It will therefore not be incorporated into the most "future-proofed" platforms and remains incompatible with their integrated TDLs. While TTNT-enabled fighters will be integrated into the Naval Integrated Fire Control Counter Air System (NIFC-CA), the US Navy's joint network for anti-aircraft and missile defence, they will not provide the same truly high-end C4ISR capability as fifthgeneration aircraft and will accordingly be unable to fulfill the same functions (see section dedicated to F-35 below). ${ }^{268}$ The TTNT datalink, while a step up from Link 16, is not central to

\footnotetext{
${ }^{263}$ Range can be extended by routing data through TTNT-enabled platforms, see Epec Engineered Technologies, "Tactical Targeting Network Technology," Microwave Journal (2018). 2009), https://www.sldinfo.com/wp-content/uploads/2009/11/TTNTWhitePaper.pdf.; Jr., "Navy, Boeing Tout Block III Super Hornet as Partner for F-35."

${ }^{266}$ Mike Fabey, "The U.S. Military's Strategy to Dominate the Air: Have the F-35 and F/A-18 Join Forces | The National Interest," The National Interest, 2017, https://nationalinterest.org/blog/the-buzz/the-usmilitarys-strategy-dominate-the-air-have-the-f-35-f-19937.

${ }^{267}$ Stephen Trimble, "Usaf Selects Datalink to Bridge Communications Gap between F-22 and F-35," FlightGlobal (2009).

${ }^{268}$ Fabey, "The U.S. Military's Strategy to Dominate the Air: Have the F-35 and F/A-18 Join Forces | The National Interest."
} 
the transformational C4ISR capabilities being developed by Canada's allies. Over the lifecycle of the future fighter, the Block III Super Hornet is unlikely to keep pace with the technical interoperability achieved by the fifth-generation warplanes of Canada's key allies.

\section{Lockheed Martin F-35 Lightning II as a networked platform}

In 2018, USAF Chief of Staff General David Goldfein said, "I grew up flying fighters, and I will tell you, when I see the F-35, I don't see a fighter, I see a computer that happens to fly." ${ }^{269}$ As noted above, tactical networking involves generating, processing and sharing mission data. The fifth-generation F-35 is a data-centric platform with unmatched capabilities in these areas. The jet's primary mission systems include an AN/APG-81 AESA radar, a passive AN/AAQ-37 Distributed Aperture System (DAS), the Electro-Optical Targeting System (EOTS) and an integrated Communications, Navigation and Identification (CNI) avionics suite. The AN/APG-81 is the successor to the AN/APG-77 VLO radar designed for the F-22 Raptor. The newer set evolves the AN/APG-77's active and passive air-to-air capabilities while adding stateof-the-art air-to-ground and electronic warfare capabilities. For example, the AN/APG-81 can track 23 aerial targets within a span of 9 seconds and engage 19 aerial targets within 2.4 seconds; it can detect an airborne contact with a one square metre radar cross-section $150 \mathrm{~km}$ away. ${ }^{270}$ The DAS is the only 360 degree, spherical awareness system in service today. It sends infrared imagery from six onboard electro-optical sensors to the pilot's helmet-visor, enabling them to see the space around the aircraft at day and night, in real time. The DAS fuses data from other sensors to identify, categorize, rank and recommend responses to threats. This information is

\footnotetext{
${ }^{269}$ Freedberg, "‘A Computer That Happens to Fly': USAF, RAF Chiefs on Multi-Domain Future." 270 "An/Apg-81," Sensor Systems, Deagal.com, 2018, accessed March 26, 2020, http://www.deagel.com/Sensor-Systems/ANAPG-81_a001381001.aspx.
} 
transmitted to the pilot's helmet-visor. EOTS is the first forward-looking infrared system with integrated search and track capability. This increases situational awareness and enables the pilot to prosecute air- and ground-based threats with greater stealth and precision. The use of Software-Defined Radio (SDR) technology in the F-35's CNI suite enables that system to carry out many of its 27 distinct functions simultaneously. ${ }^{271}$ SDRs combine reconfigurable radio frequency hardware with computer processors to run software that produces a desired waveform. ${ }^{272}$ They are extremely energy- and space-efficient. The F-35's CNI suite reportedly operates over 10 radio channels and more than 40 waveforms; data is harvested from at least 30 conformal antennas built into the aircraft. ${ }^{273}$ Onboard computers automatically analyze and assess this data, fusing together disparate pieces into useful tactical information. ${ }^{274}$ In the words of one interview subject, "in the F-35, the airplane is the copilot.". Billie Flynn, "we don’t have data anymore, we have knowledge."276

Sensor fusion in the F-35 is supported by shared data from other closely-networked platforms. As the F-35's mission computer builds a tactical picture for the pilot, it automatically incorporates data from allied platforms to corroborate and triangulate data harvested from onboard sensors. The composite map of information presented to the pilot in the DAS and on the WAD is referred to as Tier 3 data. Throughout the data fusion process, the aircraft transmits only

\footnotetext{
${ }^{271}$ Bronk, Maximum Value for the F-35: Harnessing Transformational Fifth-Generation Capabilities for the Uk Military, 4.

${ }^{272}$ Communications, Navigation and Identification (Cni) Avionics for the F-35 Lightning II: New Dimensions for the Warfighter in Digital Battlespace (San Diego, CA: Northrop Grumman Information Systems, 2012), http://www.northropgrumman.com/Capabilities/SDRs/Documents/F35-CNI_datasht.pdf. ${ }^{273}$ Ibid.

274 "Mission Systems and Sensor Fusion | F-35 Lightning II," Lockheed Martin Corporation, 2018, accessed November 22, 2018, https://www.f35.com/about/capabilities/missionsystems.

275 "Author Interview with Subject D."

${ }^{276}$ Justin Bachman, "State-of-the-Art? America's Two Best Fighter Jets Can't Even Communicate with Each Other," The National Post, News, 2018, https://nationalpost.com/news/world/state-of-the-artamericas-two-best-fighter-jets-cant-even-communicate-with-each-other.
} 
its own onboard sensor data, or Tier 1 data, to other compatible platforms. This ensures that tactical networks host only reliable first-hand data and second-hand data is not compounded erroneously during fusion. ${ }^{277}$ The F-35's fused sensors and systems generate a tactical picture of unprecedented detail. High-end technical interoperability is integral to this capability.

MADL is the F-35's primary TDL. Compared to Link 16 and TTNT, MADL offers two key advantages: VLO characteristics and far superior automation and integration with aircraft systems. MADL achieves low probability of detection and low probability of intercept by transmitting short bursts of very-high-frequency radio emissions in the gigahertz range (Link 16 and TTNT use the lower-frequency megahertz range) in the exact direction of another MADLenabled platform, which can then transmit that signal precisely onwards in a "daisy chain system." ${ }^{278}$ MADL is strictly a directional datalink; it does not broadcast emissions widely. Although specific technical characteristics like the format of data transmissions and the richness of transmitted data are classified, it is public knowledge that MADL automatically shares and receives data from multiple onboard sensors - and the richness (and sensitivity) of data transmissions can be controlled by the pilot. ${ }^{279}$ These capabilities imply a level of technical interoperability not seen before. MADL currently enables a flight of up to four F-35s operating within the LOS to seamlessly and securely exchange sensor data in real time. The datalink's participant capacity will almost certainly be expanded in the future. ${ }^{280}$

With sensor fusion and MADL onboard, the F-35 pilot does not need to function concurrently as a tactician and systems operator. They do not need to scan and mentally process

\footnotetext{
${ }^{277}$ Zazulia, "F-35 Data Fusion: How the Smartest Fighter Shares What It Sees - Avionics."

278 "Author Interview with Subject D."; Trimble, "Usaf Selects Datalink to Bridge Communications Gap between F-22 and F-35."

279 “Author Interview with Subject D."; Zazula, "F-35: Is the Trillion Dollar Fighter Finally Worth It?." ${ }^{280}$ Bronk, Maximum Value for the F-35: Harnessing Transformational Fifth-Generation Capabilities for the UK Military, 4.
} 
each piece of raw sensor or mission data to generate situational awareness. Instead, the aircraft deals with this data in the background, and the pilot is free to fly the aircraft. With their sensors in constant communication, a flight of F-35s can collectively manage its joint situational awareness and generate a dynamic COP. We can therefore start to consider such tactical formations not as made up of individual platforms, but as a singular systems network, with each aircraft fulfilling and trading functions and ultimately contributing to the effectiveness of the whole. Lockheed Marin systems analyst Greg Lemons argues that we can "best think of [MADL] as a way to extend one avionics system into multiple aircraft." ${ }^{281}$ In a 2008 interview, then-head of the F-35 Program Office USAF Major General Charles Davis echoed this sentiment, saying, "we talk a lot about international operations, coalition operations. What [the F-35] basically means is that you have a netted airborne network that spans all those...countries." 282 The F-35 moves the maximum technical interoperability of fighter aircraft up to Level 3 of the LISI model: Domain-based interoperability in an integrated environment.

MADL is currently unique to the F-35 and not compatible with other airborne datalinks. Technical interoperability with a greater variety of networked platforms can be achieved in three ways. First, the F-35's CNI suite has an integrated Link 16 capability that permits the type to communicate directly with legacy assets. While J-series messages are not stealthy and can therefore betray the emitting platform's location, the F-35 can use its sensors to find coverage gaps in an adversary's sensor arrays and angle its Link 16 broadcast, which is transmitted in a

\footnotetext{
${ }^{281}$ Nick Zazulia, "F-35: Is the Trillion-Dollar Fighter Finally Worth It?," Avionics International, no. August/September 2018 (2018).

282 Article, "Interoperability Seen as Key to Future Fighter Platforms," Defense Daily International, 2008, accessed 2020/4/3/, https://ink.gale.com/apps/doc/A184192806/AONE?u=ocul_carleton\&sid=AONE\&xid=b6997040. Gale Academic OneFile.
} 
very short burst, to maintain concealment. ${ }^{283}$ However, Link 16 lacks the security and technical capability to transmit some of the most detailed and sensitive data generated by the F-35. ${ }^{284}$ Second, trials in the US have proven that airborne communications gateways hosted on third platforms can be modified to receive MADL transmissions from F-35s and translate them into Link 16 messages, which can then be broadcast to Link 16-enabled platforms situated throughout the battlespace. ${ }^{285}$ However, the seven USAF aircraft currently equipped with the required Battlefield Airborne Communications Node (BACN) are already in very short supply. ${ }^{286}$ These platforms are also expensive to purchase and operate, and Canada currently has no formal plans to procure any. Furthermore, the restrictions described earlier in this paragraph would also apply to airborne gateways broadcasting mission data received from F-35s over Link 16. The third solution will almost certainly be the most effective and durable over the long-term. The DoD Joint Requirements Oversight Council has approved MADL for use on all US VLO platforms. ${ }^{287}$ The system is likely to become the new TDL standard for manned and unmanned stealth platforms designed and manufactured in the US. The starting point for this standard is the more than 3,100 F-35s that Lockheed Martin expects to manufacture through the late $2030 \mathrm{~s}^{288}$

\footnotetext{
${ }^{283}$ Sydney J. Freedberg Jr., "Boeing's Block III Super Hornet 'High End' Complement to F-35: Stackley," Breaking Defense, 2017, https://breakingdefense.com/2017/04/boeings-block-iii-super-hornethigh-end-complement-to-f-35-stackley/.

${ }^{284}$ Gareth Jennings, "RAF Demos F-35B and Typhoon Interoperability," Jane's Defence Weekly (2017).

${ }^{285}$ See Northrop Grumman and Royal Air Force Demonstrate Enhanced Airborne Communications Interoperability between 5th and 4th Generation Fast-Jet Aircraft (London, UK: Northrop Grumman Corporation, 2017).

${ }^{286}$ John Keller, "EQ-4B UAV to Provide Battlefield Networking and Situational Awareness," Military \& Aerospace Electronics, C4ISR (2017).; Tyler Rogoway, "We Chew the Fat About BACN with Program Boss and Airman Who Used It in Combat," The Drive, The War Zone (2017).

${ }^{287}$ Akers, Understanding Voice and Data Link Networking: Northrop Grumman's Guide to Secure Tactical Data Links., 8-5.

${ }^{288}$ Kris Osborn, "Air Force Seeks Jets Beyond C-17 and Even JSF," Military.com, 2013, https://www.military.com/daily-news/2013/12/17/air-force-seeks-jets-beyond-c17-and-even-jsf.html.
} 


\section{The F-35: airpower transformation and CIS upgrades}

As the first fifth-generation warplane to enter widespread service, the F-35 fulfills a broader forcing function for operators wishing to realize its full potential. This argument was introduced in Chapter 5. In 2018, a senior RAF officer asserted that interactions between F-35 operators are shaping approaches to airpower modernization. ${ }^{289}$ Today, they share technologies, concepts, tactics, training, maintenance and logistics in what could be called a "fifth-generation club." ${ }^{290}$ One interview subject noted that "Canada's key allies are creating a high-fusion environment with the F-35." ${ }^{291}$ Indeed, the USAF is working with global partners on the ability of F-35s to operate together as a unique fleet, with emphasis given to the use of sensor fusion as a connective tissue between aircraft. ${ }^{292}$ In an example of this effort, F-35s operated by the USAF, RAF and Israeli Air Force took part in simulated air combat during Exercise Tri-Lighting over the eastern Mediterranean Sea in June 2019. ${ }^{293}$ The platform is clearly being leveraged and developed in innovative ways. Advanced ConOps and the type's upgrade path are important factors to consider when assessing the technical interoperability of the F-35 over its lifecycle.

Thanks to its sensor suite, networked capability and VLO characteristics, the F-35 promises unique tactical advantages and operational flexibility. Fourth-generation fighters like the CF-18 typically fly combat missions in tight four-ship formations. This number is needed for situational awareness and survivability; four-ship flights can generate significant tactical effects.

\footnotetext{
${ }^{289}$ Robbin Laird, "Recrafting the Fighter Role," FrontLine Defence, 2018, https://defence.frontline.online/article/2018/6/10980-Recrafting-the-Fighter-role.

${ }^{290}$ Adamson, and Snyder, The Challenges of Fifth-Generation Transformation.

291 "Author Interview with Subject D."

${ }^{292}$ Laird, "Recrafting the Fighter Role."

${ }^{293}$ Christine D. Millette, "Tri-Lightning: Three-Nation F-35 Exercise Demonstrates Air Power Interoperability," Article, Citizen Airman, 2019, https://link.gale.com/apps/doc/A600162611/AONE?u=ocul_carleton\&sid=AONE\&xid=698447ec.
} 
By comparison, F-35s have proven to be proficient tactical effects generators when deployed in tandem or even as single units. ${ }^{294}$ This new tactical profile stems from the type's enhanced situational awareness and survivability. The same attributes also enable the type to operate in tactical formations at greater distances and cover more area than legacy fighters in a Combat Air Patrol (CAP) ${ }^{295}$ Finally, with network-enabled ISR and AEW\&C capabilities, the F-35 is a true multi-mission platform. ${ }^{296}$ Its avionics are designed for rapid re-tasking during operations, precluding the need for systems to be fitted externally or reprogrammed for different missions. The F-35 is both a next-generation tactical fighter and an agile C4ISR platform. High-end tactical networking is central to the fulfilment of both functions.

The United States Marine Corps (USMC) and USN are now implementing ConOps for strike missions that leverage the F-35's next-generation capabilities in different ways. Both rely on the type's technical interoperability and, given the collaborative approach of the operators, are likely to be adopted by other militaries, all of whom are Canada's partners. First, the USMC plans to replace its entire warplane fleet - a current total of 245 aircraft, with the F-35. It will take delivery of 353 F-35Bs and 67 carrier-optimized F-35Cs. ${ }^{297}$ Given this force composition and the USMC's prioritization of operational self-sufficiency, it follows that interoperability with other air assets may be a lower priority for that service. The Marines have therefore developed a ConOp where the F-35 is used as a penetrative strike asset. A small formation of USMC F-35s operating deep within an A2/AD environment and coordinating their engagement

\footnotetext{
294 "Author Interview with Subject E."

295 "Author Interview with Subject D."

${ }^{296}$ Bronk, Maximum Value for the F-35: Harnessing Transformational Fifth-Generation Capabilities for the UK Military, vii.; Stephenson, Anatomy of a Buy: The Four Dimensions of Procuring a Fighter Fighter for Canada, 3.

${ }^{297}$ United States Marine Corps, 2019 Marine Corps Aviation Plan (Arlington, VA: United States Marine Corps, 2019).
} 
over MADL will have far greater situational awareness and freedom of action than a commander stationed well behind the frontlines who must rely on data from stand-off ISR assets to form a tactical picture. ${ }^{298}$ Beyond being a survivable strike platform, the F-35 in this ConOp requires less reach-back than existing types in terms of both ISR support and C2 taskings. This means that it can operate away from vulnerable AEW\&C aircraft and ground installations. The USMC ConOp leverages the F-35's technical interoperability at the tactical and operational levels.

The current USN fast-jet fleet is the youngest of the three US armed services. The Navy operates 512 Super Hornets. This evolved fourth-generation fleet is large and relatively young. Up to 369 F-35Cs will be purchased to replace the classic Hornet in Navy service. ${ }^{299}$ These will operate alongside F/A-18E/Fs from carrier flight decks until the 2040s. In a piece published in 2015, Vice Admiral Mike Shoemaker, then-commander of Naval Air Forces, described the complimentary roles that each type will play in the Carrier Strike Group's “integrated warfighting package." ${ }^{300}$ F-35s will “penetrate threat envelopes," suppressing enemy air defences while gathering and fusing reconnaissance and targeting data. This is then disseminated to a variety of Navy combatants using MADL and Link 16 bursts. Because the F-35 is limited to carrying munitions and fuel internally in denied environments, the Super Hornet's external payload is leveraged for "lethality and flexibility." ${ }^{301}$ Using the protective cover and targeting information provided by F-35s, Super Hornets can venture close enough to launch stand-off

\footnotetext{
${ }^{298}$ Bronk, Maximum Value for the F-35: Harnessing Transformational Fifth-Generation Capabilities for the UK Military, 4.

${ }^{299}$ James Drew, "Us Navy Considers Reduced Annual F-35C Buy," FlightGlobal (13 August, 2015 2015).

${ }^{300}$ Mike Shoemaker, "Admiral's View: The Case for Aircraft Carriers and Air Wings," DoD Buzz, Military.com, 2015, accessed November 24, 2018, https://www.military.com/dodbuzz/2015/08/11/admirals-view-the-case-for-aircraft-carriers-and-airwings.

${ }^{301}$ Ibid.
} 
munitions against targets. In this ConOp, the F-35 allows the F/A-18E/F to remain undetected or at least further away than it would otherwise need to be, and the F/A-18E/F provides the 'punch' that the F-35, when operating as a stealth platform, cannot. The Super Hornet's relevance in this high-end strike mission hinges on the F-35's support, which could previously only be provided by dedicated (and relatively vulnerable) electronic warfare and AEW\&C aircraft. ${ }^{302}$ While the USN's warfighting package is made stronger through integrated capability, the fifth-generation type is clearly the force leader and multiplier, relegating the legacy type to a subordinate role.

The F-35 also has the potential to transform the NIFC-CA system, which, as an integrated air detection and defence framework, is broadly similar to the NORAD framework. The type has proven capable of using MADL to transmit firing solutions directly to naval units equipped with the AEGIS combat system, thereby saving the time that would normally be required to feed the data through an E-2D AEW\&C platform, the traditional 'quarterback' for aerial engagements and relay between USN aircraft and ship-based weapons systems. ${ }^{303}$ The removal of the E-2D from this particular NIFC-CA 'kill-chain' not only saves precious time, but also gives the joint force greater flexibility to adapt to a changing tactical picture. The direct exchange of sensor returns and taskings between assets operating in different domains enables MDC2 - the transformational concept now being implemented by Canada's closest allies. One of the future fighter's core missions is to serve as Canada's response function in a modernized NORAD framework. The F-35's fifth-generation technical interoperability is likely to be supported by the Americans as a standard for this framework and the renewed NWS. Widely networked F-35s could engage incoming threats in a more efficient and agile manner.

\footnotetext{
302 "Author Interview with Subject D."

${ }^{303}$ Sam LaGrone, "F-35, SM-6 Live Fire Test Points to Expansion in Networked Naval Warfare," USNI News (2016).
} 
The F-35 will also lead fourth-generation fighters in the air-to-air mission. In multinational Red Flag exercises, RAF and German Luftwaffe Typhoons have been made more effective by operating alongside USAF F-22s. The F-22s maintain higher speeds and altitudes, using their sensors and stealth to direct the engagement and defeat advanced threats. ${ }^{304}$ Indeed, a USAF F-35 pilot recognized that in his jet, "[he can] see the whole war, and where all the other players are, from a god's-eye view." ${ }^{305}$ Fifth-generation fighters can use tactical networking to enhance their own situational awareness before transmitting this knowledge to legacy types. In Red Flag exercises, fifth-generation fighters have brought older types into aerial engagements and dramatically increased their persistence. By acting as both air superiority fighters and C4ISR platforms, the F-22 and F-35 make for powerful force multipliers and enable distributed, adaptable C2. Here again, fourth-generation fighters are relegated to a subordinate role.

The F-35, a clean-sheet design, will receive regular capability upgrades over the course of its service life. By comparison, the Gripen E and Block III Super Hornet are already heavily modified variants of older types. Their basic airframe designs predate the digital era and their systems architectures have less capacity for incorporating future upgrades than the data-centric architecture of the F-35. ${ }^{306}$ Under Lockheed Martin's continuous capability development and delivery (C2D2) strategy, the F-35 receives weekly over-the-air software updates. ${ }^{307}$ Block IV capability, the next milestone in the platform's development, is centred on improved mission

\footnotetext{
${ }^{304}$ Bronk, Maximizing European Combat Air Power: Unlocking the Eurofighter's Full Potential, 14. ${ }^{305}$ Bachman, "State-of-the-Art? America's Two Best Fighter Jets Can't Even Communicate with Each Other."

306 "Author Phone Interview with Subject A."; Stephenson, Anatomy of a Buy: The Four Dimensions of Procuring a Fighter Fighter for Canada, 4.; Zazula, "F-35: Is the Trillion Dollar Fighter Finally Worth It?."; "F-35 Software Development | F-35 Lightning II," Lockheed Martin Corporation, 2019, accessed November 25, 2019, https://www.f35.com/about/life-cycle/software.

${ }^{307}$ Zazula, "F-35: Is the Trillion Dollar Fighter Finally Worth It?."
} 
systems and compatibility with new air-to-surface munitions. ${ }^{308}$ In the mid-2020s, the DAS will be updated with five times its current resolution; the longer-term development goal is to integrate artificial intelligence (AI) and machine learning into onboard systems such that the DAS uses full augmented reality (AR) and AI-recommended decision-making. ${ }^{309}$ Overall, some 60 major software and hardware upgrades are planned for the F-35 out to the end of this decade. ${ }^{310}$

With the US military pushing to maximize the type's information-sharing capability, the F-35's continuous in-service upgrades will have two effects on its technical interoperability that merit discussion here. ${ }^{311}$ First, regular software upgrades to ISR systems, mission computers and MADL will inevitably improve the quality of data that the F-35 shares. Like the rest of the platform, the type's technical interoperability will mature with time - bringing not just F-35s but entire joint forces closer together. Second, the number and variety of platforms that can be networked to the F-35 through MADL is certain to increase with future upgrades. The US is currently developing next-generation unmanned aerial vehicles (UAVs), a sixth-generation fighter aircraft and the replacement for the B-2, known as the B-21 Raider. These types, which will all possess VLO capability, are likely to be equipped with MADL. Fifth-generation fighters are set to receiving a teaming capability for use with UAVs - and CAF officials have recognized Canada's future need for one. ${ }^{312}$ Existing US C4ISR aircraft use specialized networks to link to certain space-based surveillance and communications assets. These networks use the Ku-band

\footnotetext{
${ }^{308}$ Kris Osborn, "Here Comes the 'New' F-35 Stealth Fighter (It Will Be Epic) | The National Interest," The National Interest, 2019, https://nationalinterest.org/blog/buzz/here-comes-new-f-35-stealth-fighter-itwill-be-epic-95281.

${ }^{309}$ Zazula, "F-35: Is the Trillion Dollar Fighter Finally Worth It?."

${ }^{310}$ Ibid.

${ }^{311}$ Bronk, Maximum Value for the F-35: Harnessing Transformational Fifth-Generation Capabilities for the UK Military, 6.

${ }^{312}$ Laird, "Recrafting the Fighter Role."
} 
portion of the electromagnetic spectrum, which happens to be the same band used by MADL. ${ }^{313}$ Indeed, the USAF is now researching the possibility of networking its fifth-generation fighters with the secretive X-37 space plane. ${ }^{314}$ With upgrades to sensor fusion and MADL, the F-35 will be a key player in future US-led multinational operations that leverage MDC2 and ultimately satisfy level 4 of the LISI model: Enterprise-based interoperability in a universal environment.

It has been established in Chapter 4 that the US is by far Canada's most important ally. It has also been established that the F-35 is set to become the most ubiquitous fast-jet in the US military inventory. As USAF F-35s are upgraded, Canada will need to keep up with fast-moving capability targets in order to maintain sufficient technical interoperability for operational relevance in NORAD and US-led contingency operations. The platform that is certain to be the most interoperable with American F-35s over its lifecycle is the F-35, which is now being offered to Canada by Lockheed Martin and the US government. Because the F-35's development costs are shared proportionately between the JSF program partners, Canada would also have less financial risk to bear when upgrading a fleet of RCAF F-35s than it would should it choose to purchase an older and less widely-used type. ${ }^{315}$ The F-35 is clearly the most interoperable and future-proofed offering in the FFCP; it is most clearly aligned with contemporary Canadian defence policy. Canada should buy an American fifth-generation fighter; it should buy the F-35.

\footnotetext{
${ }^{313}$ Joseph Trevithick and Tyler Rogoway, "Master Chart Showing US Military Aircraft and Their DataLinks Includes RQ-170 Sentinel," The Drive, 2018, https://www.thedrive.com/the-warzone/20381/master-chart-showing-us-military-aircraft-and-their-data-links-includes-rq-170-sentinel. 314 "Air Force Seeks New Networking Capability by Linking F-35, F-22 Stealth Fighters and X-37 Space Plane," Military \& Aerospace Electronics, 2019, https://www.militaryaerospace.com/communications/article/14072577/space-plane-stealth-fighterscommunicate.

${ }^{315}$ National Defence, Next Generation Fighter Capability Annual Update (Ottawa, ON: Government of Canada, 2013), 11.; Lee Berthiaume, "Canada Forced to Pay Bigger Share of F-35 Fighter Jet Development Costs - Even Though It May Never Buy Any," The National Post (Ottawa, ON), News: World, 2019, https://nationalpost.com/news/world/plan-to-buy-more-fighter-jets-puts-canada-on-hookfor-bigger-share-of-f-35-costs.; "Author Interview with Subject D."
} 


\section{Chapter 7: The competition to replace the CF-18}

Neoclassical realism maintains that the intervention of the state can shape short-term policy outcomes. Indeed, political gamesmanship has fundamentally changed the fighter procurement file in Canada and shaped the FFCP. As discussed in Chapter 2, the F-35 became a source of intense political debate in Canada following the release of the OAG's report in April 2012, with the Liberal and New Democratic parties seizing on the opportunity to criticize Conservative decision-making and painting the F-35 as the wrong platform for Canada. ${ }^{316}$ However, DND continued to insist that the F-35 was the only type with the technical capability to meet Canada's operational requirements. ${ }^{317}$ Two individuals interviewed for this study argued that the uppermost echelons of the Conservative government, the federal public service and the CAF understood that the future fighter ultimately needed to be the F-35 - because of Canada's operational requirements and that platform's unique capabilities. ${ }^{318}$ In a meeting in 2014 , thenDeputy Minister of Public Works Michelle D’Auray reportedly expressed her belief to thenClerk of the Privy Council Wayne Wouters that the notion of Canada holding an open competition to select the CF-18 replacement was insupportable. ${ }^{319}$

Still, the Liberal Party stuck with its criticisms of the F-35 and pledged not to buy the type during the federal election campaign in 2015. Instead, a Liberal government would hold a fighter procurement competition. Liberal leader Justin Trudeau elaborated to reporters:

The Conservative government never actually justified or explained why they felt Canada needed a fifth-generation fighter. They just talked about it like it was obvious. It was obvious, as we saw through the entire process, that they were particularly, and some might say unreasonably or unhealthily, attached to the F-35 aircraft... The fact is we need an aircraft that's going to meet Canada's No. 1 priority, which is defending North American airspace, and there are a wide

\footnotetext{
316 Staff, "Stephen Harper Must Resign over Bungled F-35 File, Say Liberals."

317 Ibid.

318 "Author Interview with Subject D."; "Author Interview with Subject E."

319 "Author Interview with Subject E."
} 
number of very credible, serious aircraft out there who can bid for that and be respectable and responsible replacements for the CF-18s instead of the F-35s. ${ }^{320}$

The Liberal Party's stance on the F-35 and the Conservative sole-source purchase - both rooted firmly in its own domestic political interests - informed its plan for the FFCP.

The Liberals defeated the Conservatives in the federal election of October 2015 and formed a majority government. Shortly thereafter, newly appointed Minister of National Defence Harjit Sajjan and his staff were briefed on the fighter procurement file. Departmental officials contended that the F-35 could not legally be excluded from an open competition, and in a fair format, it would likely win. ${ }^{321}$ Chief of the Defence Staff (CDS) Jonathan Vance informed senior members of government that the F-35 was the only available platform capable of meeting the CAF's operational requirements. ${ }^{322}$ While this new information forced the Liberals to somewhat soften their public stance on the F-35, the decision was still taken to hold an open procurement competition. ${ }^{323}$

The FFCP was launched in December 2017 and the F-35 was permitted to participate. However, the project's classified technical requirements were changed from the previous solesource acquisition to promote competition. Richard Shimooka explains a day-long information session hosted by government officials for potential FFCP suppliers in January 2018:

Government representatives broadly outlined their requirements for the project, which reflected the compromises it had to make in order to have a plausible attempt at a competition. This became immediately evident from the sections focusing on capability. The RCAF was pressured to shift many of its previously mandatory requirements to a rated scale, while in other areas it was prohibited from updating

\footnotetext{
320 "F-35 Fighter Jet Bursts onto Election Agenda; Trudeau Says Liberal Government Wouldn't Buy It," Ottawa Citizen (Ottawa, ON), News: Politics, 2015, https://ottawacitizen.com/news/politics/f-35-fighterjet-bursts-onto-election-agenda-trudeau-says-liberal-government-wouldnt-buy-it.

${ }^{321}$ Richard Shimooka, The Catastrophe: Assessing the Damage from Canada's Fighter Replacement Fiasco (MacDonald-Laurier Institute, 2019), https://macdonaldlaurier.ca/files/pdf/20190502_MLI_COMMENTARY_Shimooka_FWeb.pdf, 6. 322 "Author Interview with Subject E."

323 "Author Interview with Subject D."
} 
the pre-2012 requirements statements to modern standards. As far as the public services were concerned, these restrictions allowed less capable aircraft to participate in the competition and also made them more competitive against the F35. It also artificially compressed the ratings in some cases in order to minimize the operational advantage of the most capable aircraft. ${ }^{324}$

The FFCP SOR is less stringent than the SOR set for the sole-source procurement. While mandatory requirements must be met for a platform to be selected, rated requirements are assigned a certain weight in the bid evaluation criteria and do not necessarily need to be met for a bid to be successful. The shift to rated requirements and the directive to not update others from their previous standards suggest that the Liberal government intended to make more aircraft capable of meeting baseline technical requirements - and for those same types to lose fewer points for failing to meet high-end technical requirements. The decision to compress ratings also makes it difficult for technically advanced aircraft to score a corresponding number of points.

In the definition phase of a capital project, the SOR is changed into a draft RFP. This is then sent to suppliers for feedback until broad agreement is reached on the evaluation criteria. Changes to the FFCP RFP were made in the spring of 2019. During this period, representatives of Lockheed Martin's competitors argued that early drafts unfairly favoured the F-35. In response, the federal government increased the weighting for air-to-air capability and reduced it for air-to-ground capability, which had been seen to favour the F-35, while also boosting the value of sustainment, thereby increasing the penalty for the F-35's high maintenance costs. ${ }^{325}$ At the time, Assistant Deputy Minister, Materiel (ADM MAT) Pat Finn acknowledged that these

\footnotetext{
${ }^{324}$ Shimooka, The Catastrophe: Assessing the Damage from Canada's Fighter Replacement Fiasco, 11. ${ }^{325}$ David Pugliese, "Some Changes Made to Canadian Fighter Jet Requirements as New Document Sent to Companies," Ottawa Citizen (Ottawa, ON), Defence Watch, 2019, https://ottawacitizen.com/news/national/defence-watch/some-changes-made-to-canadian-fighter-jetrequirements-as-new-document-sent-to-companies/.
} 
changes had been made at the request of Boeing, Airbus and Saab. ${ }^{326}$ Canada's capability requirements were changed not because of operational needs, but at the behest of self-interested competitors. Their modification has helped to level the playing field at the F-35's expense. The final RFP was released in July 2019.

In the RFP evaluation criteria, FFCP bids are judged on technical merit, cost and offsets to Canadian industry under the ITB policy. ${ }^{327}$ Technical merit accounts for 60 percent of possible points, while cost and industrial offsets account for a further 20 percent each. ${ }^{328}$ If a supplier offers low acquisition and in-service costs and a comprehensive industrial package, then its bid will score well on those criteria. If the platform being offered is less technically advanced - it meets the mandatory technical requirements but not each rated one - then it could still score well on the technical criteria, especially with the changes made to those requirements for the FFCP. In such a scenario, the less advanced platform becomes competitive with a more advanced type that may be costlier and does not come with the same, tailorable economic package. Indeed, one interview subject argued that the ITB pillar was changed from 10 percent to 20 percent of the total bid to promote competition. ${ }^{329}$ The government itself boasts that the procurement "attributes one of the highest weightings to economic benefits for Canada in its history," with maximum

326 "Airbus, Boeing May Pull out of Fighter Jet Race They Say Is Rigged for F-35," CBC News, Business, 2019, https://www.cbc.ca/amp/1.5204973.

327 The ITB policy requires that suppliers offer work to Canadian industry as part of their bids, see Government of Canada, "The Industrial and Technological Benefits Policy," Innovation, Science and Economic Development Canada, 2018, accessed February 23, 2020, https://www.wddeo.gc.ca/eng/11978.asp.

${ }^{328}$ Valerie Insinna, "Canada's Final Solicitation for Its Next-Gen Fighter Is Out. Who Will Bid for the Contract?," Defense News, 2019, https://www.defensenews.com/air/2019/07/23/canadas-final-

solicitation-for-its-next-gen-fighter-is-out-who-will-bid-for-the-contract/.

329 "Author Interview with Subject D." 
points afforded only to contractual guarantees - guarantees that cannot be offered by Lockheed Martin, given the competitive nature of JSF program contracts. ${ }^{330}$

Finally, in the wake of the Boeing-Bombardier trade dispute, Minister of Innovation, Science and Industry Navdeep Bains warned that the federal government would consider a company's "economic behaviour" in the FFCP and penalize those judged to have caused harm to Canada. That clause reportedly still exists in the project's bid evaluation criteria. ${ }^{331}$ A recent news article on the FFCP reads that "the competition is complicated by questions and past concerns about both of the American offerings." 332 It is unclear what impact this consideration could have on the Boeing offering.

The new format and requirements for the FFCP suggest that the policy on the fighter file has clearly changed from the Conservatives to the Liberals. The issues discussed in this chapter call into question whether the FFCP is being held in good faith. Indeed, the federal government may now be managing the process with undue bias against the F-35, with one interview subject arguing that it has worked to minimize any perception of the FFCP favouring that type. ${ }^{333}$ These dynamics are of consequence to the research question; it is unclear that the FFCP will weigh the choice between fourth-generation and fifth-generation fighters and the choice between American and European types. Another interview subject summed up the issue: "In the FFCP, capability may not be a determining factor in who wins, because it is an open competition with a variety of factors being evaluated." 334 Instead, cost and ITB benefits may outweigh considerations of technical capability and interoperability in the selection process.

\footnotetext{
${ }^{330}$ Public Services and Procurement Canada, Canada Announces Next Step in Future Fighter Competition (Gatineau, QC: Government of Canada, 2019).

${ }^{331}$ Connolly, "Pushing Fighter Jet Deadline Raises Questions on Which Jets Can Do the Work: Experts."

332 Ibid.

333 "Author Interview with Subject D."

334 "Author Interview with Subject C."
} 


\section{Chapter 8: FFCP Technical Requirements}

SSE states that the CAF will "acquire 88 advanced fighter aircraft to enforce Canada's sovereignty and to meet Canada's North American Aerospace Defense Command (NORAD) and

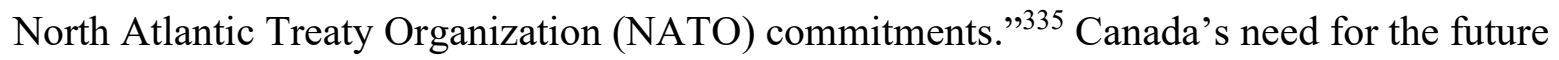
fighter is aligned with the three focuses of Canadian defence policy. The FFCP SOR is classified. However, slide decks from the Future Fighter Industry Day held in January 2018 speak to the CAF's operational requirements. The SOR reportedly has three central components: "Interoperable with NORAD and NATO; Adherence with 5/2 Eyes intelligence levels; Providing Operational Advantage against technologically advanced threats.." ${ }^{336}$ Technical interoperability with NORAD and NATO is presented as the top priority for the future fighter. However, it remains unclear exactly what degree of technical interoperability is to be considered sufficient in light of changing allied networking standards, the different CIS used by the competitors and the reduced technical requirements. The second component of the SOR is information security, which is closely related to technical interoperability. The future fighter must be capable of securely hosting Five- and Two-Eyes data. While this is a basic mandatory requirement, it remains unclear whether each of the three competitors can meet it - and what the implications are for the national origin of the future fighter.

\section{Past requirements: information-sharing}

Details of the SOR written under the Conservative government can be used to deduce the technical interoperability required by the FFCP today. In early 2010, DND analysis concluded

\footnotetext{
${ }^{335}$ Defence, Strong, Secure, Engaged: Canada's Defence Policy, 13.

${ }^{336}$ National Defence, Future Fighter Capability Project: Replacing Canada's Current Fighter Aircraft (Ottawa, ON: Government of Canada, 2018), slide 18.
} 
that of the CAF's 28 mandatory requirements for the CF-18 replacement, there were six that could only be met by the F-35. Two of these are particularly noteworthy, and with the inclusion of fourth-generation types in the FFCP, can no longer be mandatory technical requirements. First, the type needed to be "capable of secure, low probability of detection/low probability of intercept directional datalink communications to allow continued operations in a high threat environment." ${ }^{337}$ Departmental officials compared Link 16 with MADL. They found that while Link 16 "transmits in all directions at a constant level of output" and can be detected by hostile sensors, MADL "transmits only in the direction of the next aircraft in the data link chain with the precise amount of power needed," thereby lowering the aircraft's probability of detection or interception and enhancing situational awareness and survivability in A2/AD environments. ${ }^{338}$ Second, the CF-18 replacement needed to be capable of "automatically incorporating off-board sensor data in order to optimize own ship censor duty cycle." ${ }^{339}$ For this requirement, officials concluded that "only an aircraft capable of automatically communicating with other friendly aircraft in order to optimize the information received from its own sensors could achieve mission success. ${ }^{340}$ This is a reference to sensor fusion, which is described in detail in Chapter 6.

The requirements set by the CAF in 2009 were most clearly satisfied by the F-35. But this does not necessarily mean that the selection process was flawed or affected by undue bias. One interview subject conveyed the DND/CAF's view that at the time, there were few fighter aircraft available for immediate purchase that could function in an increasingly networked environment both at home and abroad. F-35 production slots were available. This individual then

\footnotetext{
${ }^{337}$ Parliament of Canada, Inquiry of Ministry: Question No. 434, by Associate Minister of National Defence (Ottawa, ON: Government of Canada, 2012).

${ }^{338}$ Ibid.

${ }^{339}$ Ibid.

${ }^{340}$ Ibid.
} 
made the point that because Canada's military equipment usually has an extended service life, operational requirements for major capital projects are written to make the CAF as capable as possible, and able to adapt to future policy directives and threats. ${ }^{341}$ The defence team concluded that because the F-35 was significantly more capable than any other type, a competition to select a replacement for the CF-18 could not be held in good faith. ${ }^{342}$ The 2009 SOR may have been high-end, but it reflected a legitimate assessment of Canada's operational needs over the lifecycle of the fighter - and advanced interoperability ranked high among them. This assessment in turn calls into question the technical requirements, and specifically the interoperability requirements, of the FFCP. One interviewee recognized that the mandatory requirements have been "watered down since 2010 to encourage competition." 343

\section{What degree of technical interoperability does Canada consider sufficient today?}

Under the current process, the federal government requires that the future fighter be "seamlessly interoperable with key allies." 344 Seamless is a subjective and somewhat problematic term. Today's CF-18 possesses secure radio and Link 16 TDL connectivity with allies and is compatible with NORAD and FVEY intelligence flows, but it generates and transmits less data than more modern types. While the CF-18 is considered fully interoperable with Canada's key allies, the CAF - which operates alongside them day in and day out - is always supportive of greater connectivity in new military platforms. ${ }^{345}$

\footnotetext{
341 "Author Interview with Subject D."

${ }^{342}$ Shimooka, The Catastrophe: Assessing the Damage from Canada's Fighter Replacement Fiasco, 5.

343 "Author Interview with Subject D."

${ }^{344}$ Future Fighter Capability Project: Replacing Canada's Current Fighter Aircraft, slide 8.

345 "Author Interview with Subject F."
} 
As a starting point for technical interoperability, the future fighter will need to be compliant with numerous NATO STANAGs. STANAGs - or common standards - ensure that a given piece of military equipment can be used in the NATO operating environment. ${ }^{346}$ These do not impose rigorous interoperability requirements and sit low on the integration continuum discussed in Chapter 2. There is little risk of the Gripen, Super Hornet or F-35 being totally incompatible with NATO STANAGs. Still, because the CAF always seeks to maintain the alliance standard, the future fighter will be required to comply with STANAG 5516, which sets out the specifications for different NATO TDL terminals to exchange data using the J-series message. ${ }^{347}$ This STANAG, signed in January 2003, resulted from a program to equip all NATO aerial combat assets with Link 16. ${ }^{348}$ Today, nearly all fourth-generation Western fighters incorporate the system; a corporate publication from 2015 estimates that approximately 5000 individual platforms are so-equipped. ${ }^{349} \mathrm{CF}-18$ pilots employ Link 16 extensively - and especially for NORAD operations. ${ }^{350}$ Given the CAF's use of this TDL and its investment in enhanced capacity through the TIC 3 Air project, it is reasonable to conclude that the future fighter will be required to possess it.

While Link 16 may be a mandatory requirement in the RFP, it is fast becoming a legacy standard. It has been established that two high-end interoperability requirements from the first CF-18 replacement project can no longer be mandatory technical requirements in the FFCP RFP.

\footnotetext{
346 "Author Phone Interview with Subject A."

347 "Author Interview with Subject B," interview by William Richardson, October 23, 2019, Ottawa, ON.; See "NATO - STANAG 5516 - Tactical Data Exchange - Link 16 | Engineering360," Standards Library, Engineering 360, 2008, accessed February 19, 2020, https://standards.globalspec.com/std/1307656/STANAG\%205516.

${ }^{348}$ Akers, Understanding Voice and Data Link Networking: Northrop Grumman's Guide to Secure Tactical Data Links, 2-3.

${ }^{349}$ Ibid, $2-2$.

350 "Author Interview with Subject D."
} 
Instead, high-end interoperability requirements now appear to be incorporated as rated technical requirements. ${ }^{351}$ These capabilities could include multi-sensor networking in support of sensor fusion, VLO networking and direct, automatic networking with different C4ISR assets - all capabilities possessed by MADL. Rated technical requirements are usually more specific than mandatory technical requirements, and are therefore the most important for discriminating between the technical capabilities of individual platforms. ${ }^{352}$ However, as argued in the previous chapter, rated requirements also carry less weight in the evaluation process and do not have to be met. An advanced capability reflected in one rated technical requirement is likely to carry little determinative weight in an RFP where technical requirements account for 60 percent of the possible points and mandatory technical requirements account for many of those. The prevalence of rated requirements somewhat levels the field for the three competitors and may de-emphasize advanced interoperability capabilities in the evaluation process. The risk is that a major point of difference between the fourth- and fifth-generation competitors could be overlooked and Canada accepts a legacy TDL like Link 16 as sufficient for the future fighter.

\section{Evaluating bids against requirements}

The technical requirements incorporated into the RFP generally prioritize capabilities over the use of specific systems, or "what" over "how." In keeping with this approach, high-level outcomes like mission effectiveness are emphasized in the evaluation criteria. ${ }^{353}$ Bids are evaluated primarily through mission profiles, which are small vignettes asking what a firm's

\footnotetext{
351 "Author Interview with Subject G."

352 "Author Interview with Subject C."

${ }^{353}$ National Defence, Future Fighter Capability Project: Delivering Canada's Future Fighter Capability (Ottawa, ON: Government of Canada, 2018), slide 8.
} 
offering could do to be successful in successively higher-end operations. ${ }^{354}$ Mission profiles include air-to-air, air-to-sea, strategic attack and missile defence; NORAD and NATO missions are also represented. ${ }^{355}$ These have been written in an agnostic way and do not explicitly require specific capabilities, thereby acknowledging that there are different ways to complete operational tasks. ${ }^{356}$ The suppliers will submit written responses that attempt to demonstrate their platforms' compliance with the requirements. Desired capabilities include detailed situational awareness, the ability to distinguish friend from foe, survivability, sustainability and interoperability. ${ }^{357}$

This format for demonstrating capability is ill-suited to discriminating between the CIS of the competing platforms. The achievement of technical interoperability is necessarily granular. In keeping with the argument of Air Chief Marshal Hillier from Chapter 5, the future fighter must be equipped with the latest CIS to be networked with key allies over its lifecycle. These are specific systems, like MADL, already in use with the US, UK, Australia and other NATO allies. They must be incorporated into the platform in intricate ways and upgraded regularly to keep pace with changing allied standards. While the RFP's focus on high-level mission outcomes allows a supplier to cite tactical networking as a driver of capability, it leaves comparatively little scope for discussion of the specific enabling systems. The RFP should discriminate more on "how." As it is, the technical interoperability required by the FFCP is not sufficiently advanced or specific to ensure the selection of the F-35.

\footnotetext{
${ }^{354}$ Stephenson, Anatomy of a Buy: The Four Dimensions of Procuring a Fighter Fighter for Canada, 6. ${ }^{355}$ David Pugliese, "Bidding Criteria for Canada's \$19b Fighter Jet Competition Will Emphasize Strategic Attack and Ground-Strike Capabilities — Seeming to Favour the F-35," The National Post, News, 2019, https://nationalpost.com/news/bidding-criteria-for-canadas-19b-fighter-jet-competition-willemphasize-strategic-attack-and-ground-strike-capabilities-seeming-to-favour-the-f-35.

356 "Author Interview with Subject G."

${ }^{357}$ Stephenson, Anatomy of a Buy: The Four Dimensions of Procuring a Fighter Fighter for Canada, 6.
} 


\section{Intelligence as a capability driver}

Shared intelligence is a key driver of Canada's tactical fighter capability. The Future Fighter Industry Day presentations read that "robust operational mission data is critical for combat effectiveness, lethality and survivability." 358 This affects the fighter ecosystem in the following areas: "Mission planning; Aircraft, offensive/defensive systems programming; Support equipment: debriefing/simulators/maintenance; Growth path to 2060 and beyond." 359 Data on adversary systems, capabilities and operations influences the way Canadian fighter aircraft are programmed, maintained and upgraded, as well as how they are used operationally. Each of the future fighter's onboard sensors will be programmed with mission data "at the [FVEY] level for Contingency Operations and the [Two-Eyes] level for NORAD operations." 360 On operations, radar returns will automatically be fed through a threat library populated with Five- and TwoEyes intelligence. ${ }^{361}$ When an adversary develops a new capability, FVEY intelligence is used to reprogram and upgrade partner aircraft in response to the new threat. The future fighter will need to be reprogrammable with FVEY data in this way. ${ }^{362}$ The technical interoperability of the future fighter relies on the selected type being able to securely receive and store allied intelligence.

\section{Technical compatibility with intelligence flows and information security}

Five- and Two-Eyes intelligence is useful and sensitive. As we have seen, compatibility with allied intelligence flows is a mandatory requirement for the future fighter. Today, classified

\footnotetext{
${ }^{358}$ Future Fighter Capability Project: Replacing Canada's Current Fighter Aircraft, slide 9.

${ }^{359}$ Ibid, slide 9.

${ }^{360}$ Ibid, slide 9.

361 "Author Interview with Subject G."

362 "Author Phone Interview with Subject A."; Shimooka, The Catastrophe: Assessing the Damage from Canada's Fighter Replacement Fiasco, 11.
} 
mission data is securely uploaded to Canadian fighter aircraft through advanced cryptographic systems. Canada has made the decision not to manufacture high-end cryptography equipment. Instead, the crypto systems used in contemporary Canadian fighter aircraft are manufactured by a handful of specific American defence firms and supplied to Canada by the National Security Agency (NSA) through bilateral technology-sharing agreements that fall under US Special Access Programs (SAPs). ${ }^{363}$ SAPs are special security protocols for the provision of classified IP to authorized individuals and organizations with a clear "need to know." ${ }^{364}$ NSA crypto keys are physically loaded onto Canadian fighter aircraft before NORAD operations. Similar keys supplied by the US are required for FVEY contingency operations. ${ }^{365}$ The future fighter needs to be technically capable of incorporating American crypto systems and allied mission data.

The US is the primary producer of intelligence and advanced cryptography systems in NORAD, FVEY and NATO and requires security guarantees before it grants external partners access to its classified products. ${ }^{366}$ In the Future Fighter Industry Day slides, the first capability listed for the FFCP is "Interoperability: NORAD, NATO, safeguard shared 5/2 Eyes intelligence." 367 In a briefing in 2018, Finn said: "We obviously have NATO and NORAD commitments, with NORAD probably being the bigger one, which means we have significant security requirements that are Canada-US." ${ }^{368}$ Canada's participation in defence partnerships imposes strict security requirements on the $\mathrm{CAF}$ - and the closer the partnership, the stricter that

\footnotetext{
363 "Author Interview with Subject C."; "Author Interview with Subject F."; Stephenson, Anatomy of a Buy: The Four Dimensions of Procuring a Fighter Fighter for Canada, 3.

${ }^{364}$ Tim McMillan and Tyler Rogoway, "Special Access Programs and the Pentagon's Ecosystem of Secrecy," The Drive, 2019, https://www.thedrive.com/the-war-zone/29092/special-access-programs-andthe-pentagons-ecosystem-of-secrecy. 365 "Author Interview with Subject F."

366 "Author Interview with Subject C."

${ }^{367}$ Future Fighter Capability Project: Replacing Canada's Current Fighter Aircraft, slide 19.

${ }^{368}$ Leblanc, "European Fighter-Jet Manufacturer Pulls out of Canadian Competition to Replace CF-18s."
} 
requirement. Crypto keys used for NORAD operations and FVEY data must be maintained, stored and upgraded in secure facilities located within Canada. ${ }^{369}$ Because the future fighter must be compatible with Five- and Two-Eyes data as well as American crypto equipment under the jurisdiction of the International Traffic in Arms Regulations (ITAR), the government has recognized that certain systems currently integrated into the competing platforms could need to be replaced by more secure American systems. ${ }^{370}$ This is to reduce the risk of intelligence leaking from the future fighter. To this end, the Future Fighter Industry Day slides state that the requirement of compatibility with allied intelligence flows could lead to "Intellectual Property and technical data [being] required for security assessments [and] approvals." ${ }^{371}$

If an operator purchases a piece of network-enabled military equipment that is compliant with the information security standards of its external intelligence sources, that product comes with signoffs from those nations or groupings. American platforms are designed and built to meet this threshold; US military equipment is precleared to host American intelligence. ${ }^{372}$ The DND/CAF can therefore acquire military equipment from US suppliers and use it operationally while forgoing the strict Five- and Two-Eyes accreditation processes for emissions controls. Canada must, however, undertake these examinations in cooperation with US government bodies before it can use network-enabled parts, systems and platforms that have been designed and/or manufactured outside Canada and the US and have not already been cleared to operate within the Five- and/or Two-Eyes groupings. Emissions controls testing requires that the tester own the entire IP for the part(s) or system(s) in question. It ensures that each network-enabled part in a

\footnotetext{
369 "Author Interview with Subject C."

${ }^{370}$ Future Fighter Capability Project: Delivering Canada's Future Fighter Capability, slide 12.

${ }^{371}$ Ibid, slide 12.

372 "Author Interview with Subject G."
} 
military platform is de-conflicted and emits signals securely. This entails isolating parts and creating firewalls within systems. ${ }^{373}$ Modern warplanes emit a significant amount of energy and with fly-by-wire controls contain many data-transmitting parts. To host Five- and Two-Eyes data and be technically interoperable with those partners, the future fighter needs to be fully secure.

\section{Information security requirements as a disadvantage?}

Mandatory security requirements may affect the three competing platforms differently. Two of these are American and can therefore host Five- and Two-Eyes intelligence without extensive electronic emissions testing or modifications. The other platform is designed in Sweden and has not been operated by or manufactured in a Five- or Two-Eyes country before. The question is therefore whether the European offering will be disadvantaged by the FFCP security requirements, and whether it can be made interoperable with allied intelligence flows in a reasonably efficient and low-risk manner. David Perry argues:

Whatever aircraft we obtain has to be fully, seamlessly interoperable at the highest levels with the American Air Force and the rest of the US defence establishment, which is going to be tougher for Europeans to do than it would be for the Americans. There's a way to do that, but it would also imply additional cost and integration risk. ${ }^{374}$

Canada will incur unwarranted risk and significant additional costs should it decide to purchase and operate a European fighter. Mandatory security requirements should therefore place the Saab Gripen E at a considerable disadvantage in the FFCP.

373 "Author Interview with Subject G."

${ }^{374}$ Leblanc, "European Fighter-Jet Manufacturer Pulls out of Canadian Competition to Replace CF-18s." 
Four risks are involved. Certain network-enabled parts and systems associated with the future fighter - including but not limited to the cryptographic equipment discussed above - are built in such a way that they are ready to receive classified data once operational. The design and construction of these items reveal enough about the format and content of the intelligence that they will host to raise information security concerns. Such components are therefore extremely sensitive and must be designed, built, stored and upgraded in secure facilities located within either the Five- or Two-Eyes communities, depending on their intended use. ${ }^{375}$ The first risk is with their integration into a platform designed outside those groupings. The authors of a major RAND Corporation study on interoperability in coalition air campaigns write:

A strong argument can be made that interoperability should be addressed early in the design, development, and acquisition process so that least-cost, longer-term solutions can be found for integrating capabilities into effective and efficient combined operations. The alternative - attempting to integrate deployed systems means that integration is likely to amount to little more than improvised workarounds that are less effective than systematic integration of elements in a larger system. ${ }^{376}$

Though this argument refers to tactical networking rather than information security, the logic is similar. The emissions accreditation process uses segmenting and workarounds to achieve technical compatibility and security. This intensive effort introduces the risk that a heavily modified European design will not be as secure or effective as a platform that has been specifically designed and manufactured to meet Five- and Two-Eyes security standards and integrate the associated systems. At the same time, such a unique fleet would be challenging to upgrade alongside evolving allied security and tactical networking standards. The purported

\footnotetext{
375 "Author Interview with Subject G."

${ }^{376}$ Hura, Interoperability: A Continuing Challenge in Coalition Air Operations, 29.
} 
solution of modifying and segmenting significant portions of the future fighter could jeopardize its achievement of seamless (and secure) interoperability with key allies over its lifecycle.

The second risk is related and pertains to the US. Finn recognized in 2019 that while the Canadian defence team will undertake emissions controls evaluations during the detailed design phase should a European type be selected as the winner of the FFCP, "the US will have a role to play in ultimate certification." 377 This role plays out at two levels. As discussed above, the US requires guarantees of information security before it shares its intelligence. However, the certification of a European platform by the US at the Two-Eyes level is an unknown for Canada, with one interview subject arguing that there would be little incentive for the US to take part. ${ }^{378}$ Moreover, many of the classified technologies referenced above are designed and produced only in the US and are ITAR-controlled. US government bodies including the State, Commerce and Defense Departments and the NSA must sanction their export to Canada for integration into the future fighter. There is simply no guarantee that the US government will grant special permission for a foreign platform - regardless of whether emissions controls testing takes place. ${ }^{379}$

Stephenson cites "significant commercial and national security interests in maintaining military and technological advantages by the US government, fighter manufacturers and equipment suppliers. ${ }^{380}$ Such interests, which include the first risk, would complicate Canadian efforts to equip a non-American platform with some of the most sensitive American CIS.

\footnotetext{
377 "New Canadian Fighter Jets Will Need U.S. Certification: DND," The Globe and Mail (Ottawa, ON), Canada, 2019, https://www.theglobeandmail.com/canada/article-new-canadian-fighter-jets-will-need-uscertification-dnd-2/.

378 "Author Interview with Subject D."

${ }^{379}$ On the need for US certification, see "New Canadian Fighter Jets Will Need U.S. Certification: DND."

${ }^{380}$ Stephenson, Anatomy of a Buy: The Four Dimensions of Procuring a Fighter Fighter for Canada, 9.
} 
Third, the federal government expects that the Communications Security Establishment (CSE) will be able to conduct emissions testing and ultimately sign off on the security of the selected platform at some level. ${ }^{381}$ However, the first and second risks are compounded by the fact that Canada has little experience testing and approving an entire platform - and particularly an advanced fighter aircraft. In a May 2019 interview, Finn pointed out that the Canadian defence team has bought non-American defence equipment in the past and modified it to meet allied security requirements. Included in this list are the Saab 9LV naval combat system and the Sea Giraffe radar used by the modernized Halifax-class frigates. ${ }^{382}$ These systems, while complex, are only components of a larger platform that has been designed and built in Canada. Modern fighter aircraft are immensely complex platforms made up of interconnected sensors and systems. The process of examining each of these components and de-conflicting many of them would require extensive cooperation between the federal government and the supplier, and could result in protracted delays to the FFCP, all before the US government is asked to sign off.

Fourth, this process could result in major modifications being made to the fighter's design. To ensure that vital changes are incorporated and a secure platform is ultimately produced, it is conceivable that a European fighter require both re-engineering and assembly in Canada. While Saab has already offered to assemble the Gripen E in Canada as part of its industrial offsets package, the entire undertaking would be time-consuming and laden with risk, while almost certainly imposing significant additional costs on the federal government and going well beyond the scope and intentions of the FFCP and its ITB pillar. ${ }^{383}$ Maintenance and in-

\footnotetext{
${ }^{381}$ Interviewee G; Also see "New Canadian Fighter Jets Will Need U.S. Certification: DND."

${ }^{382}$ Attariwala, "Saab Gripen E/F."

383 "IMP Joins Bid to Assemble Canada's New Fighter Jets in Nova Scotia," The Chronicle Herald, Business, 2020, http://www.thechronicleherald.ca/business/local-business/imp-joins-bid-to-assemble-
} 
service support initiatives for the future fighter will also need to be secured for Five- and TwoEyes interoperability. The acquisition of a European fighter by Canada would necessitate the establishment of a new, secure supply chain and the construction of unique heavy maintenance facilities. Parts could not be sourced from Europe because of security constraints or from Canada's Five- and Two-Eyes partners because of incompatibility. RCAF Saab Gripens could not be serviced or upgraded in Sweden or Brazil; Canada's security partners would also lack compatible support facilities. ${ }^{384}$

The cost to Canada of purchasing a Swedish fighter would be higher than advertised. The British effort to secure the Eurofighter Typhoon for use by the RAF on FVEY networks was reportedly extremely expensive and drove up the type's acquisition cost. ${ }^{385}$ Canada would need to secure a European platform for use on both the Five- and Two-Eyes networks, with the latter process being even more exacting than the former. While the government has reportedly written in the RFP that it would not be willing to finance such an exercise, the cost of evaluations and modifications will need to be reflected somewhere, and may appear in the price set out in Saab's contract proposal. ${ }^{386}$ However, a modern fighter platform has never been tested to this standard before. If the Gripen E prevails in the FFCP, Canada should expect to shoulder the considerable but currently unknown financial burden of securing it for shared networks. Given the integration and financial risk, Canada should purchase a fighter that is designed and manufactured in the US.

canadas-new-fighter-jets-in-nova-scotia-419518/.; "Author Interview with Subject C."; "Author Interview with Subject E."; "Author Interview with Subject G."

384 "Author Interview with Subject C."

385 "Author Interview with Subject C."; "Author Interview with Subject G."

386 "Author Phone Interview with Subject A."; "Author Interview with Subject C." 


\section{Changing requirements (and deadlines) for the sake of competition}

Mandatory security requirements are central to the future fighter's achievement of technical interoperability with key allies. Instead of disqualifying or penalizing certain types for non-compliance, however, the government has introduced a phased bid compliance process that grants leeway to European suppliers attempting to meet them. ${ }^{387}$ This has not had the desired effect. Following the withdrawal of Dassault in November 2018, eligible suppliers were given additional time to address mandatory security requirements. Finn elaborated:

We can't have an aircraft that doesn't meet it, but what we've done is we've created the test in a different way. ... If your proposal, your aircraft, cannot meet [a requirement] today, we are not saying automatically that you're out; but you have to tell us what is your solution to meet it, at what price and what schedule. ${ }^{388}$

All eligible suppliers were instructed to submit a Preliminary Security Offer in September 2019. ${ }^{389}$ However, Saab and Airbus were not given the full technical details of the relevant classified systems. ${ }^{390}$ Even with the extra time then, Airbus assessed that the requirements were too onerous and withdrew from the FFCP in August 2019. ${ }^{391}$ Despite the government's attempts to run an open competition with numerous viable competitors, the field has been whittled down by Canada's unique interoperability needs and related security requirements.

By the time it submitted its Preliminary Security Offer to the federal government in early October 2019, Saab was the only European supplier remaining in the FFCP. ${ }^{392}$ But throughout

\footnotetext{
${ }^{387}$ Connolly, "Pushing Fighter Jet Deadline Raises Questions on Which Jets Can Do the Work: Experts."

${ }^{388}$ Leblanc, "European Fighter-Jet Manufacturer Pulls out of Canadian Competition to Replace CF-18s."

389 "New Canadian Fighter Jets Will Need U.S. Certification: DND."

${ }^{390}$ Pugliese, "Will Other Firms Withdraw from Fighter Jet Competition Leaving F-35 Last Plane Standing?."

${ }^{391}$ Berthiaume, "Airbus Pulls out of Canadian Fighter Jet Competition Following Complaints - BNN Bloomberg."

392 Defence, "Future Fighter Capability Project."
} 
the process, the firm has been publically bullish on its prospects of meeting NORAD and FVEY security requirements. In June 2018, Richard Smith, Head of Gripen Marketing and Sales, said:

Given our proven ability to deliver NATO operational capability, we can do the same working with the Canadian authorities to ensure any needed capabilities to operate in NORAD airspace. Canada will have the access to the aircraft system and can configure and use it as they want - Brazil is a perfect example of that...If Canada selects [the] Gripen, the country would have the Gripen's IP and the freedom to integrate new systems as per their own requirements, and that means [the] Gripen would support high-tech Canadian industry and innovation. ${ }^{393}$

In May 2019, Saab sales executive Per Alriksson claimed that "moving forward with Gripen E, we see no problem whatsoever to integrate that fighter into a NORAD context." 394 There are three issues here. First, Saab suggests that the Gripen's interoperability with NATO proves that the type can adapt to alliance interoperability requirements, but as we have seen, the interoperability requirements for NORAD are far stricter than for NATO. Second, Saab has offered to provide the Gripen's IP to Canada so that it can modify the platform to its own requirements. ${ }^{395}$ This has clearly been framed to maximize scoring on the ITB pillar. But as argued above, the required modifications would be labour-intensive and costly. Third, because Brazil's interoperability requirements differ markedly from Canada's, the Brazilian Gripen acquisition model wherein technology is transferred from Saab in Sweden before joint development and assembly takes place domestically would have limited application for

\footnotetext{
${ }^{393}$ Attariwala, "Saab Gripen E/F."

${ }^{394}$ David Pugliese, "In Pursuit of \$19b Contract, Sweden's Saab Offers to Build Fleet of Fighter Jets in Canada," The National Post, News, 2019, https://nationalpost.com/news/in-pursuit-of-19b-contractswedens-saab-offers-to-build-fleet-of-fighter-jets-in-canada.

${ }^{395}$ One interview subject suggested that Saab's business model likely involves selling the design to Canada, a relatively high-profile buyer, to demonstrate the viability of the program to other potential customers, "Author Interview with Subject C."
} 
Canada. ${ }^{396}$ A straight technology transfer or bilateral development partnership would not be feasible for Canada. As argued above, efforts would need to take place strictly in-country.

The federal government gave the remaining eligible suppliers feedback on their Preliminary Security Offers in February 2020. Soon afterwards, it announced that the March 30 deadline for the submission of bids had been extended to June 30 "at the request of industry." 397 According to that release, "this extension allows eligible suppliers to address recent feedback on their security offers, ensuring that Canada receives competitive proposals that meets its technical, cost and economic benefits requirements." ${ }^{398}$ Global News has been informed that the feedback in question includes "specific assessments about whether a firm would be able to meet the Canadian government's requirements for interoperability with key allies, including [FVEY and the US], and whether allies would be comfortable with them." ${ }^{399}$ While the government has not indicated which firm requested the extension, Lockheed Martin and Boeing spokespersons have stated that their firms did not request it. Saab's public statement, however, was equivocal, reading that while the firm could not comment on "confidential elements of the RFP process," it was still prepared to submit a bid in keeping with the government's schedule. ${ }^{400}$ These developments suggest that Saab's Preliminary Security Offer failed to satisfy Canada's technical requirements and the extension has been granted so that the firm can address the government's concerns as well as the likely concerns of Canada's Five- and Two-Eyes partners. Saab has the

\footnotetext{
${ }^{396}$ Saab AB, "Gripen for Brazil | Saab Brazil," Saab AB, 2019, accessed March 24, 2020, https://saab.com/region/brazil/gripen-brazil/gripen-for-brazil/.

${ }^{397}$ Connolly, "Pushing Fighter Jet Deadline Raises Questions on Which Jets Can Do the Work: Experts."

${ }^{398}$ Ibid.

${ }^{399}$ Ibid.

${ }^{400}$ Ibid.
} 
most work to do to make its offering compliant. So far, the government has been willing to accommodate the firm's clear disadvantage for the sake of competition. 


\section{Chapter 9: Findings and implications}

This study considers Canada's freedom of choice in the selection of the future fighter. Canada has a long history of close military cooperation with a powerful patron state - first the UK and later the US. These arrangements have provided it with assurances of defence and what Canadian politicians have judged to be acceptable levels of sovereignty at a relatively low cost. The partnership with the US has made interoperability with all levels of the US defence establishment a key component of contemporary Canadian defence policy. Nowhere is the imperative for interoperability more evident than in NORAD, a unique binational military command. Membership in NATO and the Five-Eyes community further cements Canada's focus on external partnerships for national defence. This study's two lines of inquiry stem from Canada's established strategic posture. Given the widespread adoption of the F-35 by Canada's allies and their implementation of next-generation C4ISR concepts, should it be selecting a fourth- or fifth-generation fighter? And second, should Canada acquire a fighter that is designed and manufactured in the US to ensure the type's interoperability with key allies? The F-35 is clearly the platform that maximizes Canada's interoperability with key allies over its lifecycle. This chapter considers whether Canada will make the choice that aligns with its own defence policy. It also uses theory to address the implications of a divergent outcome.

\section{Summary of findings}

Chapter 6 provided an evaluation of the networked capabilities of the platforms under consideration to ascertain which of the types will be the most interoperable with Canada's key allies over its lifecycle. Despite the bullish claims of its manufacturer, the Gripen E is found to possess a legacy tactical networking capability. The Block III Super Hornet incorporates the TTNT datalink, which is similar to Link 16/MIDS in form and function but features enhanced 
performance. Both aircraft incorporate updated avionics and are claimed to be capable of some degree of sensor fusion. ${ }^{401}$ However, it is clearly the F-35 which is the most interoperable. The type's integrated sensors and CIS permit both on- and off-board sensor fusion, generating unparalleled situational awareness for operators. Fifth-generation fighters are also contributing to the development of advanced ConOps which make use of MDC2. Finally, they are expected to remain in service and operationally relevant for longer than fourth-generation types. The F-35's lengthy upgrade path is evidence that its CIS will be developed for decades to come. The analysis in Chapter 6 demonstrates that fifth-generation fighters are more interoperable than fourth-generation fighters now and will be even more interoperable in the future.

Chapters 7 and 8 set out evidence on whether the F-35 will be selected, with focus given to the competitive format of the selection process, the weighting of different criteria in the RFP and the mandatory and rated technical requirements. These chapters provide several conclusions. The competitive format of the FFCP has almost certainly been shaped by politically-motivated bias against the F-35. ${ }^{402}$ Short-term political interests are also an underlying factor in the significant weighting given to cost and guaranteed industrial offsets in the RFP and the restructuring of technical requirements for the competition. Finally, the Liberal government has enacted measures to keep all eligible suppliers competitive in the face of mandatory (and strict) Five- and Two-Eyes security requirements. As demonstrated in Chapter 8, it is unclear that a fighter platform designed and manufactured outside the Five- and Two-Eyes communities can be

\footnotetext{
${ }^{401}$ See Saab, "Gripen E | Ready for the Future | Saab."; Canada, "Super Hornet Block III: The Complete Solution for Canada."

${ }^{402}$ At a recent public event, Conservative Party leadership candidate Peter MacKay said that he would buy the F-35 if he became Prime Minister, Alex McColl, "Mackay Ironically Lining up against FighterJet Jobs in His Own Backyard," The Chronicle Herald (Calgary, AB), Opinion, 2020, http://www.thechronicleherald.ca/opinion/local-perspectives/alex-mccoll-mackay-ironically-lining-upagainst-fighter-jet-jobs-in-his-own-backyard-420208/?itm_source=parsely-api.
} 
made compatible with those requirements at all. What is clear is that the effort to approve such a platform for use on shared networks would be complicated and expensive for both Canada and its primary defence partner, the US.

The conclusions reached in these chapters illustrate a troubling disconnect. In keeping with the prevailing focus of SSE, the future fighter is indeed required to be "seamlessly interoperable" with key allies, with then-Minister of Public Services and Procurement Judy Foote saying in late 2016 that "from [the government's] perspective, we're working with the American government, so we have to look at an American plane. ${ }^{403}$ Yet altogether, the structuring of the FFCP and the actions of the Liberal government to bolster competition call into question the preparedness of the executive to make a final decision that accommodates Canada's need for high-end interoperability with the US defence establishment at the technical, tactical, operational and strategic levels. Today, the requirement of interoperability is clearly not as stringent as it was in 2010. At the same time, Boeing and Saab have highlighted their industrial packages as well as the costs associated with their platforms. ${ }^{404}$ The firms are both likely to win points for prioritizing these pillars - points that will help to offset their offerings' technical deficiencies, including their lack of certain interoperable technologies.

\footnotetext{
${ }^{403}$ Future Fighter Capability Project: Replacing Canada's Current Fighter Aircraft, slide 8.; David Pugliese, "European-Built Fighter Aircraft: Did They Ever Stand a Chance in Canada's Competition?," Ottawa Citizen (Ottawa, ON), Defence Watch, 2019, https://ottawacitizen.com/news/national/defencewatch/european-built-fighter-aircraft-did-they-ever-stand-a-chance-in-canadas-competition/. ${ }^{404}$ Canada, "Super Hornet Block III: The Complete Solution for Canada."; "Saab's Compelling Offer to Canada," Saab AB, 2020, accessed March 11, 2020, https://saab.com/gripen/news/blog/gripenblog/2020/saabs-compelling-offer-to-canada/.; "IMP Joins Bid to Assemble Canada's New Fighter Jets in Nova Scotia."
} 


\section{Implications}

Under the neoclassical realist theory of international politics, national leaders that ignore a structural reality for an extended period imperil their nation's continued existence. ${ }^{405}$ Domestic constraints may produce short-term aberrations of foreign and defence policy, but over the longterm, security-seeking states must implement policies that correspond with their relative material power. The CAF's pursuit of interoperability with key allies is fundamentally a reflection of Canada's relative material power. The same can be said of the interoperability requirement for the future fighter. Discussion in Chapter 2 established that a failure to achieve technical interoperability with allied systems can reverberate up through the levels of interoperability. To this end, and in keeping with the neoclassical realist paradigm, Canada's decision on the future fighter can be expected to have broader consequences not just for the CAF but for national defence. These will vary according to the future fighter's generation and national origin.

As discussed in Chapters 4 and 5, bilateral negotiations are now underway to renew the NORAD framework; modernization efforts are expected to continue through this decade and the next. A fourth-generation future fighter would undermine Canada's long-term position in the binational command. Fifth-generation fighters are already a mainstay of NORAD response forces. The F-22 is the sole type assigned to the Alaskan NORAD Region - the binational command's most active in terms of detections and intercepts. ${ }^{406}$ With the delivery of its first F35 in September 2019, the Vermont Air National Guard became the first NORAD unit to field the type. ${ }^{407}$ Canada's selection of a fourth-generation type over a fifth-generation type would

\footnotetext{
${ }^{405}$ Lobell, Ripsman, and Taliaferro, Neoclassical Realism, the State, and Foreign Policy, 7. 406 "Alaskan NORAD Region," About NORAD, North American Aerospace Defense Command, 2020, accessed March 26, 2020, https://www.norad.mil/About-NORAD/Alaskan-NORAD-Region/.

${ }^{407}$ Ryan Mercer, "More F-35 Fighter Jets Arrive at Vermont Air National Guard," Burlington Free Press (Burlington, VT), News, 2019, https://www.burlingtonfreepress.com/story/news/2019/12/06/vermont-airnational-guard-now-has-five-f-35-fighter-jets/2622942001/.
} 
effectively constitute a rejection of the opportunity to advance the technical interoperability and joint effectiveness of NORAD response forces. Although final decisions have not yet been taken on the specific capabilities that will be incorporated into the next-generation NWS, fourthgeneration fighters will almost certainly be less capable of direct networking with that system's anticipated multi-domain sensors. Given its widespread adoption of fifth-generation fighters, the US may not choose to develop backwards compatibility for the next NWS or the necessary upgrades for fourth-generation aircraft. Canada could be forced to develop a costly Band-Aid solution on its own. Should it not buy a fifth-generation type, Canada could even end up having to renegotiate its responsibility for the Canadian NORAD Region because the CAF lacked the high-end interoperability and capability of USAF fifth-generation fighters. The US could deem a fourth-generation future fighter fleet to be inadequate against advanced threats like Russian and Chinese fifth-generation strike fighters and high-performance cruise missiles. ${ }^{408}$ Such an outcome would have lasting consequences for Canada's sovereignty and security.

The ramifications of purchasing a fourth-generation fighter would be felt by Canada beyond NORAD. One interview subject argued that beyond 2040, by which point most allied air forces will have retired their legacy fast-jet fleets, a fourth-generation RCAF tactical fighter force would rapidly fall behind in terms of both technical interoperability and operational relevance. ${ }^{409}$ Such an orphan fleet could increasingly be relegated to a supporting role not just on NORAD missions, but also in US-led contingency operations, NATO operations and air campaigns involving the FVEY partners. In such a situation, Canada would gradually lose one means of achieving the valued partner status that comes with making high-end contributions to

\footnotetext{
408 "Author Interview with Subject C."

409 "Author Interview with Subject G."
} 
coalition warfare. ${ }^{410}$ Moreover, every polar country except Russia is set to operate the F-35. Should Canada not purchase a fifth-generation type, its interoperability with those partners would be compromised and its position in Artic defence negotiations undermined. ${ }^{411}$ LieutenantGeneral Hood recognized the importance of maintaining operational relevance when he testified that Canada's interoperability in 20 to 30 years must be a factor in the future fighter decision. ${ }^{412}$

In the FFCP, Canada has the choice between two American and one Swedish aircraft. The American platforms are pre-cleared to host intelligence classified at the Five- and Two-Eyes levels. The Swedish platform is not. Should it select the Saab Gripen E, Canada would likely face ramifications at each level of interoperability throughout the future fighter's service life, and potentially even beyond. At the technical level, there is no guarantee that the US would grant a Gripen E in Canadian service full access to classified Five- and Two-Eyes networks, even if the Government of Canada were to undertake emissions security evaluations after selecting the platform. The US could easily deny access on the grounds of technical compatibility, information security or commercial interests before refusing to export the sensitive crypto systems that host shared intelligence. While this worst-case scenario may seem remote, the US government has explicitly supported the bids of two American suppliers in the FFCP and Canada already receives disproportionate returns for its modest investments in the bilateral defence partnership. There would be little incentive for the US to suddenly pivot and support Canada's effort to introduce a foreign type into NORAD service. Furthermore, the prospect of a relatively unfamiliar and unproven Swedish platform using sensitive American equipment and intelligence to integrate with American forces and contribute indefinitely to homeland defence would almost

\footnotetext{
${ }^{410}$ Massie, "Bandwagoning for Status: Canada's Need of the F-35," 262

${ }^{411}$ Stone, "From Policy and Strategy to Outcomes," in Canadian Defence Policy in Theory and Practice, 91.

${ }^{412}$ Defence, Canada and the Defence of North America: NORAD and Aerial Readiness, 43.
} 
certainly cause disquiet on Capitol Hill and at the Pentagon. The Gripen E could easily be viewed as a liability by Canada's powerful southern neighbour. Joseph Crook, a spokesperson for the US embassy in Ottawa, stated the American position: "We continue to believe in the importance of NATO and NORAD interoperability as a crucial component of Canada's acquisition of defence assets. ${ }^{" 413}$ From an American perspective, Canada selecting a European type may just not make sense.

Should a Canadian Gripen fail either completely or partially to secure access to classified allied networks, the anticipated ripple effect would start at the tactical level, with RCAF fighters relegated to using less sensitive intelligence and engaging in restricted tactical networking. At the operational level, reduced technical and tactical interoperability would affect the ability of Canadian warplanes to participate in joint operations with US and FVEY forces, not least in NORAD, where Canadian and American fighters could no longer be considered operationally interchangeable. At the strategic level, Canada's interoperability with the US would be particularly affected. Should Canada introduce a new NORAD response force that is not fully interoperable with the US military and has limited capacity for integration with the nextgeneration NWS, the US could conceivably propose new terms for the binational framework that downgrade the previously egalitarian partnership and give Canada fewer assurances of security and sovereignty. Given the disparity in material power, Canada would not be in no position to refuse them. In what is admittedly a worst-case scenario, the purchase of the Saab Gripen could degrade the bilateral partnership that Canada relies on for national defence. More broadly, the purchase could be interpreted by key allies as a signal that Canada assigns less value to its

\footnotetext{
${ }^{413}$ Daniel Leblanc, "U.S. Government Again Urges Canada to Acquire American Fighter Jets, Despite Pentagon Threats," The Globe and Mail, Politics, 2019, https://www.theglobeandmail.com/politics/article-us-government-urges-canada-to-acquire-americanfighter-jets-in-2/.
} 
defence partnerships than claimed. This is the risk, recognized by the neoclassical realist paradigm, that could ultimately imperial the country's long-term security. Given Canada's established strategic posture, the slightest risk of this scenario transpiring must be treated as unacceptable by national leaders of all political stripes.

\section{Example of Canada passing up an advanced military capability: BMD}

Canada has passed up the opportunity to field advanced military capabilities alongside the US before. In February 2005, the Martin government declined the Bush administration's invitation to participate in the Ballistic Missile Defence (BMD) program. The US BMD system, which is designed to defeat a limited number of incoming intercontinental ballistic missiles (ICBMs), uses layers of surface-to-air missiles (SAMs) to intercept ICBMs at various stages of flight. ${ }^{414}$ The US Missile Defense Agency continues to develop, test and field this system. Had Canada agreed to participate, mid-course defence elements might have been stationed in the north and west of the country to intercept ICBMs coming over the North Pole or northern Pacific Ocean. ${ }^{415}$ Though the US had no operational need to include Canada in its BMD program and was primarily seeking the political legitimacy of external involvement, the initiative represented an opportunity for Canada to strengthen the bilateral defence partnership with the US and increase its control over the defence of its own territory. ${ }^{416}$ Canada's refusal to participate in BMD cost it an important guarantee of security from the US. In 2014, the Standing Senate Committee on National Security and Defence wrote:

\footnotetext{
${ }^{414}$ For two of the systems used, see "Aegis Ballistic Missile Defence (Bmd) System," Naval Technology, https://www.naval-technology.com/projects/aegis-ballistic-missile-defence-bmd-us/.; "Terminal High Altitude Area Defense (THAAD)," Lockheed Martin Corporation, 2019, accessed March 29, 2020, https://www.lockheedmartin.com/en-us/products/thaad.html.

${ }^{415}$ Nossal, "The Imperatives of Canada's Strategic Geography," 16-17.

${ }^{416}$ Ibid, 16.; Also see Vucetic, "Canadian Strategic Cultures: From Confederation to Trump," 37.
} 
Canada cannot simply assume that all of its territory will be protected by default under the existing U.S. BMD system. Because Canada is not a BMD participant, decisions on when, where and whether to intercept an incoming ballistic missile would be made not under the auspices of the binational NORAD structure but, rather, by the U.S. alone under its domestic defence command, United States Northern Command (USNORTHCOM)... The committee is concerned that our military officials at NORAD will be asked to "leave the room" when it comes to determining how to deal with a ballistic missile attack that threatens Canada or North America. ${ }^{417}$

The Senate's concern is applicable to the FFCP. The future fighter will be Canada's primary force contribution to NORAD through the middle of this century. Should it pass up the opportunity to field the most technically advanced platform and integrate further with US response forces, Canada would run the risk of being asked to "leave the room" for discussions on how to defend against high-end airborne threats to the continent. In such a scenario, NORAD would be degraded and USNORTHCOM augmented. Canada's say would be diminished.

\section{Joint interoperability and the future fighter}

This study has not considered the joint interoperability of CAF systems and platforms as a factor in the future fighter decision because it falls outside the scope. However, joint interoperability is reportedly being used as a proxy for multinational interoperability in the RFP mission scenarios, and according to one interview subject, joint interoperability "is probably the CAF's biggest challenge." ${ }^{418}$ The joint interoperability of the future fighter will also vary according to the national origin and generation of the selected type. The arguments for both considerations mirror those addressing multinational interoperability. Purchasing a fifthgeneration platform today will secure the interoperability of the RCAF's tactical fighter force

\footnotetext{
${ }^{417}$ Parliament of Canada, Canada and Ballistic Missile Defence: Responding to the Evolving Threat, by Senate Standing Committee on National Security and Defence (Ottawa, ON: Government of Canada, 2014).

418 "Author Interview with Subject G."; "Author Interview with Subject F."
} 
with Canada's military platforms of tomorrow. The CAF's other key players in the future multidomain battlespace will include the space-based C4ISR capabilities highlighted in Chapter 5, a variety of new land-based C4ISR capabilities, the Remotely Piloted Aircraft System (RPAS), the Canadian Surface Combatant and the expected replacement for the CP-140 Aurora ${ }^{419}$ Those data-centric platforms will be upgraded throughout their service lives. All will participate in the MI3 now being developed; all will contribute to the CAF becoming a more integrated joint force in keeping with the C4ISR Strategic Vision; all will move the CAF closer to the seamless and continual networking envisaged by the Future Air Operating Concept. A fifth-generation RCAF fighter would be the best equipped to keep pace with evolving joint interoperability standards. In keeping with discussion in Chapter 4, Canada and the US have long cooperated on defence development and production. Canada has been a formal part of the US National Technology and Industrial Base (NTIB) since $1992 .{ }^{420}$ Acquiring an American type is also a rational choice for the technical interoperability of a military which already operates numerous American-made platforms and C4ISR systems. Moreover, Five- and Two-Eyes intelligence is a major contributor to the CAF's joint effectiveness.

\footnotetext{
${ }^{419}$ For further information, see Chris Thatcher, "Land C4ISR: The Bridge to a Better Way to Buy High Tech? | Canadian Army Today," Canadian Army Today, 2019, https://canadianarmytoday.com/land-c4isrthe-bridge-to-a-better-way-to-buy-high-tech/.; National Defence, "Canadian Surface Combatant," Defence equipment purchases and upgrades, Government of Canada, 2019, accessed March 28, 2020, https://www.canada.ca/en/department-national-defence/services/procurement/canadian-surfacecombatant.html.; National Defence, "Remotely Piloted Aircraft System (RPAS)," Services, Government of Canada, last modified 2019, accessed March 28, 2020, https://www.canada.ca/en/department-nationaldefence/services/procurement/remotely-piloted-aircraft-system.html.; Ken Pole, "Canada Joins Alliance Seeking New Maritime Surveillance Aircraft," Skies, 2018, https://www.skiesmag.com/news/canadajoins-alliance-seeking-new-maritime-surveillance-aircraft/.

${ }^{420}$ Heidi Peters, Defense Primer: The National Technology and Industrial Base (Washington D.C.: Congressional Research Service, 2020), https://fas.org/sgp/crs/natsec/IF11311.pdf.
} 


\section{Five Eyes and warplane procurement}

Small- $n$ case studies are not typically designed to be generalizable. This one is tailored to a specific topic: the relationship between Canada's focus on partnerships for defence and the future fighter. However, Canada is not the only country that must contend with strict interoperability requirements for its network-enabled military platforms. As demonstrated in Chapters 4 and 8, Canada's FVEY partners must adhere to the same security standards when developing the networked capabilities of their warplanes. This study has argued that given the sensitivity and limited availability of the enabling technologies, Canada can most clearly satisfy Five- and Two-Eyes security requirements by acquiring a platform that has been pre-cleared for use on those networks. Of the competitors in the FFCP, the only types that satisfy these criteria are American. The same logic may be applicable to the FVEY more broadly. Australia, the UK and US operate fast-jet fleets of varying sizes; the Royal New Zealand Air Force (RNZAF) has gone without an air combat capability since late 2001. All fast-jets in service with the FVEY partners are designed and manufactured in the US - the largest military power and defence manufacturer in the grouping, and its de facto setter of interoperability standards. ${ }^{421}$ Because Australia and the UK joined the NTIB in 2016, the defence industries of the partners are formally linked. ${ }^{422}$ Firms headquartered in the US maintain significant presences in Australia, Canada and the UK. There are several convincing arguments for the FVEY partners to buy American - and maintaining technical interoperability standards is one of them.

\footnotetext{
${ }^{421}$ The sole exception is the Eurofighter Typhoon operated by the RAF alongside the F-35. As discussed in Chapter 1, this type was cleared for use with FVEY intelligence during development and at a considerable cost to Britain, "Author Interview with Subject C."; It should also be noted that Airbus Defence and Space and BAE Systems have sizeable operations in the US and a history of cooperation with the US government and military, "Author Phone Interview with Subject A."

${ }^{422}$ Peters, Defense Primer: The National Technology and Industrial Base.
} 
The second piece of the study that has clear implications for the FVEY community is Canada's decision to hold a procurement competition for its future fighter in the fifth-generation environment. Australia, the UK and US are all F-35 operators. The CCEB and AFIC, which are tasked with maximizing the technical interoperability of the FVEY air forces, are undoubtedly centres for the development of a fifth-generation "high-fusion environment" by the partners. ${ }^{423}$ The FVEY community is adopting fifth-generation warplanes - and it will no doubt adopt the advanced operational concepts that their networking enables. In this context, it may not be prudent for the FVEY partners, including Canada, to run procurement competitions for fighter aircraft when there is only one fifth-generation type available to them. Indeed, neither Australia nor the UK ran procurement competitions before selecting the F-35 as their next-generation tactical fighters. When the Australian government announced its intention to purchase the JSF in 2002, it informed other suppliers that it would not be accepting competitive bids for the procurement contract. ${ }^{424}$ In the words of then-Defence Minister Robert Hill, "it would be unfair to competitors to hold out a carrot that I don't think is really there." ${ }^{425}$ Like Canada, the UK has been a member of the JSF program since the mid-1990s. Whitehall announced its intention to acquire a total of 138 aircraft in 2006 without ever mooting a competitive selection process. ${ }^{426}$ Given the specificity of FVEY interoperability requirements and the unique capabilities of fifthgeneration aircraft, procurement competitions introduce the risk that partners field types that are

\footnotetext{
423 "Author Interview with Subject D."

${ }^{424}$ Aldo Borgu, A Big Deal: Australia's Future Air Combat Capability (Barton, AU: Australian Strategic Policy Institute, 2004), https://www.aspi.org.au/report/big-deal-australias-future-air-combat-capability, 1. ${ }^{425}$ Ibid, 11.

${ }^{426}$ Jonathan Glancey, "Inside the F-35, the Futuristic Fighter Jet," The Telegraph (London, UK), UK News: Defence, 2013, https://www.telegraph.co.uk/news/uknews/defence/9780450/Inside-the-F-35-thefuturistic-fighter-jet.html.
} 
not up to community standards. Because combined capability and interoperability are major

FVEY focuses, such an outcome would be detrimental to the entire network.

\section{Study limitations}

The findings are affected by limitations, which will be set out here. While a greater number of individuals were invited to participate, seven expert interviews were ultimately conducted, making for a relatively limited sample size that could amplify any biases in the answers given. Retired officials were at liberty to discuss the issues more freely than current practitioners, given considerations of confidentiality and professionalism. Nonetheless, much evidence remains classified, which has resulted in arguments about details of the SOR and RFP being necessarily speculative, albeit supported by research. Because this study has dealt with an ongoing process, its conclusions and projections are also necessarily speculative.

A detailed analysis of cost and industrial offsets as intervening phenomena has not been undertaken because such an exercise would be beyond the scope of this study. This decision was also taken because the costs and industrial packages of the three competitors have either been not publically disclosed or not yet firmed up. Moreover, firms and militaries use a variety of metrics to define flyaway costs, flight-hour costs and sustainment costs, making the available projections difficult to compare. ${ }^{427}$ While the F-35's flyaway cost has decreased to approximately US $\$ 78$ million as production gathers pace, the type still costs US $\$ 44,000$ per hour to fly, or slightly more than twice as much as the legacy Super Hornet. Lockheed Martin plans to halve that cost before 2025, but it is unclear whether its target can be met. ${ }^{428}$ The USN Super Hornet has a unit cost of US \$75.1 million in FY2020, with Boeing claiming that the Block III model will cost

\footnotetext{
${ }^{427}$ Chris Thatcher, "Saab Gripen E: Dark Horse," Skies, 2020, https://www.skiesmag.com/features/saabgripen-e-dark-horse/.

${ }_{428}$ Kyle Mizokami, "The F-35 Is Cheap to Buy (but Not to Fly)," Popular Mechanics, 2019, https:/www.popularmechanics.com/military/aviation/a29626363/f-35-cheap/.
} 
approximately US $\$ 18,000$ to operate per flight-hour. ${ }^{429}$ However, the type is not yet widely in service so the second figure is only an estimate. Finally, there is no publically available costing for the Saab Gripen E. One indication is the agreement reached in 2012 between the Swedish Defence Material Administration and Saab to modify 60 Gripen Cs to the E standard at a cost of US $\$ 7.4$ billion, or approximately US $\$ 123.3$ million per aircraft. ${ }^{430}$ This figure, however, cannot be considered representative of cost per unit with any confidence. In terms of industrial packages, Saab has announced its plan to build the Gripen E in Canada while Boeing has said that it will commit to " 100 percent" of the ITB policy obligation. ${ }^{431}$ For the F-35's offering, Canada remains a JSF program partner and its industry retains the right to compete for program contracts. The lack of reliable, publically available data on both pillars prevents a more comprehensive treatment and comparison.

\section{Future research directions}

As Canada and its external partners procure advanced military capabilities in the digital era, further inquiries on several of the topics introduced in this study are called for. First, closer consideration should be given to military procurement in the FVEY context. As technical interoperability becomes even more sophisticated and granular in its achievement, the question of formally standardizing the C4ISR systems and military platforms used by the FVEY members may be pertinent. The suggestion of this study is that given the implementation of nextgeneration C4ISR concepts, it will be increasingly untenable for one or more of the FVEY partners to operate network-enabled military equipment that is outdated or incompatible with the

\footnotetext{
${ }^{429}$ Department of Defense, Fiscal Year (FY) 2020 Budget Estimates: Navy (Arlington, VA: United States Government, 2019), 1-3.; Canada, "Super Hornet Block III: The Complete Solution for Canada."

430 "Gripen E Multirole Fighter Aircraft," Air Force Technology, 2020, https://www.airforcetechnology.com/projects/gripen-e-multirole-fighter-aircraft/.

${ }^{431}$ Canada, "Super Hornet Block III: The Complete Solution for Canada."
} 
equipment of the other partners. Second, regardless of whether Canada acquires the F-35, more consideration must be given to how the CAF will sustain the capability and technical interoperability of high-end C4ISR systems going forward. Such platforms will require regular updates to keep pace with advancing technology and evolving allied standards. Focus is now being given to leveraging the agile method of project management and capability delivery in Canadian defence procurement. ${ }^{432}$ This effort must continue. Third, frank discussions must also be held in government and academia over the continuing relevance and effectiveness of the ITB policy. ${ }^{433}$ While governments must admittedly consider a variety of factors when acquiring expensive military capabilities, this study has reaffirmed that promises of tailorable economic packages have the potential to sway major capital projects at the expense of technical capability.

\footnotetext{
${ }^{432}$ See David Perry, Mark McKiel, Kevin Aguanno, Jerry McLean, Al Amlani, Debra Zibes, "Industry Perspectives in Procurement Agility: Defence Procurement in the $43^{\text {rd }}$ Parliament," Defence Deconstructed Podcast, January 3, 2020, https://www.cgai.ca/industry_perspectives_in_procurement_agility.; David Perry, Gianluca Cairo, Mollie Royds, Levent Özmutlu, "Agile High-Tech Procurement in the Government of Canada," Defence Deconstructed Podcast, Canadian Global Affairs Institute, December 27, 2019, https://www.cgai.ca/agile_high_tech_procurement_in the_government_of_canada.

${ }^{433}$ See Craig Stone, "Defence Procurement Offsets and their Economic Value in Canada," CDA Institute, https://cdainstitute.ca/defence-procurement-offsets-and-their-economic-value-in-canada/.; David Perry, Stephanie Batstone, Rich Foster, Craig Stone, Brian Botting, Nicholas Todd "Is the ITB Policy Delivering? Defence Procurement in the $43^{\text {rd }}$ Parliament," Defence Deconstructed Podcast, Canadian Global Affairs Institute, December 20, 2019, https://www.cgai.ca/is the itb policy delivering
} 


\section{Chapter 10: Conclusion}

One interview subject recounted a recent conversation with senior members of the CAF wherein they conveyed their belief "in a wink over the phone that the technical requirements in the FFCP are so stringent that operational considerations will win the day, and whoever has the best technology will win." ${ }^{434}$ This individual claimed unequivocally that today, "the RCAF believes that the process is pure enough that the technical requirements will win out." ${ }^{\circ 35}$ If the RCAF gets its way, Canada will field an American fifth-generation fighter alongside its closest allies. Yet it remains unclear whether this outcome will come to pass.

The neoclassical realist paradigm maintains that in the short-term, foreign and defence policy outcomes do not always mirror relative power distributions. With the format and structure of the FFCP, the Liberal government appears to have prioritized its own short-term political interests over the CAF's long-term capability and indeed, the country's long-term defence. The decision to run an open, competitive process came after non-partisan experts warned that such an exercise could not be held in good faith. Tellingly, the decision was also made after the Liberal Party had come out strongly against the F-35 in the wake of the Spring 2012 OAG report, painting the type and its acquisition as examples of gross mismanagement by the Conservative government. In 2015, the Liberals pledged not to buy the F-35 at all. The competitive process that was promised instead launched in late 2017, with the accompanying press release claiming that the FFCP would deliver "the right aircraft at the right price," with the maximum economic benefits for Canadians. ${ }^{436}$ Significant weighting was accordingly given to cost and industrial

\footnotetext{
434 "Author Interview with Subject E."

${ }^{435}$ Ibid.

${ }^{436}$ Public Services and Procurement Canada, Government Launches Open and Transparent Competition to Replace Canada's Fighter Aircraft (Ottawa, ON: Government of Canada, 2017).
} 
offset packages in the evaluation criteria. Though the SOR and RFP remain classified, technical requirements have been watered down from the attempted sole-source acquisition of the F-35. The Liberal government has also taken steps since launching the FFCP to accommodate suppliers offering types that are less technically advanced but come with tailorable economic packages and lower acquisition and operating costs. Significantly, it has altered the strict Fiveand Two-Eyes interoperability requirements, which contributed to the withdrawal of Dassault and Airbus and now appear to be causing problems for Saab. The Liberal government has changed Canada's fighter policy in its pursuit of short-term political interests. Two interview subjects reasoned that it could select the Saab Gripen E purely for political reasons. ${ }^{437}$

However, the party in government now finds itself in a "Catch 22" situation. It wishes to avoid the harsh political and public criticism that it would inevitably draw for changing its position on the F-35 - and has structured the selection process accordingly. But there is simply no legal means of preventing Lockheed Martin and the US government from entering the F-35 in the FFCP, which is an open competition. Moreover, since 2011, the JSF program has stabilized markedly and the F-35 has matured considerably; the CAF's leadership supports the acquisition of the most technically advanced type and has written the FFCP SOR to maximize the chance of that happening. The Liberal government, also sensitive to the program's economic importance and the optics of a potential withdrawal, has maintained Canada's membership in the JSF program. ${ }^{438}$ Following protests from senior officials in the US defence establishment, the federal government has restructured the ITB pillar in the RFP to accommodate the JSF program's

437 "Author Interview with Subject C."; "Author Interview with Subject E."

${ }^{438}$ Lee Berthiaume, "Plan to Buy More Fighter Jets Puts Canada on Hook for Bigger Share of F-35 Costs," CBC News, Politics, 2019, https://www.cbc.ca/news/politics/canada-pays-more-f35-program1.4999240 . 
practice of awarding industrial contracts on a competitive basis. ${ }^{439}$ While the Liberals may eventually select the F-35 as Canada's future fighter, they seem prepared to do so only if they can demonstrate that they ran an exhaustive selection process and gave the type's competitors every defensible chance of success.

Whatever its eventual outcome, the federal government has introduced unwarranted risk into the selection process for the future fighter. Canadian defence policy is predicated on making meaningful contributions to alliances and defence partnerships. In return, Canada receives guarantees of security and sovereignty from key allies - and especially the US. ${ }^{440}$ Those nations are now embracing fifth-generation fighter aircraft and their associated ConOps. If Canada is to remain a valued member of NORAD, NATO and FVEY, it must continue to contribute high-end capabilities to those frameworks; it must remain fully interoperable with them at all levels. Canada can satisfy these crucial long-term imperatives by purchasing a fifth-generation fighter designed and manufactured in the US. There is only one such type: the Lockheed Martin F-35 Lightning II. This has been a case study of a process that is still unfolding. It is not yet clear which type will be selected to serve as Canada's future fighter and it would be ill-advised to make a firm prediction. However, this very uncertainty encapsulates the main argument. At this point in time, it is unclear that Canada will choose the right aircraft.

\footnotetext{
${ }^{439}$ Lee Berthiaume, "Looser Procurement Rules for F-35 Fighter Jets Will Hurt Canada, Rival Companies Say," Global News (Ottawa, ON), Canada, 2019, https://globalnews.ca/news/5331846/f35-fighter-jetprocurement-canada/.

440 "Author Interview with Subject C."
} 


\section{Bibliography}

AB, Saab. "Gripen for Brazil | Saab Brazil." Saab AB. 2019. Accessed March 24, 2020. https://saab.com/region/brazil/gripen-brazil/gripen-for-brazil/.

AB, Saab. Link 16 Added to Gripen's Datalink Systems. Saab AB, 2007.

AB, Saab. "The Key to Gripen's Longevity." Saab AB, March 15, 2019. https://saab.com/gripen/news/blog/gripen-blog/2019/the-key-to-gripens-longevity/.

Adamson, André, and Matthew Snyder. The Challenges of Fifth-Generation Transformation. Kalkar, Germany: Joint Air Power Competence Centre, 2018.

"Aegis Ballistic Missile Defence (BMD) System." Naval Technology. https://www.navaltechnology.com/projects/aegis-ballistic-missile-defence-bmd-us/.

"A History of Canada's Cf-18 Hornets | CBC News." CBC News. Canada: In Depth. 2011, https://www.cbc.ca/news/canada/cf-18-hornets-1.1003648.

"Air Force Seeks New Networking Capability by Linking F-35, F-22 Stealth Fighters and X-37 Space Plane." Military \& Aerospace Electronics, 2019. https://www.militaryaerospace.com/communications/article/14072577/space-planestealth-fighters-communicate.

"Airbus, Boeing May Pull out of Fighter Jet Race They Say Is Rigged for F-35." CBC News. Business, 2019, https://www.cbc.ca/amp/1.5204973.

Akers, Daniel. Understanding Voice and Data Link Networking: Northrop Grumman's Guide to Secure Tactical Data Links. San Diego, CA: Northrop Grumman, 2014.

"Alaskan Norad Region." About NORAD. North American Aerospace Defense Command. 2020. Accessed March 26, 2020. https://www.norad.mil/About-NORAD/Alaskan-NORADRegion/.

"AN/APG-81." Sensor Systems. Deagal.com. 2018. Accessed March 26, 2020. http://www.deagel.com/Sensor-Systems/ANAPG-81_a001381001.aspx.

Arellano, Nestor. "Force Development Chief, Military Brass Outline Canada's C4isr Objectives." Vanguard, 2016. https://vanguardcanada.com/2016/04/21/forcedevelopment-chief-military-brass-outline-canadas-c4isr-objectives/.

Attariwala, Joetey. "FFCP: Set to Replace CF-18." Canadian Defence Review. 2020. http://www.canadiandefencereview.com/zmags.php?p=Lz1PCWUFaA. 
Attariwala, Joetey. "Saab Gripen E/F." Canadian Defence Review. 2018. http://www.canadiandefencereview.com/Featured_content?blog/110.

"Author Interview with Subject B." interview by William Richardson. October 23, 2019. Ottawa, ON.

"Author Interview with Subject C." interview by William Richardson. November 5, 2019. Ottawa, ON.

"Author Interview with Subject D." interview by William Richardson. November 19, 2019. Ottawa, ON.

"Author Interview with Subject E." interview by William Richardson. November 18, 2019. Ottawa, ON.

"Author Interview with Subject F." interview by William Richardson. November 22, 2019. Ottawa, ON.

"Author Interview with Subject G." interview by William Richardson. December 6, 2019. Ottawa, ON.

"Author Phone Interview with Subject A." interview by William Richardson. October 22, 2019. Ottawa, ON.

Bachman, Justin. "State-of-the-Art? America's Two Best Fighter Jets Can't Even Communicate with Each Other." The National Post. News. 2018, https://nationalpost.com/news/world/state-of-the-art-americas-two-best-fighter-jets-canteven-communicate-with-each-other.

Belanger, John. Saab Press Briefing. CANSEC 2018. Ottawa, ON: Saab AB, 2018.

Berthiaume, Lee. "Airbus Pulls out of Canadian Fighter Jet Competition Following Complaints Bnn Bloomberg." BNN Bloomberg (Ottawa, ON). News. 2019, https://www.bnnbloomberg.ca/airbus-pulls-out-of-canadian-fighter-jet-competitionfollowing-complaints-1.1309296.

Berthiaume, Lee. "Canada Forced to Pay Bigger Share of F-35 Fighter Jet Development Costs Even Though It May Never Buy Any." The National Post (Ottawa, ON). News: World. 2019, https://nationalpost.com/news/world/plan-to-buy-more-fighter-jets-puts-canada-onhook-for-bigger-share-of-f-35-costs.

Berthiaume, Lee. "Looser Procurement Rules for F-35 Fighter Jets Will Hurt Canada, Rival Companies Say." Global News (Ottawa, ON). Canada. 2019, https://globalnews.ca/news/5331846/f35-fighter-jet-procurement-canada/. 
Berthiaume, Lee. "Plan to Buy More Fighter Jets Puts Canada on Hook for Bigger Share of F-35 Costs." CBC News. Politics. 2019, https://www.cbc.ca/news/politics/canada-pays-moref35-program-1.4999240.

Bland, Douglas. "Canada and Military Coalitions: Where, Who and with Whom?" In Geopolitical Integrity. Edited by Hugh Segal. Canadian Electronic Library. Books Collection. Montreal, QC: IRPP, 2005.

Bland, Douglas. "Military Interoperability: As Canadian as a Beaver." In The Canadian Forces and Interoperability: Panacea or Perdition? Edited by Ann Lynn Griffiths. Halifax, N.S: Centre for Foreign Policy Studies, Dalhousie University, 2002.

Blenkinsop, Philip. "Belgium Chooses Lockheed's F-35 over Eurofighter: Belga." Reuters, 2018.

Boeing Canada. "Super Hornet Block III: The Complete Solution for Canada." The Boeing Company. 2019. Accessed February 18, 2020. http://www.boeing.ca/products-andservices/defense-space-security/f-a-18-super-hornet.page.

Borgu, Aldo. A Big Deal: Australia's Future Air Combat Capability. Barton, AU: Australian Strategic Policy Institute, 2004.

Brewster, Murray. "Canadian, U.S. Military Leaders Agree on Framework to Retool Norad | Cbc News." CBC News. Politics. 2019, https://www.cbc.ca/news/politics/norad-canada-usmilitary-1.5240855.

Bronk, Justin. Maximizing European Combat Air Power: Unlocking the Eurofighter's Full Potential. London, UK: Royal United Services Institute for Defence and Security Studies, 2015.

Bronk, Justin. Maximum Value for the F-35: Harnessing Transformational Fifth-Generation Capabilities for the Uk Military. London, UK: Royal United Services Institute for Defence and Security Studies, 2016.

Burke, David. "New Satellite System Could Make Canadian Soldiers Safer Abroad | CBC News." CBC News. Nova Scotia. 2019, https://www.cbc.ca/news/canada/nova$\underline{\text { scotia/satellite-department-of-national-defence-radarsat-constellation-military- }}$ $\underline{1.5266508 .}$

Byers, Michael, and Stewart Webb. "Canada's F-35 Purchase Is a Costly Mistake." Canadian Foreign Policy Journal 17, no. 3 (2011): 217-27. https://dx.doi.org/10.1080/11926422.2011.638193.

Canada, Auditor General of. Chapter 2: Replacing Canada's Fighter Jets. Ottawa, ON: Office of the Auditor General of Canada, 2020. 
Canada, Auditor General of. Report 3-Canada's Fighter Force-National Defence. Ottawa, ON: Government of Canada, 2018.

Canada, Government of. "The Industrial and Technological Benefits Policy." Innovation, Science and Economic Development Canada. 2018. Accessed February 23, 2020. https://www.wd-deo.gc.ca/eng/11978.asp.

Canada, Liberal Party of. Real Change: A New Plan for a Strong Middle Class. Liberal Party of Canada, 2015.

Canada, National Defence. "Canadian Surface Combatant." Defence equipment purchases and upgrades. Government of Canada. 2019. Accessed March 28, 2020. https://www.canada.ca/en/department-national-defence/services/procurement/canadiansurface-combatant.html.

Canada, National Defence. "Future Fighter Capability Project - Canada.Ca." Last modified 202002-25. Accessed February 10, 2020. https://www.canada.ca/en/department-nationaldefence/services/procurement/fighter-jets/future-fighter-capability-project.html.

Canada, National Defence. Future Fighter Capability Project: Delivering Canada's Future Fighter Capability. Ottawa, ON, 2018.

Canada, National Defence. Future Fighter Capability Project: Replacing Canada's Current Fighter Aircraft. Ottawa, ON, 2018.

Canada, National Defence and the Canadian Armed Forces. "North Warning System." Government of Canada. 2012. Accessed January 25, 2020. http://www.forces.gc.ca/en/news/article.page?doc=north-warning-system/hgq87x9w.

Canada, National Defence and the Canadian Armed Forces. New Satellite Will Enhance Canadian Armed Forces' Communications Capabilities. Ottawa, ON: Government of Canada, 2017.

Canada, National Defence. "Remotely Piloted Aircraft System (RPAS)." Services. Government of Canada. Last modified 2019-08-12. Accessed March 28, 2020. https://www.canada.ca/en/department-national-defence/services/procurement/remotelypiloted-aircraft-system.html.

Canada, National Defence. Strong, Secure, Engaged: Canada's Defence Policy. Ottawa, ON: Government of Canada, 2017.

Canada, National Defence. Next Generation Fighter Capability Annual Update. Ottawa, ON, 2013.

Canada, Public Services and Procurement. Canada Announces Next Step in Future Fighter Competition - Canada.Ca. Gatineau, QC: Government of Canada, 2019. 
Canada, Public Services and Procurement. "Future Fighter Capability Project." Government of Canada. Accessed January 15, 2020. https://www.tpsgc-pwgsc.gc.ca/app-acq/amddp/air/snac-nfps/CF-18-eng.html.

Canada, Public Services and Procurement. Government Launches Open and Transparent Competition to Replace Canada's Fighter Aircraft. Ottawa, ON: Government of Canada, 2017.

Carvin, Stephanie. "Canadian Defence and New Technologies." In Canadian Defence Policy in Theory and Practice. Edited by Thomas Juneau, Srdjan Vucetic, and Philippe Lagassé. Canada and International Affairs. Cham, Switzerland: Palgrave Macmillan, Springer Nature, 2019.

Charron, Andrea, and James Fergusson. From NORAD to NOR[A]D: The Future Evolution of North American Defence Cooperation. Calgary, AB: Canadian Global Affairs Institute, 2018.

Charron, Andrea, and Jim Fergusson. NORAD: Beyond Modernization. Winnipeg, MB: University of Manitoba, 2019.

Communications, Navigation and Identification (CNI) Avionics for the F-35 Lightning II: New Dimensions for the Warfighter in Digital Battlespace. San Diego, CA: Northrop Grumman Information Systems, 2012.

Collins, Rockwell. Tactical Targeting Network Technology and Connectivity. Second Line of Defense, 2009.

Connolly, Amanda. "Pushing Fighter Jet Deadline Raises Questions on Which Jets Can Do the Work: Experts." Global News. Canada. February 29, 2020, https://globalnews.ca/news/6600416/canada-fighter-jet-competition/.

Cox, James. "Canada and the Five Eyes Intelligence Community." Open Canada (December 18 2020).

Crosby, Ann. "Defining the Debate: A Response to Danford Middlemiss and Denis Stairs." In The Canadian Forces and Interoperability: Panacea or Perdition? Edited by Ann Lynn Griffiths. Halifax, N.S: Centre for Foreign Policy Studies, Dalhousie University, 2002.

Cruz, Charlie. "Netwars Based Study of a Joint Stars Link 16 Network." Air Force Institute of Technology, 2004. https://apps.dtic.mil/dtic/tr/fulltext/u2/a423871.pdf.

"Defense Standardization Program: International Standardization." United States Department of Defense. Accessed February 15, 2020. https://www.dsp.dla.mil/Programs/InternationalStandardization/. 
Department of Defense. Dictionary of Military and Associated Terms. 2016. https://fas.org/irp/doddir/dod/jp1_02.pdf.

Department of Defense. Fiscal Year (FY) 2020 Budget Estimates: Navy. Arlington, VA, 2019.

Department of the U.S. Army. Army Regulation 34-1: Multinational Force Interoperability. 2015.

Doubleday, Justin. U.S., Canada to Finish North Warning System Analysis by Next Spring. Vol. 33. Arlington: Inside Washington Publishers, 2017.

Drew, James. "US Navy Considers Reduced Annual F-35C Buy." FlightGlobal (13 August, 2015).

Eckstein, Megan. "Navy Says Ending Super Hornet Line Frees up Resources for Life Extension Work - USNI News." USNI News (Capitol Hill), 2020.

https://news.usni.org/2020/03/10/navy-says-ending-super-hornet-line-frees-up-resourcesfor-life-extension-work.

England, C.J. "Air and Space Interoperability Council and the RCAF." Canadian Forces College, 2016. https://www.cfc.forces.gc.ca/259/290/298/286/england.pdf.

F-22 Demonstrates 'Supercruise' for First Time. Wright-Patterson Air Force Base, OH: Air Force News, 1999.

"F-35 Capabilities." Lockheed Martin Corporation. 2018. Accessed December 10, 2019. https://www.lockheedmartin.com/en-us/products/f-35/f-35-capabilities.html.

"F-35 Fighter Jet Bursts onto Election Agenda; Trudeau Says Liberal Government Wouldn't Buy It." Ottawa Citizen (Ottawa, ON). News: Politics, 2015, https://ottawacitizen.com/news/politics/f-35-fighter-jet-bursts-onto-election-agendatrudeau-says-liberal-government-wouldnt-buy-it.

"F-35 Software Development | F-35 Lightning II." Lockheed Martin Corporation. 2019. Accessed November 25, 2019. https://www.f35.com/about/life-cycle/software.

Fabey, Mike. "The U.S. Military's Strategy to Dominate the Air: Have the F-35 and F/A-18 Join Forces | the National Interest." The National Interest. 2017. https://nationalinterest.org/blog/the-buzz/the-us-militarys-strategy-dominate-the-air-havethe-f-35-f-19937.

Faughn, Anthony W. Interoperability: Is It Achievable? Cambridge, MA: Harvard University, 2002. 
Fergusson, James. Beneath the Radar: Change and Transformation in the Canada-U.S. North American Defence Relationship. Calgary, AB: Canadian Defence and Foreign Affairs Institute, 2009.

Fergusson, James. "The Right Debate: Airpower, the Future of War, Canadian Strategic Interests, and the Jsf Decision." Canadian Foreign Policy Journal 17, no. 3 (2011): 20416. https://dx.doi.org/10.1080/11926422.2011.638195.

Freedberg, Sydney J. "'A Computer That Happens to Fly’: USAF, RAF Chiefs on Multi-Domain Future." Breaking Defense. 2018. https://breakingdefense.com/2018/04/a-computer-thathappens-to-fly-usaf-raf-chiefs-on-multi-domain-future/.

Freedberg, Sydney J. "Boeing's Block III Super Hornet 'High End' Complement to F-35: Stackley." Breaking Defense. 2017. https://breakingdefense.com/2017/04/boeings-blockiii-super-hornet-high-end-complement-to-f-35-stackley/.

Freedberg, Sydney J. "Navy, Boeing Tout Block III Super Hornet as Partner for F-35." Breaking Defense. 2018. https://breakingdefense.com/2018/05/navy-boeing-tout-block-iii-superhornet-as-partner-for-f-35/.

Gertler, Jeremiah. F-35 Joint Striker Fighter (JSF) Program. Washington D.C.: Congressional Research Service, 2018.

Gilbert, Jonathan. The Neglected Capability: RCAF Tactical Datalinks. Toronto, ON: Canadian Forces College, 2019.

Glancey, Jonathan. "Inside the F-35, the Futuristic Fighter Jet." The Telegraph (London, UK). UK News: Defence. 2013, https://www.telegraph.co.uk/news/uknews/defence/9780450/Inside-the-F-35-thefuturistic-fighter-jet.html.

Government of Canada Announces Comprehensive Response to Chapter 2 of the 2012 Spring Report of the Auditor General of Canada. Ottawa, ON: Government of Canada, 2012.

Government of Australia Department of Defence. Force of the Future: Towards the World's First 5th Generation Air Force, by Royal Australian Air Force. Canberra, Australia, 2015.

"Gripen E Multirole Fighter Aircraft." Air Force Technology, 2020. https://www.airforcetechnology.com/projects/gripen-e-multirole-fighter-aircraft/.

Group, C4ISR Architectures Working. Levels of Information Systems Interoperability (LISI). Arlington, VA: Department of Defense, 1998.

Head to Head: Gripen Vs Typhoon. Vol. 46. Coulsdon: Jane's Information Group, 2013. 
Hess, Jacob, Aaron Kiser, El Moustafa Bouhafa, and Shawn Williams. The Combat Cloud: Enabling Multidomain Command and Control across the Range of Military Operations. Maxwell Air Force Base, Alabama: Air University: Air Command and Staff College, 2019.

House of Commons. Canada and the Defence of North America: NORAD and Aerial Readiness. 42 Parliament. 1 sess., by Defence, Standing Committee on National. Ottawa, ON, 2016.

Huebert, Rob. "The Future of Canadian Airpower and the F-35." Canadian Foreign Policy Journal 17, no. 3 (2011): 228-38. https://dx.doi.org/10.1080/11926422.2011.638196.

Hura, Myron. Interoperability: A Continuing Challenge in Coalition Air Operations. RAND Corporation. 2000.

"IMP Joins Bid to Assemble Canada's New Fighter Jets in Nova Scotia." The Chronicle Herald. Business. 2020, http://www.thechronicleherald.ca/business/local-business/imp-joins-bidto-assemble-canadas-new-fighter-jets-in-nova-scotia-419518/.

Insinna, Valerie. "Canada's Final Solicitation for Its Next-Gen Fighter Is Out. Who Will Bid for the Contract?" Defense News. 2019. https://www.defensenews.com/air/2019/07/23/canadas-final-solicitation-for-its-next-genfighter-is-out-who-will-bid-for-the-contract/.

Insinna, Valerie. "F-35 Price Falls Below \$90m for First Time in New Deal." Defense News (Washington D.C.). Air. September 2018, https://www.defensenews.com/air/2018/09/28/f-35-price-falls-before-90m-for-first-timeever-in-new-deal/.

Insinna, Valerie. "Inside America's Dysfunctional Trillion-Dollar Fighter-Jet Program." The New York Times (New York, NY). At War. 2019, https://www.nytimes.com/2019/08/21/magazine/f35-joint-strike-fighter-program.html.

"Interoperability Seen as Key to Future Fighter Platforms." Defense Daily International. 2008. Accessed 2020/4/3/, https://ink.gale.com/apps/doc/A184192806/AONE? $=$ =ocul_carleton\&sid=AONE\&xid=b 6997040. Gale Academic OneFile.

Jennings, Gareth. "RAF Demos F-35B and Typhoon Interoperability." Jane's Defence Weekly (2017).

Jockel, Joseph. "NORAD: Interoperability At "The Zenith"." In The Canadian Forces and Interoperability: Panacea or Perdition? Edited by Ann Lynn Griffiths. Halifax, N.S: Centre for Foreign Policy Studies, Dalhousie University, 2002.

Keller, John. "EQ-4B UAV to Provide Battlefield Networking and Situational Awareness." Military \& Aerospace Electronics, C4ISR (2017). 
LaGrone, Sam. "F-35, SM-6 Live Fire Test Points to Expansion in Networked Naval Warfare." USNI News (2016).

Laird, Robbin. "Recrafting the Fighter Role." FrontLine Defence. 2018. https://defence.frontline.online/article/2018/6/10980-Recrafting-the-Fighter-role.

Larson, Eric. Interoperability of U.S. And NATO Allied Air Forces Supporting Data and Case Studies, edited by Gustav Lindstrom, Myron Hura, Ken Gardiner, and Jim Keffer. Santa Monica: RAND Corporation, 2003.

Leblanc, Daniel. "European Fighter-Jet Manufacturer Pulls out of Canadian Competition to Replace CF-18s." The Globe and Mail (Toronto, ON). Canada. 2018, https://www.theglobeandmail.com/canada/article-european-fighter-jet-manufacturerpulls-out-of-canadian-competition-to/.

Leblanc, Daniel. "U.S. Government Again Urges Canada to Acquire American Fighter Jets, Despite Pentagon Threats." The Globe and Mail (Toronto, ON). Politics. 2019, https://www.theglobeandmail.com/politics/article-us-government-urges-canada-toacquire-american-fighter-jets-in-2/.

Lobell, Steven E., Norrin M. Ripsman, and Jeffrey W. Taliaferro. Neoclassical Realism, the State, and Foreign Policy. GB: Cambridge University Press - M.U.A, 2009. https://ebookcentral-proquest-com.proxy.library.carleton.ca/lib/oculcarletonebooks/reader.action?docID $=412786$.

Massie, Justin. "Bandwagoning for Status: Canada's Need of the F-35." Canadian Foreign Policy Journal 17, no. 3 (2011): 251-64. https://dx.doi.org/10.1080/11926422.2011.638197.

McColl, Alex. "Commentary: Alternative Saab Fighter Could Save Navy by Dodging Extravagant F-35s." The Chronicle Herald. Opinion. 2019, http://www.thechronicleherald.ca/opinion/national-perspectives/commentary-alternativesaab-fighter-could-save-navy-by-dodging-extravagant-f-35s-352103/.

McColl, Alex. "Mackay Ironically Lining up against Fighter-Jet Jobs in His Own Backyard." The Chronicle Herald (Calgary, AB). Opinion. 2020, http://www.thechronicleherald.ca/opinion/local-perspectives/alex-mccoll-mackayironically-lining-up-against-fighter-jet-jobs-in-his-own-backyard420208/?itm source=parsely-api.

Mercer, Ryan. "More F-35 Fighter Jets Arrive at Vermont Air National Guard." Burlington Free Press (Burlington, VT). News. 2019, https://www.burlingtonfreepress.com/story/news/2019/12/06/vermont-air-national-guardnow-has-five-f-35-fighter-jets/2622942001/. 
Middlemiss, Danford W., and Denis Stairs. The Canadian Forces and the Doctrine of Interoperability: The Issues. Montreal, QC: Institute for Research on Public Policy, 2002.

Millette, Christine D. "Tri-Lightning: Three-Nation F-35 Exercise Demonstrates Air Power Interoperability." Citizen Airman, 2019. https://link.gale.com/apps/doc/A600162611/AONE?u=ocul_carleton\&sid=AONE\&xid=6 $\underline{98447 \mathrm{ec} .}$

"Mission Milestones - Radarsat." Canadian Space Agency, Government of Canada. 2019. Accessed March 10, 2020. https://www.asc-csa.gc.ca/eng/satellites/radarsat/updates.asp.

"Mission Systems and Sensor Fusion | F-35 Lightning II." Lockheed Martin Corporation. 2018. Accessed November 22, 2018. https://www.f35.com/about/capabilities/missionsystems.

Mizokami, Kyle. "The F-35 Is Cheap to Buy (but Not to Fly)." Popular Mechanics, 2019. https://www.popularmechanics.com/military/aviation/a29626363/f-35-cheap/.

NATO. Backgrounder: Interoperability for Joint Operations. Brussel, Belgium: North Atlantic Treaty Organization, 2006.

NATO Glossary of Terms and Definitions. Brussels, Belgium: North Atlantic Treaty Organization, 2018.

"NATO - STANAG 5516 - Tactical Data Exchange - Link 16 | Engineering360." Standards Library. Engineering 360. 2008. Accessed February 19, 2020. https://standards.globalspec.com/std/1307656/STANAG 5516.

"NATO Standardization Office (NSO)." North Atlantic Treaty Organization. 2017. Accessed February 6, 2020. http://www.nato.int/cps/en/natohq/topics_124879.htm.

NATO Standard AJP-6: Allied Joint Doctrine for Communication and Information Systems, by Organization, North Atlantic Treaty. 2017.

NATO. "Strategic Concepts." North Atlantic Treaty Organization. 2018. Accessed February 10, 2020. http://www.nato.int/cps/en/natohq/topics_56626.htm.

"New Canadian Fighter Jets Will Need U.S. Certification: DND." The Globe and Mail (Ottawa, ON). Canada. 2019, https://www.theglobeandmail.com/canada/article-new-canadianfighter-jets-will-need-us-certification-dnd-2/.

Northrop Grumman and Royal Air Force Demonstrate Enhanced Airborne Communications Interoperability between 5th and 4th Generation Fast-Jet Aircraft. London, UK: Northrop Grumman Corporation, 2017. 
Nossal, Kim Richard. "Canada and the United States in a Hyperpower Era." In The Canadian Forces and Interoperability: Panacea or Perdition? Edited by Ann Lynn Griffiths. Halifax, N.S: Centre for Foreign Policy Studies, Dalhousie University, 2002.

Nossal, Kim Richard. "The Imperatives of Canada's Strategic Geography." In Canadian Defence Policy in Theory and Practice. Edited by Thomas Juneau, Philippe Lagassé, and Srdjan Vucetic. Canada and International Affairs. Cham, Switzerland: Palgrave Macmillan, 2019.

Olivier, Darren. "The Gripen Data Link." FlightCom: African and Middle East Aviation. 2019. https://www.flightcommagazine.com/single-post/2019/03/05/The-Gripen-data-link.

Osborn, Kris. "Air Force Seeks Jets Beyond C-17 and Even JSF." Military.com. 2013. https:/www.military.com/daily-news/2013/12/17/air-force-seeks-jets-beyond-c17-andeven-jsf.html.

Osborn, Kris. "Here Comes the 'New' F-35 Stealth Fighter (It Will Be Epic)| The National Interest." The National Interest. 2019. https://nationalinterest.org/blog/buzz/here-comesnew-f-35-stealth-fighter-it-will-be-epic-95281.

Parliament of Canada. Inquiry of Ministry: Question No. 434, by Defence, Associate Minister of National. Ottawa, ON, 2012.

Parliament of Canada. Canada and Ballistic Missile Defence: Responding to the Evolving Threat, by Defence, Senate Standing Committee on National Security and. Ottawa, ON, 2014.

Pernin, Christopher, Jakub Hlavka, Matthew Boyer, John Gordon, Michael Lerario, Jan Osburg, Michael Shurkin, and Daniel Gibson. Targeted Interoperability: A New Imperative for Multinational Operations. RAND Corporation, 2019.

Perry, David, Gianluca Cairo, Mollie Royds and Levent Özmutlu. “Agile High-Tech Procurement in the Government of Canada." Defence Deconstructed Podcast. Canadian Global Affairs Institute, December 27, 2019.

https://www.cgai.ca/agile_high tech_procurement_in_the_government_of_canada

Perry David, Mark McKiel, Kevin Aguanno, Jerry McLean, Al Amlani, Debra Zibes. "Industry Perspectives in Procurement Agility: Defence Procurement in the $43^{\text {rd }}$ Parliament." Defence Deconstructed Podcast, January 3, 2020. https://www.cgai.ca/industry perspectives in procurement agility.

Perry, David, Stephanie Batstone, Rich Foster, Craig Stone, Brian Botting, Nicholas Todd. "Is the ITB Policy Delivering? Defence Procurement in the $43^{\text {rd }}$ Parliament." Defence Deconstructed Podcast. Canadian Global Affairs Institute, December 20, 2019. https://www.cgai.ca/is the itb_policy_delivering 
Peters, Heidi. Defense Primer: The National Technology and Industrial Base. Washington D.C.: Congressional Research Service, 2020.

Pole, Ken. "Canada Joins Alliance Seeking New Maritime Surveillance Aircraft." Skies. 2018. https://www.skiesmag.com/news/canada-joins-alliance-seeking-new-maritimesurveillance-aircraft/.

Pugliese, David. "Bidding Criteria for Canada’s \$19b Fighter Jet Competition Will Emphasize Strategic Attack and Ground-Strike Capabilities - Seeming to Favour the F-35." The National Post. News. 2019, https://nationalpost.com/news/bidding-criteria-for-canadas19b-fighter-jet-competition-will-emphasize-strategic-attack-and-ground-strikecapabilities-seeming-to-favour-the-f-35.

Pugliese, David. "Boeing Confirms It Is Taking Part in Canada's Future Fighter Jet Competition." The Ottawa Citizen (Ottawa, ON). News: Defence Watch. 2019, https://ottawacitizen.com/news/national/defence-watch/boeing-confirms-it-is-taking-partin-canadas-future-fighter-jet-competition.

Pugliese, David. "European-Built Fighter Aircraft: Did They Ever Stand a Chance in Canada's Competition?" The Ottawa Citizen (Ottawa, ON). Defence Watch. 2019, https://ottawacitizen.com/news/national/defence-watch/european-built-fighter-aircraftdid-they-ever-stand-a-chance-in-canadas-competition/.

Pugliese, David. "In Pursuit of \$19b Contract, Sweden's Saab Offers to Build Fleet of Fighter Jets in Canada." The National Post. News. 2019, https://nationalpost.com/news/inpursuit-of-19b-contract-swedens-saab-offers-to-build-fleet-of-fighter-jets-in-canada.

Pugliese, David. "Some Changes Made to Canadian Fighter Jet Requirements as New Document Sent to Companies." Ottawa Citizen (Ottawa, ON). Defence Watch. 2019, https://ottawacitizen.com/news/national/defence-watch/some-changes-made-to-canadianfighter-jet-requirements-as-new-document-sent-to-companies/.

Pugliese, David. "String of Radar Stations in Canadian Arctic Nearly Obsolete - and Modernizing Them Will Cost Billions." The National Post (Cambridge Bay, Nunavut). News. 2018, https://nationalpost.com/news/modernizing-warning-radars-in-the-arcticwill-cost-canada-and-the-us-billions-of-dollars.

Pugliese, David. "Will Other Firms Withdraw from Fighter Jet Competition Leaving F-35 Last Plane Standing?" The Ottawa Citizen (Ottawa, ON). News: Defence Watch. 2019, https://ottawacitizen.com/news/national/defence-watch/will-other-firms-withdraw-fromfighter-jet-competition-leaving-f-35-last-plane-standing.

Regehr, Ernie. Replacing the North Warning System: Strategic Competition or Arctic Confidence? The Simons Foundation, 2018. 
Ripsman, Norrin M., Jeffrey W. Taliaferro, and Steven E. Lobell. Neoclassical Realist Theory of International Politics. New York: Oxford University Press, 2016.

http://www.oxfordscholarship.com/10.1093/acprof:oso/9780199899234.001.0001/acprof9780199899234.

Rogoway, Joseph Trevithick and Tyler. "Master Chart Showing US Military Aircraft and Their Data-Links Includes RQ-170 Sentinel." The Drive. 2018. https://www.thedrive.com/thewar-zone/20381/master-chart-showing-us-military-aircraft-and-their-data-links-includesrq-170-sentinel.

Rogoway, Tim McMillan and Tyler. "Special Access Programs and the Pentagon's Ecosystem of Secrecy." The Drive. 2019. https://www.thedrive.com/the-war-zone/29092/specialaccess-programs-and-the-pentagons-ecosystem-of-secrecy.

Rogoway, Tyler. "We Chew the Fat About BACN with Program Boss and Airman Who Used It in Combat." The Drive, The War Zone (2017).

Rose, Gideon. "Neoclassical Realism and Theories of Foreign Policy." World Politics 51, no. 1 (1998): 144-72. https://dx.doi.org/10.1017/S0043887100007814.

Royal Canadian Air Force. "CF-188 Hornet." Air Force: Aircraft. Government of Canada. Accessed January 10, 2020. http://www.rcaf-arc.forces.gc.ca/en/aircraft-current/cf188.page.

Royal Canadian Air Force. Future Concepts Directive Part 2: Future Air Operating Concept. Ottawa, ON: National Defence and the Canadian Armed Forces, 2016.

Saab. "Gripen E | Ready for the Future | Saab." Saab AB. 2019. Accessed December 5, 2019. https://saab.com/gripen/our-fighters/gripen-fighter-system/gripen-e-series/gripen-e/.

"Saab's Compelling Offer to Canada." Saab AB. 2020. Accessed March 11, 2020. https://saab.com/gripen/news/blog/gripen-blog/2020/saabs-compelling-offer-to-canada/.

Segal, Hugh. "Geopolitical Integrity for Canada." In Geopolitical Integrity. Edited by Hugh Segal. Canadian Electronic Library. Books Collection. Montreal [Que: IRPP, 2005].

Seligman, Lara. "The Countries Where F-35 Sales Are Taking Off." Foreign Policy (2018).

Shimooka, Richard. The Catastrophe: Assessing the Damage from Canada's Fighter Replacement Fiasco. MacDonald-Laurier Institute, 2019.

Shimooka, Richard. The Fourth Dimension: The F-35 Program, Defence Procurement, and the Conservative Government, 2006-2015. Ottawa, ON: Conference of Defence Associations Institute, 2016. 
Shoemaker, Mike. "Admiral's View: The Case for Aircraft Carriers and Air Wings." DoD Buzz. Military.com. Last modified November 11, 2015. Accessed November 24, 2018. https://www.military.com/dodbuzz/2015/08/11/admirals-view-the-case-for-aircraftcarriers-and-air-wings.

Staff, The National Post. "Stephen Harper Must Resign over Bungled F-35 File, Say Liberals." The National Post. News: Canada. 2012, https://nationalpost.com/news/canada/stephenharper-must-resign-over-bungled-f-35-file-say-liberals.

Stephenson, Al. Anatomy of a Buy: The Four Dimensions of Procuring a Fighter Fighter for Canada. Canadian Global Affairs Institute, 2019.

Stocker, Jeremy. "The Canadian Military Relationship with the United States: An Overseas Commentary." In The Canadian Forces and Interoperability: Panacea or Perdition? Edited by Ann Lynn Griffiths. Halifax, N.S: Centre for Foreign Policy Studies, Dalhousie University, 2002.

Stone, J. Craig and Adam Chapnick. "From Policy and Strategy to Outcomes." In Canadian Defence Policy in Theory and Practice. Edited by Thomas Juneau, Philippe Lagassé, and Srdjan Vucetic. Canada and International Affairs. Cham, Switzerland: Palgrave Macmillan, 2019.

Stone, Craig. "Defence Procurement Offsets and their Economic Value in Canada." CDA Institute. https://cdainstitute.ca/defence-procurement-offsets-and-their-economic-valuein-canada/.

Szondy, David. "Us Navy Receives First Upgraded F/a-18 Super Hornet Block III." New Atlas, 2020. https://newatlas.com/military/us-navy-receives-fa18-super-hornet-block-iii/.

Technologies, Epec Engineered. "Tactical Targeting Network Technology." Microwave Journal (2018).

"Terminal High Altitude Area Defense (THAAD)." Lockheed Martin Corporation. 2019. Accessed March 29, 2020. https://www.lockheedmartin.com/en-us/products/thaad.html.

Thatcher, Chris. "Land C4ISR: The Bridge to a Better Way to Buy High Tech? | Canadian Army Today." Canadian Army Today. 2019. https://canadianarmytoday.com/land-c4isr-thebridge-to-a-better-way-to-buy-high-tech/.

Thatcher, Chris. "Saab Gripen E: Dark Horse." Skies. 2020. https://www.skiesmag.com/features/saab-gripen-e-dark-horse/.

Tirpak, John. "The Sixth Generation Fighter." Air Force Magazine. 2009. https://www.airforcemag.com/article/1009fighter/. 
Trimble, Stephen. "Usaf Selects Datalink to Bridge Communications Gap between F-22 and F35." FlightGlobal (2009).

United States Marine Corps. 2019 Marine Corps Aviation Plan. Arlington, VA, 2019.

Valle, Orvelin. "Saab Just Unveiled Its Attempt to Outdo the F-35." Business Insider. 2016. https://www.businessinsider.com/saab-f-35-competitor-gripen-e-2016-7.

Van Evera, Stephen. Guide to Methods for Students of Political Science. Ithaca, NY: Cornell University Press, 1997. www.jstor.org/stable/10.7591/j.ctvrf8bm7.

Viasat. "Mids-Lvt Link 16 Tactical Airborne Terminal." Viasat, Inc., 2020. Accessed March 4, 2020. https://www.viasat.com/products/link-16-mids-lvt1.

Vucetic, Srdjan and Massey, Justin. "Canadian Strategic Cultures: From Confederation to Trump." In Canadian Defence Policy in Theory and Practice. Edited by Thomas Juneau, Philippe Lagassé, and Srdjan Vucetic. Canada and International Affairs. Cham, Switzerland: Palgrave Macmillan, 2019.

Vucetic, Srdjan. "Canada and the F-35: What's at Stake?", Canadian Foreign Policy Journal 17, no. 3 (2011): 196-203. https://dx.doi.org/10.1080/11926422.2011.638199.

Vucetic, Srdjan. "F-35 Sales Are America's Belt and Road." CIPS Blog, Centre for International Policy Studies, University of Ottawa, 2019. https:/www.cips-cepi.ca/2019/09/22/f-35sales-are-americas-belt-and-road/.

Williams, Alan S. Canada, Democracy and the F-35. The Claxton Papers, 16. Kingston, ON: Defence Management Studies Program, School of Policy Studies, Queen's University, 2012.

World Air Forces 2018. FlightGlobal: Reed Business Information Limited, December 2017.

Zadalis, Tim. Multi-Domain Command and Control. Kalkar, Germany: Joint Air Power Competence Centre, 2018.

Zazula, Nick. "F-35: Is the Trillion Dollar Fighter Finally Worth It?" Avionics International. 2018. http://interactive.aviationtoday.com/avionicsmagazine/august-september-2018/f35-is-the-trillion-dollar-fighter-finally-worth-it/.

Zazulia, Nick. "F-35 Data Fusion: How the Smartest Fighter Shares What It Sees - Avionics." Avionics International, 2018. https://www.aviationtoday.com/2018/09/04/f-35-datafusion/.

Zazulia, Nick. "F-35: Is the Trillion-Dollar Fighter Finally Worth It?", Avionics International, no. August/September 2018. 
Ørvik, Nils. "The Basic Issues in Canadian National Security: Defence against Help." Canadian Defence Quarterly 11, no. 1 (1981): 8-15. 